\title{
Technical Analysis of Installed Micro-Combined Heat and Power Fuel-Cell Systems
}

K Brooks

A Makhmalbaf

October 2014

Pacific Northwest

NATIONAL LABORATORY

Proudly Operated by Battelle Since 1965 


\title{
DISCLAIMER
}

This report was prepared as an account of work sponsored by an agency of the United States Government. Neither the United States Government nor any agency thereof, nor Battelle Memorial Institute, nor any of their employees, makes any warranty, express or implied, or assumes any legal liability or responsibility for the accuracy, completeness, or usefulness of any information, apparatus, product, or process diselosed, or represents that its use would not infringe privately owned rights. Reference herein to any specific commercial product, process, or service by trade name, trademark, manufacturer, or otherwise does not necessarily constitute or imply its endorsement, recommendation, or favoring by the United States Government or any agency thereof, or Battelle Memorial Institute. The views and opinions of authors expressed herein do not necessarily state or reflect those of the United States Government or any agency thereof.

\author{
PACIFIC NORTHWEST NATIONAL LABORATORY \\ operated by \\ BATTELLE \\ for the \\ UNITED STATES DEPARTMENT OF ENERGY \\ under Contract DE-AC05-76RL01830
}

Printed in the United States of America

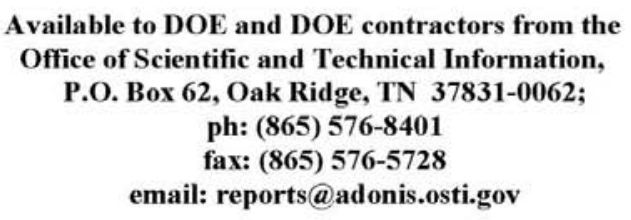

Available to the public from the National Technical Information Service, U.S. Department of Commerce, 5285 Port Royal Rd., Springfield, VA 22161 ph: (800) 553-6847 fax: (703) 605-6900 email: orders@ntis.fedworld.gov online ordering: http://www.ntis.gov/ordering.htm 


\section{Technical Analysis of Installed Micro-Combined Heat and Power Fuel-Cell Systems}

K Brooks

A Makhmalbaf

October 2014

Prepared for

U.S. Department of Energy

Energy Efficiency and Renewable Energy

Office of Fuel-Cell Technology

Pacific Northwest National Laboratory

Richland, Washington 99352 



\section{Executive Summary}

Combined heat and power fuel-cell systems (CHP-FCSs) provide consistent electrical power and hot water with greater efficiency and lower emissions than alternative sources. These systems can be used either as baseload, grid-connected, or as off-the-grid power sources. This report presents a technical analysis of $5 \mathrm{kWe}$ CHP-FCSs installed in different locations in the United States. At some sites as many as five $5 \mathrm{kWe}$ system are used to provide up to $25 \mathrm{kWe}$ of power. Systems in this power range are considered "micro"-CHP-FCS. To better assess performance of micro-CHP-FCS and understand their benefits, the U.S. Department of Energy worked with ClearEdge Power to install fifteen $5 \mathrm{kWe}$ polybenzimidazole (PBI) high-temperature proton exchange membrane fuel cells (CE5 models) in the commercial markets of California and Oregon. Pacific Northwest National Laboratory evaluated these systems in terms of their economics, operations, and technical performance. These units were monitored from September 2011 until June 2013. During this time, about 190,000 hours of data (approximately equivalent to 22 years) were collected and more than 17 billion data points were analyzed. Beginning in July 2013, 10 of these systems were gradually replaced with ungraded systems (M5 models) containing phosphoric acid fuel-cell technology. The new units were monitored up to July 2014 until they went offline. ${ }^{1}$ This second phase provided an additional 44,000 hours of data (5 years) and more than 4 billion data points were recorded and analyzed. During these two phases, data were collected at once per second and data analysis techniques were applied to understand behavior of these systems.

The results of this analysis indicate that systems installed in the second phase of this demonstration performed better in terms of availability, consistency in generation, and reliability. The average net electrical power output increased from 4.1 to $4.9 \mathrm{kWe}$, net heat recovery from 4.7 to $5.4 \mathrm{kWth}$, and system availability improved from $94 \%$ to $95 \%$. The average net system electric efficiency increased from $33 \%$ to $36 \%$, average net heat recovery efficiency improved from $38 \%$ to $41 \%$, and the overall net efficiency of CHP-FC systems, was enhanced from $71 \%$ to $76 \%$ on average. The temperature of water sent to the site to provide heating however was reduced by about $16 \%$ from $51^{\circ} \mathrm{Cto} 43^{\circ} \mathrm{C}$. This was a control strategy and the temperature can be controlled depending on building heat demands.

More importantly, the number of shut downs and maintenance events required were reduced from a total of 231 shutdowns for CE5 to 32 for M5. In one year, from July 2012 to June 2013, there were eight CE5 units in operation and a total of 134 scheduled and unscheduled shutdowns took place. From July 2013 to June 2014 (one year timeline), between 2 and 10 units were in operation and 32 shut downs were reported. On average, the number of shut downs reported per unit per month was 0.8 for CE5 systems and 0.46 for M5 units. This is about $42 \%$ reduction in number of maintenances required to keep systems running at manufacture's rated performance. Results of time-series data also show that degradation of the net electric system efficiency and total system efficiency were much greater in CE5's compared to M5's. For instance, the standard deviation of overall system efficiency for one of the CE5 units reduced from 5.8 to 0.7 . This means the M5 unit was degraded 88\% less than its peer CE5 unit in the mean time between shut downs required for maintenance.

\footnotetext{
${ }^{1}$ This decision of terminating data collection was independent of the performance of CHP-FCSs. ClearEdge was bought by Doosan at that time and the new manufacturer did not continue to support data collection and maintenance of these units.
} 



\section{Acknowledgments}

This research was supported by the U.S. Department of Energy (DOE) Office of Energy Efficiency and Renewable Energy (EERE) Fuel-Cell Technologies (FCT) Program. The authors wish to thank Peter Devlin of the U.S. DOE EERE FCT, for his support and direction. The authors also would like to acknowledge Dr. Siva Pilli for his technical support. 



\section{Acronyms and Abbreviations}

$\begin{array}{ll}\text { BOP } & \text { balance-of-plant (as in balance-of-plant components in a system) } \\ \text { CHP } & \text { combined heat and power } \\ \text { DOE } & \text { U.S. Department of Energy } \\ \text { FCS } & \text { fuel-cell system } \\ \text { HHV } & \text { higher heating value } \\ \text { HTPEM fuel cell } & \text { high-temperature polymer electrolyte membrane (fuel cell) } \\ \text { kW } & \text { kilowatt } \\ \text { kWe } & \text { kilowatts electrical } \\ \text { kWth } & \text { kilowatts thermal } \\ \text { LHV } & \text { lower heating value } \\ \text { MTBFO } & \text { mean time between forced outage } \\ \text { O\&M } & \text { operating and maintenance } \\ \text { PEM } & \text { proton exchange membrane } \\ \text { PBI } & \text { polybenzimidazole } \\ \text { SO } & \text { sulfur oxides } \\ \text { SPA } & \text { Steam Pump Assembly } \\ \text { VOC } & \text { volatile organic compounds }\end{array}$





\section{Contents}

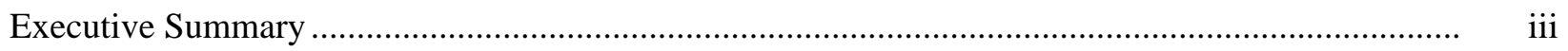

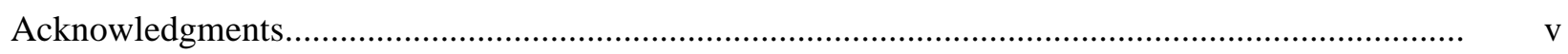

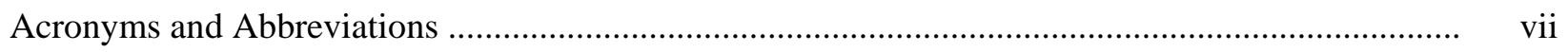

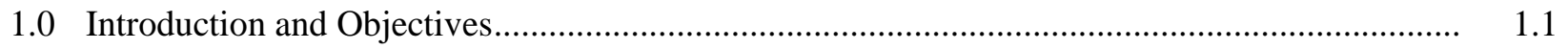

2.0 Technical and Engineering Performance Assessment ....................................................... 2.1

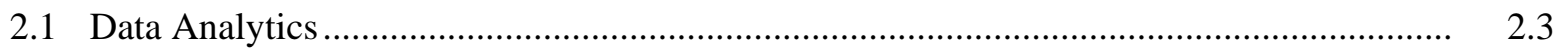

2.2 Technical Assessment - Phase I................................................................................ 2.8

2.3 Technical Assessment - Phase II ......................................................................... 2.15

2.4 System Performance Comparison - Phase I vs. Phase II ................................................ 2.18

2.5 Electricity and Heat Utilization.................................................................................. 2.26

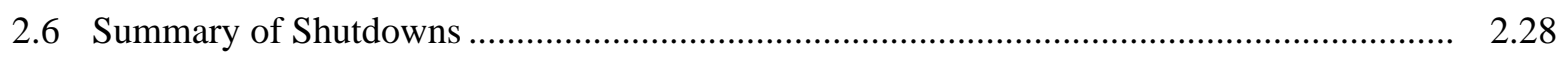

2.7 Performance Comparison of CE5 and M5 Models with DOE Technical Targets .............. 2.31

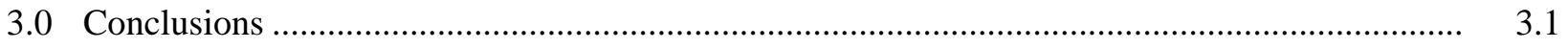

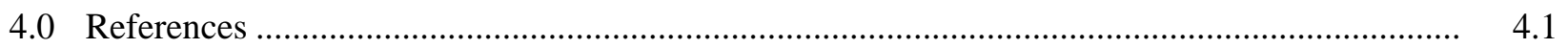

Appendix A Time-Series Performance of CE5 Units in Phase I ..................................................... A.1

Appendix B Time-Series Performance Data for M5 Units in Phase II ............................................ B.1 



\section{Figures}

2.1 Two Micro-CHP-FCS Units in Portland, Oregon - System Initially Installed During Phase I.. 2.2

2.2 Remote Desktop Connection Interface via Excel [Screen shot illustrates selection of time

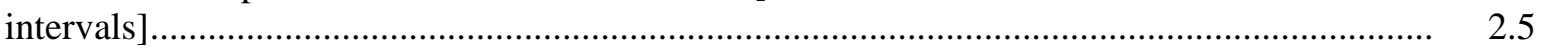

2.3 Net Electric Power Output and Net Electric Power Efficiency .............................................. 2.6

2.4 Net System Heat Recovery Efficiency ................................................................................. 2.7

2.5 Time-Series Data Showing Net System Overall Efficiency of the Representative System........ $\quad 2.8$

2.6 Total Number of System Availability Hours During the Operation Period and since Deployment of Each CE5 Unit in Phase I.............................................................................. 2.9

2.7 CE5 in Phase I Is Shown on the Left and M5 Installed During Phase II is Shown on the

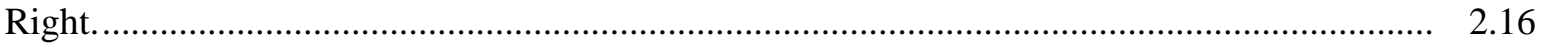

2.8 Total Number of Hours of Operation for Each M5 Unit Installed in Phase II .......................... 2.17

2.9 Comparing Hours of Operations of CE5 vs. M5 Units ........................................................... 2.20

2.10 Average Net Electric Power Output (kWe) of CE5 vs. M5 Models ........................................ 2.21

2.11 Average Net System Electric Power Efficiency [\%] of CE5 vs. M5 Models ........................... 2.21

2.12 Average Net Heat Recovery (kWth) of CE5 vs. M5 Models................................................... 2.22

2.13 Average Net Heat Recovery Efficiency [\%] of CE5 vs. M5 Models......................................... 2.22

2.14 Overall Net System Efficiency [\%] of CE5 vs. M5 Models .................................................. 2.22

2.15 Temperature of Water Sent to Site $\left[{ }^{0} \mathrm{C}\right]$ for CE5 vs. M5 Models .............................................. 2.23

2.16 Percentage of System Availability in CE5 Models vs. M5 ..................................................... 2.23

2.17 Comparison of Net Electric Power Output of CE5 after BOP in Phase I Shown on the Left and M5 in Phase II Shown on the Right.............................................................................. 2.24

2.18 Comparison of Net Electric Efficiency in CE5 after BOP in Phase I Shown on the Left and M5 in Phase II Shown on the Right

2.19 Comparison of System Overall Efficiency of CE5 after BOP in Phase I Shown on the Left and M5 in Phase II Shown on the Right.

2.20 Distribution of Net Electric Power Output [W] of CE5 (Unit 131) vs. that of M5 (Unit P2)

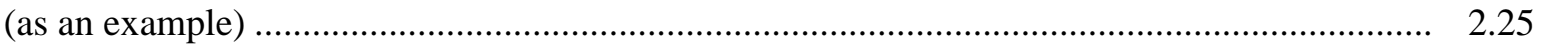

2.21 Distribution of Net Electric Power Efficiency of CE5 (Unit 131) vs. that of M5 (Unit P2)

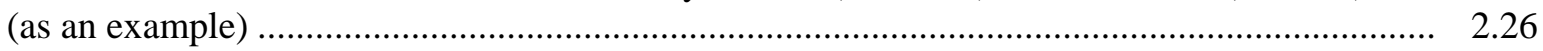

2.22 Summary of Buildings’ Electricity Demand and Utilization .................................................. 2.27

2.23 Summary of Buildings' Heat Demand ............................................................................... 2.27

2.24 Summary of Shutdowns and their Causes in Phase I .......................................................... 2.28

2.25 Meantime between Failures (MTBF) in Phase I (CE5) vs. Phase II (M5) ................................. 2.31

2.26 Histograms of Time to Restart Comparison for CE5 vs. M5 Systems....................................... 2.31 



\section{Tables}

2.1 Summary of Sites, Building Types, and Locations ............................................................. 2.1

2.2 Summary of Project History...................................................................................... 2.2

2.3 Raw Data, Recorded at One-Second Time Intervals by ClearEdge ........................................ 2.3

$2.4 \quad$ Heat and Power Utilization Data Collected for Two Sites........................................................ 2.4

2.5. Summary of Building Type, Location, Number of Units, System Installation, and Shutdown

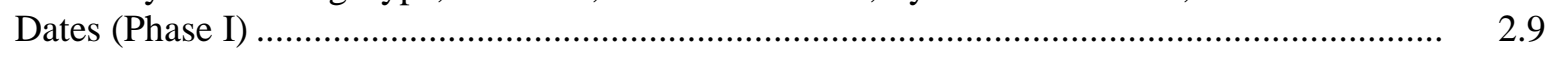

2.6 Manufacturer-Rated CHP-FCS Performance Specifications (in Phase I)................................ 2.10

2.7 Detailed Assessment for the 10 CE5 Systems Installed During the Initial Months of

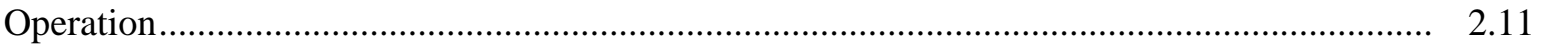

2.8 Detailed Assessment for the 15 CE5 Systems in Operation after Set-Point Change ................. 2.12

2.9 Detailed Assessment of eight CE5 Systems in Operation during the Third Time Period in

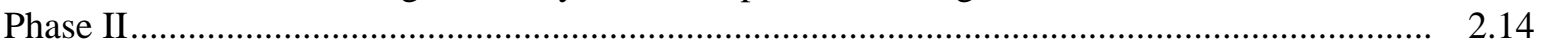

2.10 Micro-CHP-FCS Performance Summary during Phase I.................................................... 2.14

2.11 Manufacturer-Rated CHP-FCS Performance Specifications in Phase II. ................................. 2.15

2.12. Summary of Building Type, Location, Number of Units, Unit Numbers, and Installation

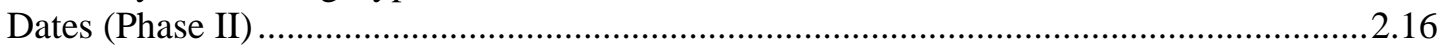

2.13 Performance Evaluation of Systems Monitored in Phase II................................................... 2..17

2.14 Micro-CHP-FCS Performance Summary in Phase II ............................................................ 2.18

2.15 Summary of Performance Evaluation of System in Phase I vs. Phase II .................................. 2.20

2.16 Monthly Failures, Runtime to Shut Down, and Duration of Shutdown Reported for Each

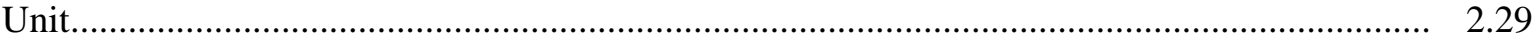

2.17 Total Failures Affecting CE5 vs. M5 Units. ....................................................................... 2.30

2.18 Summary of DOE Preliminary Technical Targets for 1-10 kWe CHP-FCS Operating on

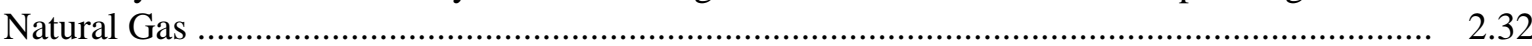





\subsection{Introduction and Objectives}

The major objectives of this study were to independently monitor and analyze real-time measured performance data from micro-combined heat and power fuel cell (micro-CHP-FCS) systems that generate 5 to $20 \mathrm{kWe}$ of power. These systems were installed at different small commercial buildings.to evaluate their engineering performance using data collected, and also to compare the real-time data with the manufacturer's stated ratings for performance. Another objective of demonstrating CHP-FCS systems and assessing their performance is to help determine and document market viability for this technology.

To achieve these objectives, the U.S. Department of Energy (DOE) and Pacific Northwest National Laboratory (PNNL) started to work with industry in the fall of 2011 to monitor performance of combined heat and power (CHP) fuel-cell systems (FCSs). Micro-CHP-FCSs for this demonstration were acquired through an open competition and ClearEdge Power won for its $5 \mathrm{kWe}+5.5 \mathrm{kWth}$ high-temperature proton exchange membrane (PEM). PNNL worked with ClearEdge to purchase and install CHP-FCS at several small commercial buildings. These included a college located in Oregon, a nursery in Southern California, a grocery in Northern California, and a recreation center in Northern California. Time-series data on the CHP-FCS were collected for nearly 4 years (from Fall 2011 to Summer 2014). Data collected were analyzed to provide "real-world" data from units "in the customer's hands" and perform an engineering and technical assessment to validate performance, durability, and reliability of systems installed. In addition to that, installation, operations, and maintenance costs were gathered as much as possible to identify advantages of CHP-FCSs for commercialization.

This is the final data analytics and report ${ }^{1}$ on a field evaluation of the fifteen 5-kW CHP-FCSs installed in the commercial buildings mentioned. Results of this analysis are important for different stakeholders such as the DOE, the fuel-cell community, the manufacturer, and most importantly for building owners and facility managers because it provides them with an independent evaluation of the technology. The economic assessment of micro-CHP-FCSs was covered in another report, Business Case for a Micro-Combined Heat and Power Fuel Cell System in Commercial Application, to help end-users make better investment decisions. The objective of the economic analysis performed was to help different stakeholders to understand lifecycle cost and payback period for the units originally installed. When these initial CE5 systems were replaced with new (i.e., M5 systems), it was done at no cost to the government. As a result, the cost of these systems was never determined to allow a second updated economic analysis.

\footnotetext{
${ }^{1}$ Related reports include:

1. Brooks KP, A Makhmalbaf, DM Anderson, JP Amaya, SP Pilli, V Srivastava, and JF Upton. 2013. Business Case for a Micro-Combined Heat and Power Fuel Cell System in Commercial Applications . PNNL-22831, Pacific Northwest National Laboratory, Richland, Washington.

2. Makhmalbaf A, KP Brooks, V Srivastava, SP Pilli, and NAF Foster. 2014. "Lesson Learned from Technical and Economic Performance Assessment and Benefit Evaluation of CHP-FCS ." In 2014 ACEEE Summer Study on Energy Efficiency in Buildings, Pacific Grove, California.
} 



\subsection{Technical and Engineering Performance Assessment}

Between September 2011 and March 2012, ClearEdge Power initially installed 15 of their microCHP-FCSs for application and demonstration at four different deployment sites: two sites in Northern California, one site in Southern California, and one site in Oregon as summarized in Table 2.1. These sites were selected and sized by taking into consideration the building total electricity demand. The intention was to keep the total electricity supplied by the CHP-FCS units below the building electricity demand. The same consideration was applied to the heat recovery. The CHP-FCSs were expected to produce heat that could be utilized by the buildings as much as possible for either space or water heating. In another study where building energy demand was simulated, results indicated that CHP-FCSs with higher electricity and heat utilizations are in general more economic with less greenhouse gas emissions when compared to CHP-FCSs with lower electricity and heat utilizations [1].

Table 2.1. Summary of Sites, Building Types, and Locations

\begin{tabular}{lllc}
\hline Partner/Site & Building & Location & \multicolumn{2}{c}{$\begin{array}{c}\text { Number of } \\
\text { Units }\end{array}$} \\
\hline Portland Community College (PCC) & College & Portland, Oregon & 2 \\
Roger's Garden & Nursery & Corona Del Mar, California & 3 \\
Oakland Hills Country Club & Recreation & Oakland, California & 5 \\
Fresh \& Easy & Grocery & San Francisco, California & 5 \\
\hline \multicolumn{1}{c}{ Total } & & & $\mathbf{1 5}$ \\
\hline
\end{tabular}

This field study included two phases. Phase I was from September 2011 to June 2013 and Phase II was from July 2013 to July 2014. Table 2.2 summarizes the project history during both phases, the major events that took place and the number of units that were affected by these events and changes during each quarter in a fiscal year. In total, all systems together were monitored for about 250,000 hours and more than 24 billion data points were collected and stored between fall 2011 and summer 2014. 
Table 2.2. Summary of Project History

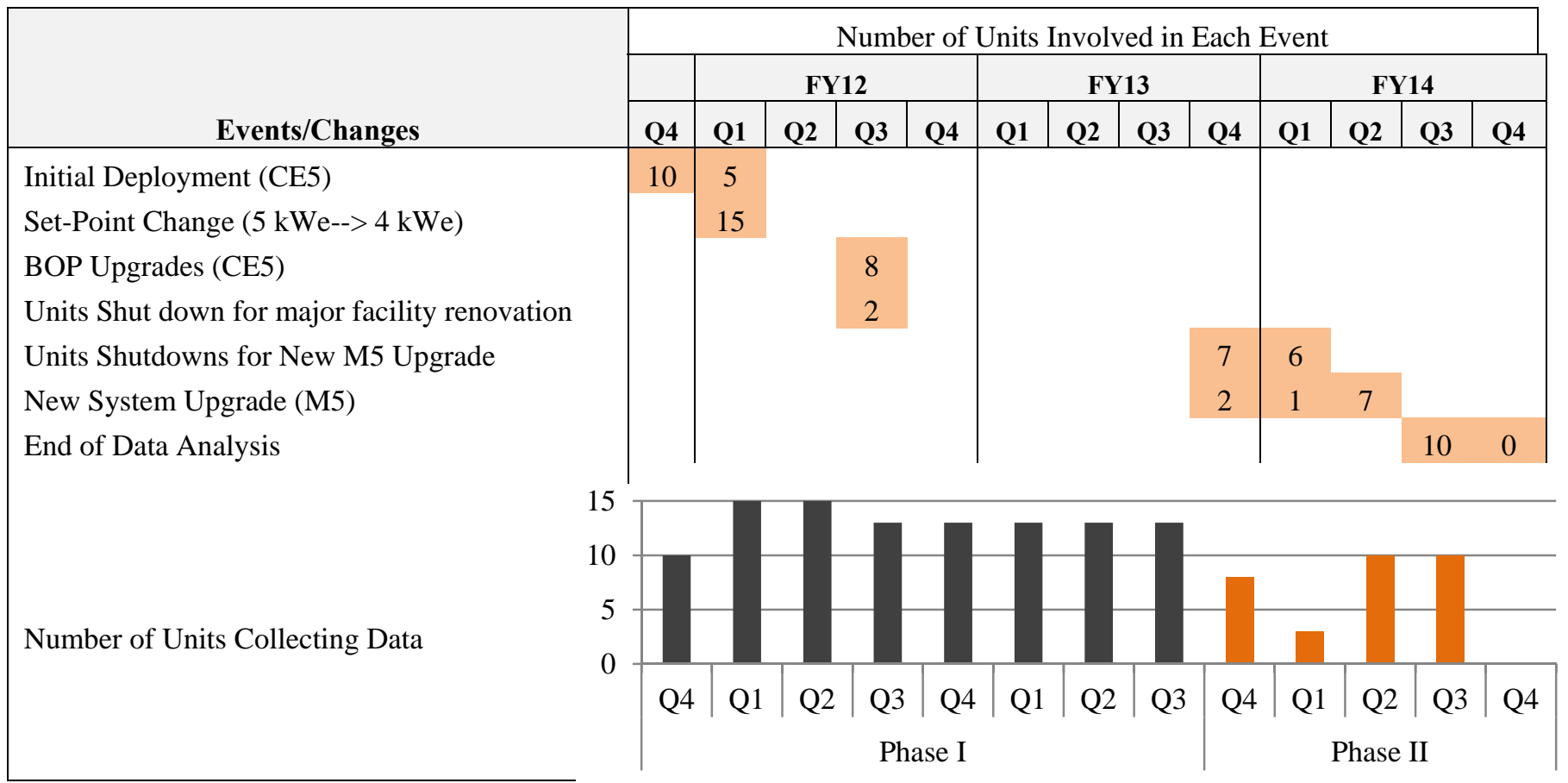

Figure 2.1 shows an installation of systems in Phase I and Phase II at the Portland Community College site in Portland, Oregon. Each system is $5 \mathrm{kWe}$. The one on the right is the initial CE5 system and the one on the left is the upgraded unit (i.e., the M5). As the image indicates, the size of the units increased from Phase I to Phase II. This size upgrade was mostly to provide more front access to the system’s parts for maintenance purposes.

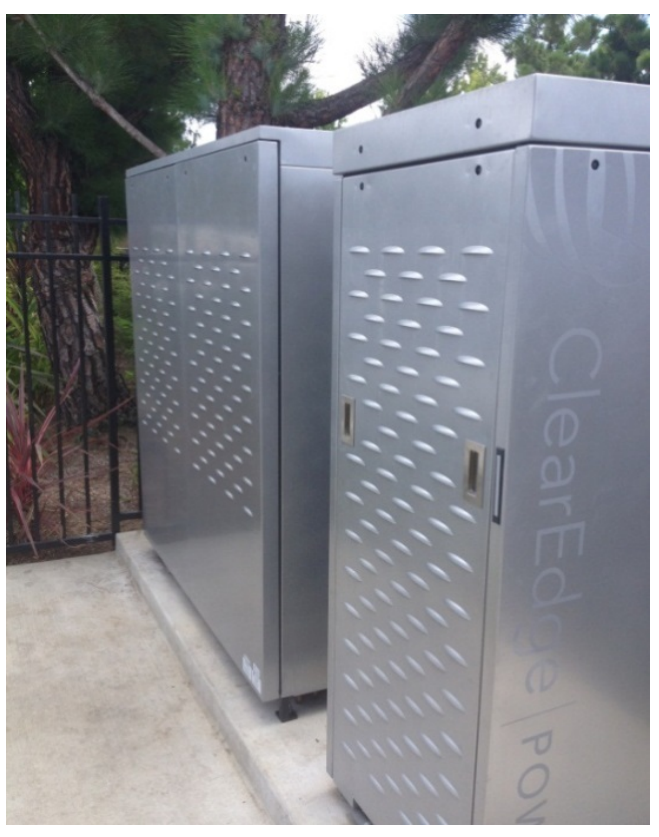

Figure 2.1. Two Micro-CHP-FCS Units in Portland, Oregon - System Initially Installed During Phase I 
This section is organized into several sub-sections. First, how data were accessed and analyzed are explained in the Data Analytics section. Then, the technical assessment carried out based on the timeseries data analysis are covered in Technical Assessment - Phase I and Technical Assessment - Phase II sections. This is followed by a comparison of system behavior during Phase I and Phase II. Finally, results obtained from data analysis and system evaluations are compared with DOE technical targets for 1 to $10 \mathrm{kWe}$ CHP-FCSs that operate on natural gas.

\subsection{Data Analytics}

Raw data needed to carry out the necessity and required analysis were collected, stored, retrieved, prepared and analyzed as described in this section.

Data Collection: Time-series performance data were collected from each unit by ClearEdge using installed sensors and data communication via an internet connection. Data were collected at each second. Although more data were available to ClearEdge for their monitoring and control, twenty six data points were shared with PNNL. A summary of raw data available to PNNL is shown in Table 2.3. These data were either directly used to analyze Natural Gas Input, Net Electric Power Output, and Temperature of Water Sent to Site, or were processed to calculate Net System Electric Efficiency, Heat Recovery Efficiency, Overall System Efficiency, Net Electric Power Output, Net Heat Recovery for External Heating, and System Availability ${ }^{1}$. Details of the methodology used to calculate these parameters are brought below under Data Analysis and more information can be found in [2] and [3].

Table 2.3. Raw Data, Recorded at One-Second Time Intervals by ClearEdge

\begin{tabular}{|c|c|c|c|c|}
\hline$\#$ & Title & Units/Type & Details & Description \\
\hline 1 & TimeStamp & $\begin{array}{l}\text { m/d/yyyy } \\
\text { hh:mm:ss }\end{array}$ & Time & Date and time \\
\hline 2 & Unit & Name & Unit\# & Unit identification name/number \\
\hline 3 & FAN255 & $\%$ & Percent & Overboard heat exchanger cooling fan speed \\
\hline 4 & FS460 & Binary & Switch & Customer cooling water flow switch \\
\hline 5 & FT501 & SLPM & Gas Flow & Natural gas inlet flow burner \\
\hline 6 & FT502 & SLPM & Gas Flow & Natural gas inlet flow reactor \\
\hline 7 & GasUsed & $\mathrm{L}$ & Gas Used & Cumulative natural gas used \\
\hline 8 & Grid1OutLine1Current & A & Current & $\begin{array}{l}\text { FCS current exported to the building's } \\
\text { electrical grid }\end{array}$ \\
\hline 9 & Grid1OutLine1Volts & V & Voltage & Grid voltage measured by inverter \\
\hline 10 & Grid1OutLine2Current & A & Current & $\begin{array}{l}\text { FCS current exported to the building's } \\
\text { electrical grid }\end{array}$ \\
\hline 11 & Grid1OutLine2Volts & V & Voltage & Grid voltage measured by inverter \\
\hline 12 & HeatGenerated & W-seconds & $\begin{array}{l}\text { Cumulative Heat } \\
\text { Generated }\end{array}$ & Approximate cumulative heat generated \\
\hline 13 & HeatGenerating & $\mathrm{W}$ & Heat Generating & Approximate heat generating \\
\hline 14 & LS400 & Binary & Switch & Water reservoir tank switch \\
\hline 15 & LS401 & Binary & Switch & Water reservoir tank switch \\
\hline 16 & LS402 & Binary & Switch & Water reservoir tank switch \\
\hline
\end{tabular}

\footnotetext{
${ }^{1}$ System operating time when compared to the total time since commissioning is quantified in terms of availability.
} 


\begin{tabular}{lllll}
\hline$\#$ & Title & Units/Type & Details & Description \\
\hline $\mathbf{1 7}$ & PowerGenerated & W-seconds & $\begin{array}{l}\text { Cumulative } \\
\text { Power }\end{array}$ & Cumulative power generated \\
$\mathbf{1 8}$ & PowerGenerating & W & Power Generating & Net Electric Power Output \\
$\mathbf{1 9}$ & RLY100 & Relay & Switch & Fuel-cell stack relay switch \\
$\mathbf{2 0}$ & SystemLoadTime & Seconds & Time on Load & Cumulative system time on load \\
$\mathbf{2 1}$ & SystemPowerSP & W & Power Set-Point & System power set-point \\
$\mathbf{2 2}$ & TE001 & ${ }^{\circ} \mathrm{C}$ & Temperature & Control electronics cabinet temperature \\
$\mathbf{2 3}$ & TE100 & ${ }^{\circ} \mathrm{C}$ & Temperature & Internal cabinet temperature \\
$\mathbf{2 4}$ & TE253 & ${ }^{\circ} \mathrm{C}$ & Temperature & Exhaust temperature \\
$\mathbf{2 5}$ & TE451 & ${ }^{\circ} \mathrm{C}$ & Temperature & Temperature of cooling water sent to site \\
$\mathbf{2 6}$ & TotalAirFlow & SLPM & Process Air Flow & Total process air into fuel-cell system \\
\hline
\end{tabular}

Additional quarterly input in the form of spreadsheets provided by ClearEdge included information about maintenance events, summary of general shut downs (e.g., general cause, date it happened, and mean time between events), control variables, and operating temperatures external to the FCS. Heat and power utilization data were collected for two sites for certain time period (this is discussed in Section 2.5 Electricity and Heat Utilization). Details of data types collected for this purpose is summarized in Table 2.4.

Table 2.4. Heat and Power Utilization Data Collected for Two Sites

\begin{tabular}{|c|c|c|}
\hline Title & Units & Description \\
\hline TimeStamp & m/d/yyyy hh:mm:ss & Date and time data was recorded \\
\hline Unit & name & Unit identification name/number \\
\hline FT460 & gpm & $\begin{array}{l}\text { Water flow to the storage tanks at Fresh and Easy (water flow } \\
\text { meter) }\end{array}$ \\
\hline GasUsedA & cu ft & Gas used by the CHP-FCS \\
\hline GasUsedB & cu ft & Gas used by the system being supplied with heat (air handler) \\
\hline PowerGenerated & W-seconds & Cumulative power generated \\
\hline PWR001Used & W-hours & Power used by the building \\
\hline PWR002Used & W-hours & Power sent back to the grid \\
\hline TE442 & ${ }^{\circ} \mathrm{C}$ & Temperature of water leaving the unit \\
\hline TE452 & ${ }^{\circ} \mathrm{C}$ & Temperature of water returning to the unit \\
\hline
\end{tabular}

Data Access: Access to the ClearEdge database was provided via internet and remote desktop connection through Excel. Raw data needed for performance assessment were retrieved using the Excel interface provided via the remote desktop connection in CSV format. These data were saved in a local machine and then they were read and processed in the same format using $\mathrm{R}$, a software environment for statistical computing and graphics. Although data were collected each second, they were retrieved and analyzed at thirty-second time intervals. This was mostly because results indicated there was not much value in processing second by second data while increasing the time step reduced data analysis and the processing time. Time-series data were also more readable when plotted and better suitable for documentation and presentation purposes. Figure 2.2 shows the Excel interface that was prepared by ClearEdge and was used by PNNL to access data. 


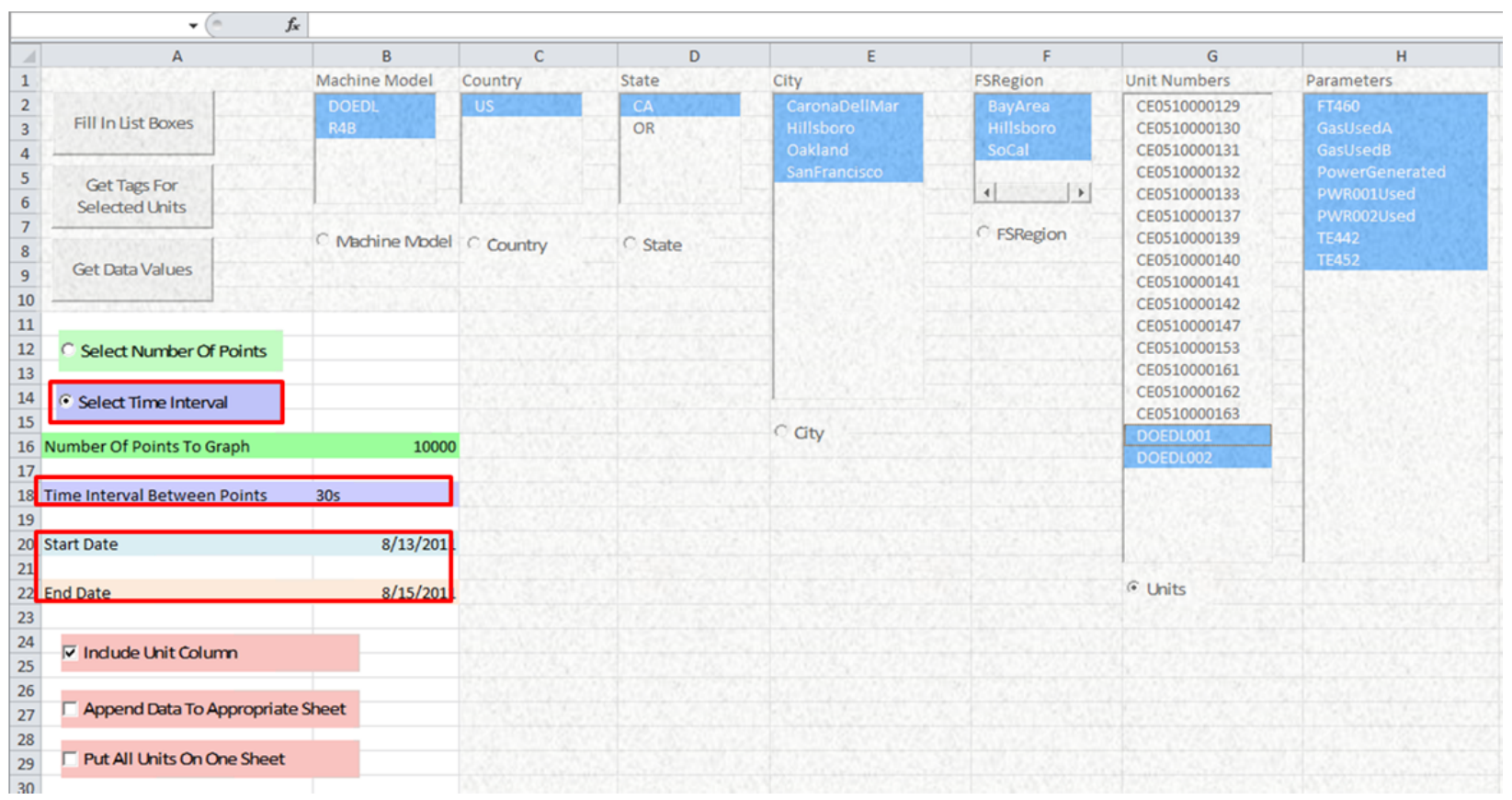

Figure 2.2. Remote Desktop Connection Interface via Excel (screen shot illustrates selection of time intervals)

Data Preparation: The main data preparation in this project was to get all data with the same time intervals and for the same period of time. This was mostly handled using the database ClearEdge had constructed. Figure 2.2 shows how time intervals between points were selected. Start and end dates were selected using the same structure. Monthly data were extracted at 30 second-intervals and then they were merged again during the analysis to plot the time-series data for several months in one graph. In addition to accurate selection of time intervals and time periods, raw data retrieved were not directly readable by R. Therefore, some data formatting changes were required so the CSV files could be read and processed by R. These formatting changes were mostly applied to time stamp data.

Data Analysis: As it was mentioned, raw data were analyzed using the R data analysis software. Codes written in $\mathrm{R}$ were used to calculate real-time parameters that describe behavior of the system over the operation time of the units. Results of this analysis are used for technical and engineering assessment of systems installed. In this section, the time-series data for one example CHP-FCS unit is shown for different calculations discussed here. This unit (unit 131 which was later changed to P2 in the second Phase of the project) was one of the three units installed at Roger's Garden in Corona Del Mar, California. This was one of the first units installed and it ran for the longest time period. Time-series data are shown for both phases of the project as explained in the following section. Data for the remaining units are included in Appendix A.

The net electric efficiency of each CHP-FCS is defined as the ratio of the net electric power output of the unit (PowerGenerating listed in Table 2.3) and the energy input to the system based on the HHV of natural gas. Equation 1 shows how the net electric efficiency is calculated.

$$
\text { Net Electric Efficiency [\%] }=\frac{\text { Net Electric Output }}{\dot{m}_{N G} * \Delta H_{N G}}
$$


Where, $\dot{m}_{N G}$ is the mass flow rate of natural gas which includes the burner and main fuel stream,

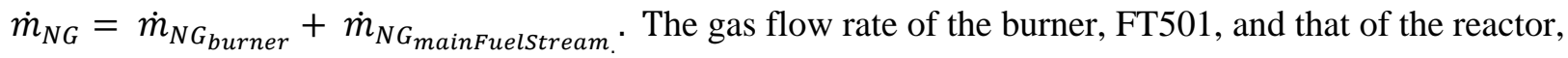
FT502, listed in Table 2.3, are used to calculate the mass flow rate of natural gas using density of natural gas, $0.79 \mathrm{~kg} / \mathrm{m}^{3}$. The energy input to the system is based on the higher heating value (HHV) of natural gas, $50 \mathrm{MJ} / \mathrm{kg}^{1}$. Data collected and presented in Table 2.3 are used to carry out this calculation at each time step. Time-series data for the net electric power output used in Equation 1 and the net electric efficiency of the representative unit (calculated) are shown in Figure 2.3. The red dashed line in these figures represents the manufacturer's specifications.
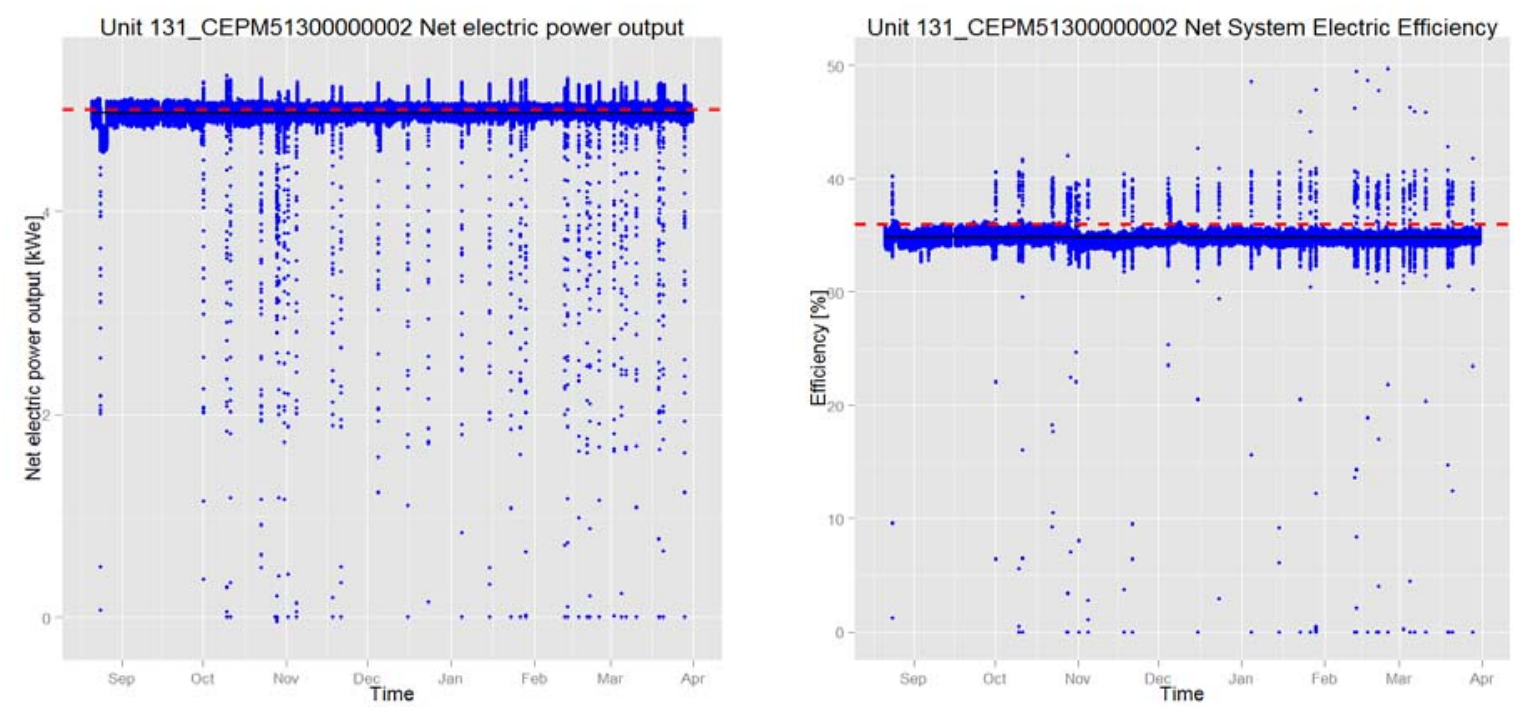

Figure 2.3. Net Electric Power Output and Net Electric Power Efficiency

The net heat recovery efficiency is defined as a ratio of the net heat recovered from the FCS for external heating to the mass flow rate of natural gas and energy input of the system. The net heat recovered from the CHP-FCS (HeatGenerating listed in Table 2.3) is a value which was calculated by ClearEdge (i.e., the manufacturer) based on an internal algorithm for estimating the heat recovery. They used this algorithm to translate the measured value for the instantaneous electrical output into a calculated estimate for the amount of exhaust heat recovered and available for external heating. They derived this value from real-time measurements from fully instrumented systems. The heat recovery of these fully instrumented systems was correlated to the power and electrical efficiency of the system. The net heat recovery efficiency was calculated using this value as illustrated in Equation 2:

$$
\text { Net Heat Recovery Efficiency [\%] }=\frac{\text { HeatGenerated }}{\dot{m}_{N G} * \Delta H_{N G}}
$$

Where, $\dot{m}_{N G}$ is the mass flow rate of natural gas which includes the burner and main fuel stream,

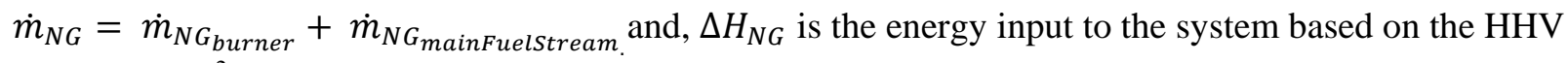
of natural gas ${ }^{2}$. Data collected and presented in Table 2.3 are used to carry out this calculation at each time step. Time-series data for the net heat recovery (i.e., HeatGenerated) from the CHP-FCS for external

\footnotetext{
${ }^{1}$ The denominators in Equations 1 and $2\left(\dot{m}_{N G} * \Delta H_{N G}\right)$ are converted to $\mathrm{W}$ to be consistent with the numerator.

${ }^{2}$ See description of Equation 1 above for details of values calculated in Equation 2.
} 
heating (used in Equation 2) and the net heat recovery efficiency of the representative unit calculated (using Equation 2) are shown in Figure 2.4.
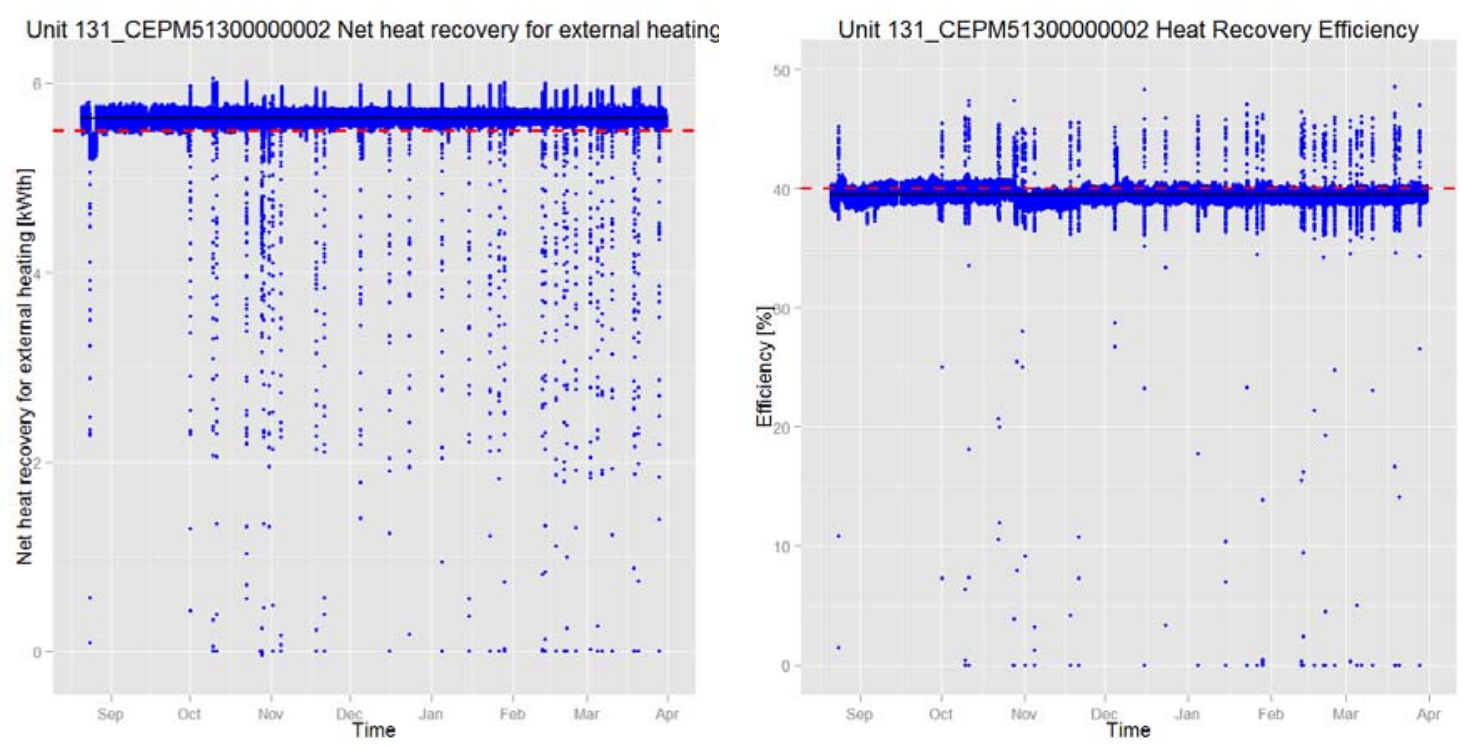

Figure 2.4. Net System Heat Recovery Efficiency

The net overall efficiency of the system is defined as the sum of net electrical efficiency and net heat recovery efficiency of the CHP-FC system as shown in Equation 3:

$$
\begin{gathered}
\text { Overal System Efficiency [\%] }= \\
\text { Net Electric Efficiency + Net Heat Recovery Efficiency } \quad \text { Eq. } 3
\end{gathered}
$$

Time-series data for the net overall system efficiency of the representative unit is shown in Figure 2.5 as an example. Results are calculated using Equation 3. 


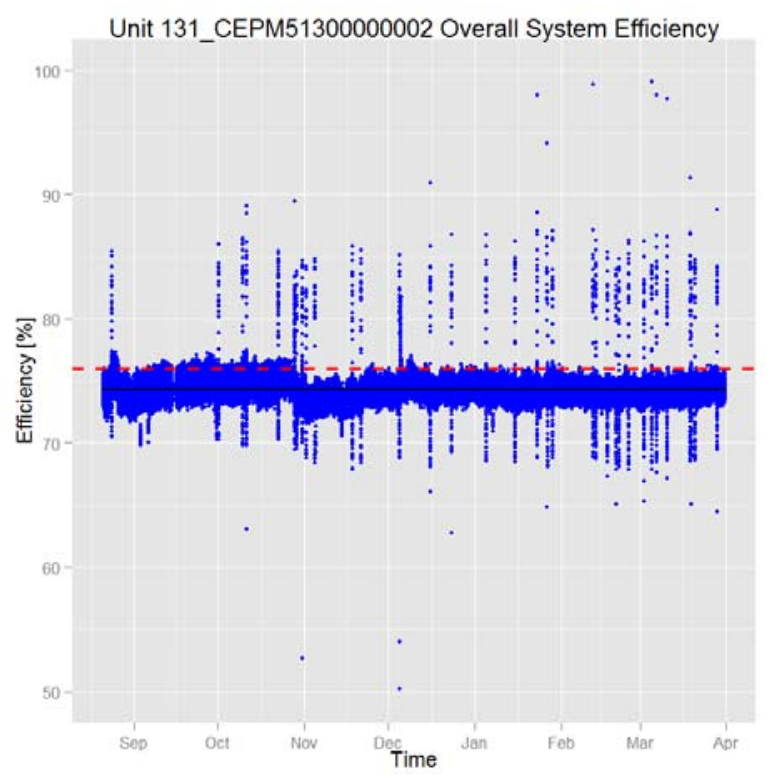

Figure 2.5. Time-Series Data Showing Net System Overall Efficiency of the Representative System

The power utilized by the building was directly metered as shown in Table 2.4 (PWR001Used). The heat utilization is estimated by calculating the mass flow rate of water multiplied by the difference of water temperature leaving the CHP-FCS and temperature of water returning (TE442 and TE452 respectively as listed in Table 2.4), as shown in Equation 4.

$$
\text { Heat Utilized }[k W]=\dot{m}_{\text {water }} *\left(T_{\text {in }}-T_{\text {out }}\right) * c p \quad \text { Eq. } 4
$$

Where, $\dot{m}_{\text {water }}$ is the mass flow rate of water and is calculated using density of water, $1000 \mathrm{~kg} / \mathrm{m}^{3}$, multiplied by the water flow rate (FT460 listed in Table 2.4 and converted to SI unit). $C_{p}$ is the specific heat of water, $4.186 \mathrm{~J} / \mathrm{gram}{ }^{\circ} \mathrm{C}$. The calculation is converted to $\mathrm{kWth}$.

\subsection{Technical Assessment - Phase I}

In Phase I, high-temperature PEM (PBI) fuel cells (CE5 systems) were installed as the initial technology to be evaluated. Table 2.5 shows a summary of the list of sites, their locations, number of units installed at each site, and the initial and final days of operation for each of the deployment sites during the first phase. The CHP-FCS units came online one at a time since monitoring started in September 2011. The first two units were installed in Portland, Oregon and started operating in September 2011. They went through commissioning in October 2011 and analysis in this report starts from that point on. The other units came online between November 2011 and March 2012. These units were shut down to prepare for installation of the next generation of fuel cells (PureCell System Model 5-M5) beginning July 2013. The two units at the Portland Community College were shut down in May 2012 as a result of major renovations to the university and were not restarted until they were replaced with the new M5 in February of 2014. 
Table 2.5. Summary of Building Type, Location, Number of Units, System Installation, and Shutdown Dates (Phase I)

\begin{tabular}{|c|c|c|c|c|c|c|}
\hline Partner/Site & $\begin{array}{l}\text { Building } \\
\text { Type }\end{array}$ & Location & $\begin{array}{l}\text { Number } \\
\text { of Units }\end{array}$ & Unit \# & $\begin{array}{l}\text { Data } \\
\text { Collection } \\
\text { Initiated }\end{array}$ & $\begin{array}{l}\text { Shutdown } \\
\text { Date }\end{array}$ \\
\hline \multirow{2}{*}{$\begin{array}{l}\text { Portland Community } \\
\text { College (PCC) }\end{array}$} & \multirow{2}{*}{ College } & \multirow{2}{*}{ Portland, OR } & \multirow{2}{*}{2} & 129 & \multirow{2}{*}{$9 / 21 / 2011$} & \multirow{2}{*}{$5 / 15 / 2012$} \\
\hline & & & & 130 & & \\
\hline \multirow{3}{*}{ Roger’s Garden } & \multirow{3}{*}{ Nursery } & \multirow{3}{*}{$\begin{array}{l}\text { Corona Del } \\
\text { Mar, CA }\end{array}$} & \multirow{3}{*}{3} & 131 & \multirow{3}{*}{$11 / 26 / 2011$} & \multirow{3}{*}{$\begin{array}{l}\text { 7/1/2013, } \\
\text { 11/1/2013, } \\
11 / 1 / 1013\end{array}$} \\
\hline & & & & 132 & & \\
\hline & & & & 133 & & \\
\hline \multirow{2}{*}{$\begin{array}{l}\text { Oakland Hills } \\
\text { Country Club }\end{array}$} & \multirow{2}{*}{ Recreation } & \multirow[t]{2}{*}{ Oakland, CA } & \multirow[t]{2}{*}{5} & $\begin{array}{l}137,139, \\
140,141,\end{array}$ & $12 / 15 / 2011$ & $11 / 1 / 1013$ \\
\hline & & & & 142 & $12 / 29 / 2011$ & $7 / 29 / 2013$ \\
\hline Fresh \& Easy & Grocery & $\begin{array}{l}\text { San } \\
\text { Francisco, CA }\end{array}$ & 5 & $\begin{array}{l}\text { 147, 153, } \\
\text { 161, 162, } \\
\text { and } 163\end{array}$ & $3 / 1 / 2012$ & 8/27/2013 \\
\hline Total & & & 15 & & & \\
\hline
\end{tabular}

The number of hours these systems were available were calculated using total number of hours systems were being monitored in Phase I minus the hours systems were not available (i.e., their power output was less than $1 \mathrm{kWe}$ ). All the units combined operated a total of about 190,000 hours which is approximately equivalent to 22 years. On average, these 15 CE5 units were available for about 13,000 hours during Phase I with a minimum of 5,000 (PCC units) ${ }^{1}$ and maximum of 16,000 hours (at Roger's Garden and Oakland Hills Country Club). The exact days of shut down for some units at Roger's Garden and Oakland Hills Country Club were never shared with PNNL, but the last date of data retrieval indicates these systems were running through sometime in November 2013.

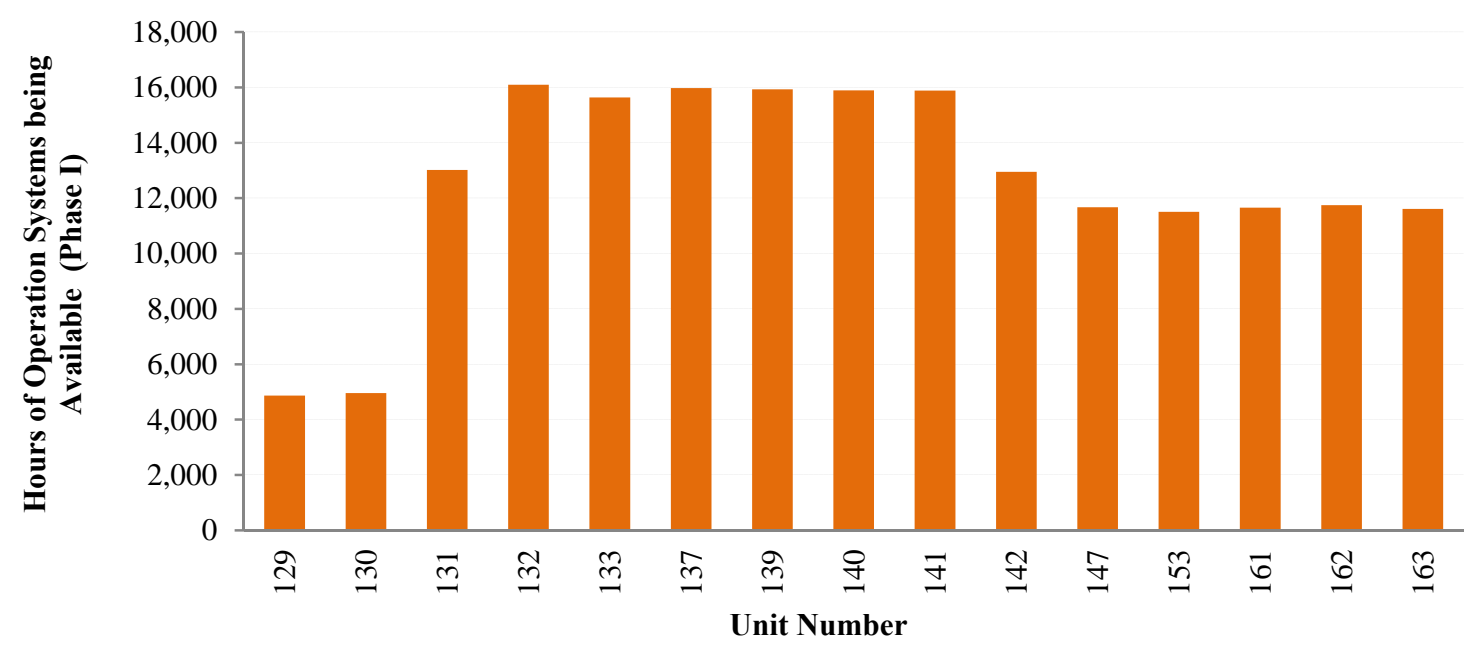

Figure 2.6. Total Number of System Availability Hours During the Operation Period and since Deployment of Each CE5 Unit in Phase I.

\footnotetext{
${ }^{1}$ Units 129 and 130 at PCC were shut down during the last week of May, 2012 per customer request which was due to site maintenance and unrelated to performance of the units. These units were never restarted in Phase I.
} 
The manufacturer-rated performance specifications for the systems installed in Phase I (i.e., CE5 units) are given in Table 2.6. As it was stated, one of the objectives of this field study and demonstration was to evaluate performance of each CHP-FCS unit as-installed versus the performance specifications of the system as-designed (i.e., as-manufactured). This comparison would help CHP-FCS manufacturers better understand behavior of systems designed under different climatic and operational conditions. It also makes it possible to improve design as well as operation of systems. In this study, PNNL data analysis led to several recommendations that resulted in system improvements and upgrades. Engineering performance parameters identified and used in this analysis were independently monitored and analyzed by PNNL.

Table 2.6. Manufacturer-Rated CHP-FCS Performance Specifications (in Phase I).

\begin{tabular}{ll}
\hline Fuel-Cell Parameters & Manufacturer-Rated FCS Performance Specifications \\
\hline Type & High-temperature PEM fuel cell \\
Membrane & Polybenzimidazole (PBI)-based membrane \\
Operating Temperature & $160^{\circ} \mathrm{C}$ \\
FCS Fuel & Natural gas \\
Electrical Output & $5 \mathrm{kWe}$ \\
Heat Recovery Output & $5.5 \mathrm{kWth}$ \\
Electrical Efficiency & $36 \%(\mathrm{HHV})$ \\
Heat Recovery Efficiency & $40 \%(\mathrm{HHV})$ \\
Heat Stream Temperature & up to $65^{\circ} \mathrm{C}$ \\
\hline
\end{tabular}

Phase I technical analysis can be divided into three distinct time periods - the initial time period from the time that the systems were deployed until February of 2012, the second time period between March 2012 and June 2012, when a change to electric power output set-point took place and finally, the third time period from July 2012 to the date systems were shut down to prepare for Phase II installations. The BOP upgrades took place in this period. These time periods and details of systems upgrades and their performance are described below.

1. . Data analysis of as-installed micro-FCS units - October 2011 to February 2012.

During this period, a total of 10 systems were installed between September and December 2011 (see Table 2.5). Initial data indicated that the systems had a long-term average production of about $4.5 \mathrm{kWe}$ of power. This was slightly below the manufacturer's stated rating of $5 \mathrm{kWe}$ electric power output. Furthermore, the power output declined for all units over this time period. Time-series data for all units can be found in Appendix A. The rate of decline averaged over all the fuel cells evaluated was about 0.16 kW per 1000 hours. This decline is the result of fuel-cell stack degradation. Results of detailed data analysis for each unit during this time period are summarized in Table 2.7. 
Table 2.7 Detailed Assessment for the 10 CE5 Systems Installed During the Initial Months of Operation

\begin{tabular}{|c|c|c|c|c|c|c|c|}
\hline Unit \# & 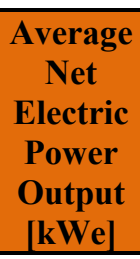 & $\begin{array}{l}\text { Average } \\
\text { Net Heat } \\
\text { Recovery } \\
* \text { [kWth] }\end{array}$ & $\begin{array}{c}\text { Temperature } \\
\text { To Site } \\
{\left[{ }^{\circ} \mathrm{C}\right]} \\
\end{array}$ & $\begin{array}{c}\text { Average } \\
\text { Net System } \\
\text { Electric } \\
\text { Efficiency } \\
{[\%]}\end{array}$ & $\begin{array}{c}\text { Average } \\
\text { Net Heat } \\
\text { Recovery } \\
\text { Efficiency } \\
* \\
{[\%]} \\
\end{array}$ & $\begin{array}{c}\text { Overall } \\
\text { Net } \\
\text { System } \\
\text { Efficiency } \\
{[\%]} \\
\end{array}$ & $\begin{array}{c}\text { Availability } \\
\mathbf{A}_{0} * * \\
\end{array}$ \\
\hline $\begin{array}{l}\text { Stated } \\
\text { value } \\
\rightarrow\end{array}$ & 5 & 6 & up to 65 & 36 & 40 & 76 & N/A \\
\hline 129 & $4.7 \pm 0.4$ & $5.3 \pm 0.4$ & $47.0 \pm 2.5$ & $33.2 \pm 2.4$ & $37.6 \pm 2.7$ & $70.8 \pm 5.0$ & 95.6 \\
\hline 130 & $4.6 \pm 0.4$ & $5.3 \pm 0.4$ & $46.5 \pm 1.9$ & $32.5 \pm 1.9$ & $36.8 \pm 2.2$ & $69.3 \pm 4.1$ & 96.3 \\
\hline 131 & $4.8 \pm 0.2$ & $5.4 \pm 0.3$ & $53.5 \pm 5.5$ & $33.3 \pm 1.8$ & $37.7 \pm 2.1$ & $71.0 \pm 3.9$ & 99.0 \\
\hline 132 & $4.8 \pm 0.2$ & $5.4 \pm 0.2$ & $51.5 \pm 5.7$ & $33.7 \pm 1.6$ & $38.2 \pm 1.8$ & $71.8 \pm 3.4$ & 97.0 \\
\hline 133 & $4.7 \pm 0.3$ & $5.3 \pm 0.4$ & $51.1 \pm 6.0$ & $34.2 \pm 2.0$ & $38.7 \pm 2.2$ & $72.9 \pm 4.2$ & 96.5 \\
\hline 137 & $4.5 \pm 0.4$ & $5.1 \pm 0.4$ & $58.8 \pm 2.8$ & $32.3 \pm 1.6$ & $36.6 \pm 1.8$ & $68.9 \pm 3.5$ & 95.5 \\
\hline 139 & $4.1 \pm 0.2$ & $4.7 \pm 0.2$ & $63.8 \pm 3.3$ & $32.1 \pm 3.0$ & $36.3 \pm 3.4$ & $68.5 \pm 6.5$ & 98.0 \\
\hline 140 & $4.0 \pm 0.4$ & $4.6 \pm 0.4$ & $63.5 \pm 3.8$ & $31.5 \pm 2.7$ & $35.7 \pm 3.0$ & $67.2 \pm 5.7$ & 93.9 \\
\hline 141 & $4.4 \pm 0.5$ & $5.0 \pm 0.5$ & $64.2 \pm 3.1$ & $33.3 \pm 1.7$ & $37.8 \pm 1.9$ & $71.2 \pm 3.6$ & 89.0 \\
\hline 142 & $4.1 \pm 0.4$ & $4.6 \pm 0.4$ & $63.4 \pm 3.8$ & $33.9 \pm 1.8$ & $38.4 \pm 2.1$ & $72.4 \pm 3.9$ & 96.8 \\
\hline
\end{tabular}

Notes: Data Analysis (net system electric efficiency) is based on HHV.

* Net heat recovery data are calculated values, derived from real-time measured values.

** Availability $\left(A_{0}\right)$ quantifies the system operating (at or above $1 \mathrm{~kW}$ ) time when compared to the total time since commissioning.

\section{Data analysis after set-point changes - March 2012 to June 2012.}

In this time period, the system set-point was changed based on PNNL's recommendations from 5 kWe to $4 \mathrm{kWe}$ for the near short term. This decision was made because the high power density had resulted in fast fuel-cell degradation. This had led to electric and heat efficiencies that were lower than manufacturer's rated performance specifications. This behavior is captured in time-series system efficiency data plotted and included in Appendix A. The fast degradation of the fuel cell also caused an unacceptable number of shut downs. Results of data analysis indicated that this recommendation resulted in more stable performance (i.e., more consistent net electric power output and overall system efficiency) and a long-term average production of about $4.0 \mathrm{kWe}$ of power. This value is consistent with the manufacturer's new set-point output of $4 \mathrm{kWe}$. However, there were some reliability issues that are manifested as decreased availability in this period from an average of $95.7 \%$ to an average of $88.9 \%$ (Table 2.8). The project team attributed these to the BOP component failures. Based on this analysis and the initial analysis performed by PNNL, BOP component upgrades were made in late-June/early-July 2012. Results of detailed data analysis for all 15 units that were in operation during this time period are summarized in Table 2.8. Time-series data for all units listed in Table 2.8 can be found in Appendix A. 
Table 2.8. Detailed Assessment for the 15 CE5 Systems in Operation after Set-Point Change

\begin{tabular}{|c|c|c|c|c|c|c|c|}
\hline Unit \# & $\begin{array}{c}\text { Average Net } \\
\text { Electric } \\
\text { Power Output } \\
\text { [kWe] }\end{array}$ & $\begin{array}{c}\text { Average Net } \\
\text { Heat } \\
\text { Recovery } \\
\text { [kWth]* } \\
\end{array}$ & $\begin{array}{c}\text { Temperature } \\
\text { To Site } \\
{\left[{ }^{0} \mathrm{C}\right]}\end{array}$ & $\begin{array}{l}\text { Average Net } \\
\text { System } \\
\text { Electric } \\
\text { Efficiency } \\
{[\%]} \\
\end{array}$ & $\begin{array}{c}\text { Average Net } \\
\text { Heat Recovery } \\
\text { Efficiency* } \\
{[\%]}\end{array}$ & $\begin{array}{l}\text { Overall Net } \\
\text { System } \\
\text { Efficiency } \\
{[\%]} \\
\end{array}$ & $\begin{array}{c}\text { Availability } \\
\mathbf{A}_{0}^{* *}\end{array}$ \\
\hline $\begin{array}{l}\text { Stated } \\
\text { value } \\
\rightarrow\end{array}$ & 4.0 & 4.5 & Up to 65 & 36 & 40 & 76 & N/A \\
\hline 129 & $3.9 \pm 0.3$ & $4.4 \pm 0.3$ & $43.8 \pm 3.4$ & $32.7 \pm 4.4$ & $37.1 \pm 5.0$ & $69.8 \pm 9.3$ & $-* * *$ \\
\hline 130 & $4 \pm 0.1$ & $4.5 \pm 0.1$ & $43.2 \pm 2.6$ & $34.0 \pm 2.6$ & $38.5 \pm 2.9$ & $72.5 \pm 5.5$ & $-* * *$ \\
\hline 131 & $3.9 \pm 0.2$ & $4.4 \pm 0.3$ & $48.8 \pm 3.6$ & $32.4 \pm 3.2$ & $36.7 \pm 3.7$ & $69.1 \pm 6.9$ & 84.1 \\
\hline 132 & $4.4 \pm 0.4$ & $5.0 \pm 0.5$ & $48.9 \pm 3.8$ & $32.7 \pm 1.1$ & $37.1 \pm 1.3$ & $69.8 \pm 2.4$ & 88.6 \\
\hline 133 & $4.2 \pm 0.4$ & $4.8 \pm 0.5$ & $47.1 \pm 4.0$ & $33.8 \pm 1.7$ & $38.3 \pm 2.0$ & $72.1 \pm 3.7$ & 75.2 \\
\hline 137 & $4.0 \pm 0.2$ & $4.5 \pm 0.2$ & $50.3 \pm 3.5$ & $33.6 \pm 2.9$ & $38.0 \pm 3.3$ & $71.6 \pm 6.3$ & 95.7 \\
\hline 139 & $4.0 \pm 0.2$ & $4.5 \pm 0.2$ & $56.5 \pm 3.2$ & $33.7 \pm 2.6$ & $38.3 \pm 2.9$ & $72.0 \pm 5.5$ & 98.8 \\
\hline 140 & $4.0 \pm 0.1$ & $4.5 \pm 0.1$ & $55.7 \pm 2.8$ & $33.7 \pm 1.2$ & $38.2 \pm 1.4$ & $71.9 \pm 2.6$ & 98.0 \\
\hline 141 & $4.0 \pm 0.2$ & $4.5 \pm 0.2$ & $57.1 \pm 3.0$ & $32.5 \pm 3.2$ & $36.9 \pm 3.7$ & $69.4 \pm 6.9$ & 92.8 \\
\hline 142 & $4.0 \pm 0.2$ & $4.5 \pm 0.2$ & $55.3 \pm 2.9$ & $34.6 \pm 2.0$ & $39.2 \pm 2.3$ & $73.8 \pm 4.2$ & 96.5 \\
\hline 147 & $3.9 \pm 0.2$ & $4.5 \pm 0.3$ & $47.3 \pm 5.2$ & $33.0 \pm 1.5$ & $37.3 \pm 1.7$ & $70.3 \pm 3.2$ & 82.2 \\
\hline 153 & $4.1 \pm 0.6$ & $4.7 \pm 0.6$ & $47.5 \pm 5.0$ & $33.3 \pm 3.0$ & $37.7 \pm 3.4$ & $71.0 \pm 6.4$ & 79.2 \\
\hline 161 & $4.0 \pm 0.1$ & $4.5 \pm 0.1$ & $47.8 \pm 5.4$ & $34.5 \pm 2.6$ & $39.2 \pm 2.9$ & $73.7 \pm 5.5$ & 88.3 \\
\hline 162 & $4.0 \pm 0.2$ & $4.5 \pm 0.3$ & $47.6 \pm 4.9$ & $34.4 \pm 2.9$ & $39.0 \pm 3.3$ & $73.4 \pm 6.2$ & 86.9 \\
\hline 163 & $4.0 \pm 0.1$ & $4.5 \pm 0.1$ & $47.6 \pm 5.4$ & $34.3 \pm 2.9$ & $38.9 \pm 3.2$ & $73.2 \pm 6.1$ & 89.1 \\
\hline
\end{tabular}

Notes: Data Analysis (net system electric efficiency) is based on HHV.

* Net heat recovery data are calculated values, derived from real-time measured values.

** Availability $\left(A_{o}\right)$ quantifies the system operating (at or above $1 \mathrm{~kW}$ ) time when compared to the total time since commissioning.

*** Availability of units 129 and 130 is not shown here as they were shut down during the last week of May, 2012 per customer request which was due to site maintenance and unrelated to CHP-FCSs performance.

3. Data analysis after balance-of-plant upgrades - July 2012 to Shutdown ${ }^{1,2}$.

Balance-of-plant (BOP) component upgrades for eight systems (the ones at Roger's Gardens and Fresh and Easy) were done during June and July 2012. There were four primary BOP changes and retrofits $^{3}$ that took place. These were:

a. Steam Pump Assembly (SPA), including in-house water flow sensor design

i. Eliminated numerous, sporadic shut downs due to erratic sensor performance

ii. Improved accuracy

iii. MTBFO improved dramatically and was increased to 4000-hour MTBFO, but with several persistent/new failure modes, which included:

\footnotetext{
${ }^{1}$ Shut down dates are tabulated for each unit in Table 2.5

${ }^{2}$ With an exception of units 129, 130, 137, 139, 140, 141, 142, which were never retrofitted with the BOP upgrades. Units 129 and 130 were down due to site maintenance since May 2012 (this was unrelated to the performance of CHP-FCSs ). Units 137, 139, 140, 141, and 142 were scheduled to have the BOP upgrades later and then that decision was modified and systems were scheduled to upgrade to the next generation units (PureCell System Model 5).

${ }^{3}$ This was referred to as the 'Retrofit C' Package.
} 
(1) Drift due to sensor clogging

(2) Filter degradation and debris

(3) Pressure sensor operation near upper limit

iv. Latest SPA design upgrade, which installed in summer 2012. This SPA was expected to bring MTBFO to 8,000 hour design target

b. New air flow sensor

i. Eliminated drift due to contamination

(1) Exceeding 10,000 hour MTBFO target

(2) The next generation technology (PureCell Model 5) will use dual (but nearly identical hardware) blower arrangement to reach solid $5 \mathrm{kWe}$

ii. Included upgraded Oil Pump Assembly (OPA) with this change

(1) Minor reliability culprit - new design eliminates some leak points and reduces cost

(2) Exceeding 12,000 hour MTBFO target

c. Improved water filtration

i. Contributes to a number of failure modes (SPA, Water Circulation Loop, FPS)

ii. Replacement period improved from $\sim 100$ hours to 2,500 hours

iii. Increased capacity design used for PureCell Model 5-5,000 hour replacement frequency

d. Improved Igniter

i. Ten-fold improvement on lifetime

(1) Includes software improvements to minimize system shut downs due to failures

ii. Nearly meeting 8,000-hour MTBFO target

iii. Purecell Model 5 were started with these igniters and ClearEdge was working on qualifying improved design

Data analysis indicated that the upgraded systems exhibited relatively more stable performance compared to their performance before these upgrades. Time-series data indicated long-term average electric power generation of about $4.0 \mathrm{kWe}$, which was the set-point selected. Furthermore, the reliability of the systems increased. This is manifested in the increased availability of units installed, which improved from $88.9 \%$ to $96.5 \%$ on average. Units 129 and 130 remained shut down during this time period because of construction site maintenance ongoing at Portland Community College, and all units at Oakland Hills Country Club were not yet retrofitted with BOP upgrades. These units were later replaced with the next generation fuel-cell technology (PureCell System Model 5).

The performance results for micro-CHP-FCS for each of the time periods covered above are summarized in Table 2.10 (as an average of all systems) and show how they compare with the manufacturer's rated performance specification. Over the duration of the operating time, the average electrical output of systems monitored was lower than $5 \mathrm{kWe}$, which was the rated electrical power output specified by the manufacturer. However, in the second and third time periods, the electric power setpoint was degraded to $4 \mathrm{kWe}$ and the average net electric power output in these time periods have much less deviation from the set-point. The average net electric efficiency, average net heat recovery efficiency and the overall net efficiency of all systems (on average) were all lower than the manufacturer's rated values during all time periods in Phase I. System availability and reliability however increased after BOP upgrades. 
Table 2.9. Detailed Assessment of eight CE5 Systems in Operation during the Third Time Period in Phase II (performance assessment of units 137, 139, 140, 141, and 142 are included in this Table although they were not retrofitted with BOP upgrades)

\begin{tabular}{|c|c|c|c|c|c|c|c|}
\hline Unit \# & $\begin{array}{c}\text { Average Net } \\
\text { Electric Power } \\
\text { Output } \\
\text { [kWe] }\end{array}$ & $\begin{array}{c}\text { Average Net } \\
\text { Heat } \\
\text { Recovery } \\
\text { [kWth] }{ }^{*} \\
\end{array}$ & $\begin{array}{c}\text { Temperature } \\
\text { To Site } \\
{\left[{ }^{\circ} \mathrm{C}\right]} \\
\end{array}$ & $\begin{array}{c}\text { Average Net } \\
\text { System } \\
\text { Electric } \\
\text { Efficiency } \\
{[\%]} \\
\end{array}$ & $\begin{array}{c}\text { Average Net } \\
\text { Heat Recovery } \\
\text { Efficiency* } \\
{[\%]}\end{array}$ & $\begin{array}{c}\text { Overall Net } \\
\text { System } \\
\text { Efficiency } \\
{[\%]} \\
\end{array}$ & $\begin{array}{c}\text { Availability } \\
\mathbf{A}_{0} \\
\end{array}$ \\
\hline $\begin{array}{l}\text { Stated } \\
\text { value } \\
\end{array}$ & 4.0 & 4.5 & up to 65 & 36 & 40 & 76 & N/A \\
\hline $129^{* * *}$ & - & - & - & - & - & - & - \\
\hline $130^{* * *}$ & - & - & - & - & - & - & - \\
\hline 131 & $3.9 \pm 0.2$ & $4.4 \pm 0.3$ & $49.7 \pm 4.5$ & $31.4 \pm 3.1$ & $35.6 \pm 3.5$ & $67.0 \pm 6.7$ & 94.8 \\
\hline 132 & $4.0 \pm 0.2$ & $4.5 \pm 0.2$ & $48.7 \pm 5$ & $32.7 \pm 2.6$ & $37.0 \pm 2.9$ & $69.7 \pm 5.4$ & 96.0 \\
\hline 133 & $4.0 \pm 0.2$ & $4.6 \pm 0.2$ & $47.7 \pm 5$ & $33.1 \pm 2.9$ & $37.6 \pm 3.2$ & $70.7 \pm 6.1$ & 95.7 \\
\hline $137^{* * * *}$ & $4.0 \pm 0.3$ & $4.5 \pm 0.3$ & $48.6 \pm 5.2$ & $32.8 \pm 2.7$ & $37.2 \pm 3.0$ & $70.0 \pm 5.7$ & 97.5 \\
\hline $139^{* * * *}$ & $4.0 \pm 0.2$ & $4.5 \pm 0.2$ & $51.2 \pm 7.4$ & $32.9 \pm 2.5$ & $37.3 \pm 2.9$ & $70.2 \pm 5.4$ & 95.3 \\
\hline $140^{* * * *}$ & $3.9 \pm 0.3$ & $4.4 \pm 0.3$ & $50.2 \pm 7.4$ & $31.4 \pm 3.4$ & $35.5 \pm 3.8$ & $66.9 \pm 7.2$ & 97.7 \\
\hline $141^{* * * *}$ & $4.0 \pm 0.2$ & $4.5 \pm 0.2$ & $50.6 \pm 8.4$ & $32.6 \pm 2.4$ & $36.9 \pm 2.7$ & $69.5 \pm 5.1$ & 97.2 \\
\hline $142^{* * * *}$ & $4.0 \pm 0.2$ & $4.5 \pm 0.2$ & $50.0 \pm 8.6$ & $33.5 \pm 2.9$ & $38.0 \pm 3.2$ & $71.5 \pm 6.1$ & 97.4 \\
\hline 147 & $4.0 \pm 0.2$ & $4.5 \pm 0.2$ & $47.8 \pm 5.5$ & $32.5 \pm 2.9$ & $36.8 \pm 3.3$ & $69.3 \pm 6.3$ & 98.5 \\
\hline 153 & $4.0 \pm 0.1$ & $4.5 \pm 0.2$ & $47.9 \pm 5.0$ & $33.7 \pm 1.8$ & $38.0 \pm 2.0$ & $71.9 \pm 3.7$ & 97.8 \\
\hline 161 & $4.0 \pm 0.1$ & $4.5 \pm 0.1$ & $47.7 \pm 5.1$ & $33.8 \pm 2.1$ & $38.0 \pm 2.4$ & $72.1 \pm 4.5$ & 96.1 \\
\hline 162 & $4.0 \pm 0.2$ & $4.5 \pm 0.2$ & $48.1 \pm 5.2$ & $35.0 \pm 2.2$ & $39.6 \pm 2.4$ & $74.6 \pm 4.6$ & 97.7 \\
\hline 163 & $4.0 \pm 0.2$ & $4.5 \pm 0.2$ & $48.4 \pm 5.1$ & $34.4 \pm 2.0$ & $39.0 \pm 2.2$ & $73.5 \pm 4.2$ & 95.5 \\
\hline
\end{tabular}

Notes: Data Analysis (net system electric efficiency) is based on HHV.

* Net heat recovery data are calculated values, derived from real-time measured values.

** Availability $\left(A_{o}\right)$ quantifies the system operating (at or above $1 \mathrm{~kW}$ ) time when compared to the total time since commissioning.

*** Units 129, 130 were shut down during this time per customer request which was due to site maintenance and unrelated to CHP-FCS performance.

**** Units 137, 139, 140,141, 142 were scheduled to have the BOP upgrades later and then then that decision was modified and systems were scheduled to upgrade to the next generation units (PureCell System Model 5). Therefore, performance results tabulated show performance of systems without BOP upgrades.

Table 2.10. Micro-CHP-FCS Performance Summary during Phase I

\begin{tabular}{|c|c|c|c|c|}
\hline & & Initial Period & $\begin{array}{l}\text { After Set-Point } \\
\text { Changes }\end{array}$ & $\begin{array}{c}\text { After BOP } \\
\text { Upgrades }\end{array}$ \\
\hline Performance Indicators & Stated Value & $\begin{array}{l}\text { Oct. } 2011 \text { to } \\
\text { Feb. } 2012\end{array}$ & $\begin{array}{l}\text { Mar. } 2012 \text { to } \\
\text { Jun. } 2012\end{array}$ & $\begin{array}{c}\text { Jul. } 2012 \text { to } \\
\text { Jul. } 2013\end{array}$ \\
\hline Number of Operating Units & -- & $10^{(\mathrm{c})}$ & $15^{\text {(d) }}$ & $8^{(e)}$ \\
\hline Average Net Electric Power Output (kWe) & 5.0 & $4.5 \pm 0.3$ & $4.0 \pm 0.2$ & $4.0 \pm 0.2$ \\
\hline Average Net Heat Recovery ${ }^{(\mathrm{a})}(\mathrm{kWt})$ & 5.5 & $5.1 \pm 0.4$ & $4.6 \pm 0.2$ & $4.5 \pm 0.1$ \\
\hline Temperature to Site $\left({ }^{\circ} \mathrm{C}\right)$ & Up to 65 & $56.3 \pm 3.8$ & $49.6 \pm 3.9$ & $48.3 \pm 5.0$ \\
\hline Average Net System Electric Efficiency ${ }^{(\mathrm{b})}$ (\%) & 36 & $33.0 \pm 2.0$ & $33.5 \pm 2.5$ & $33.3 \pm 2.4$ \\
\hline Average Net Heat Recovery Efficiency ${ }^{(\mathrm{b})}(\%)$ & 40 & $37.4 \pm 2.3$ & $38.0 \pm 2.8$ & $37.8 \pm 2.8$ \\
\hline Overall Net System Efficiency $^{(\mathrm{b})}(\%)$ & 76 & $70.4 \pm 4.4$ & $71.6 \pm 5.4$ & $71.1 \pm 5.2$ \\
\hline Availability $\mathrm{A}_{\mathrm{o}}(\%)$ & & $95.7 \pm 2.7$ & $88.9 \pm 7.39$ & $96.5 \pm 1.3$ \\
\hline
\end{tabular}

a. The average heat recovery values are calculated by the manufacturer, and do not represent a measured value.

b. Efficiencies are based on HHV.

c. Units 147, 153, 161, 162, and 163 were installed in March 2012.

d. Units 129 and 130 were taken down due to site maintenance in May 2012 (unrelated to the performance of CHP-FCSs).

e. Units 137, 139, 140,141, and 142 were scheduled to have the BOP upgrades later and then that decision was modified and systems were scheduled to upgrade to the next generation units (PureCell System Model 5). 


\subsection{Technical Assessment - Phase II}

In Phase II, 10 out of 15 systems were replaced with the new-generation units (PureCell System Model 5, or M5). The other five CE5 systems (at Fresh and Easy) were shut down but were never upgraded as a result of infrastructure improvements that were required but never performed. In these models, the high-temperature PEM (PBI membranes) technology was replaced with phosphoric acid fuel cell (UTC Power Technology) to achieve higher power availability and longer lifetime. The CE5 technology used in Phase I consisted of 102 cells using PBI membranes and molded carbon plats. The PBI MEAs degradation rate in these fuel cells did not meet design intents. The lower plate lifetime (when compared to the expected lifetime) was because of acid absorption and structural issues. Therefore, CE5 was discontinued in this project and the alternative technology (UTC Power Technology) was deployed.

The most substantial change incorporated in the units already in place was the UTC's stack, which meant a redesign of the electrical system because it ran at lower voltage. To replace the stacks with UTC ones, the unit had to be repackaged due to the larger platform of the power electronic module. To do this, ClearEdge decided to also improve ventilation, water filtration, and airflow in the units. They also added a heat exchanger module on top of the unit and glycol cooling. This allowed the system to reject heat using the liquid cooling loop instead of the CE5's air system, which was limiting installations at some indoor locations.

The manufacturer-rated performance specifications for systems designed and deployed in the second Phase of this micro CHP-FCS demonstration are summarized in Table 2.11. The subset of stacks in the new units was expected to have 80,000 hours of field experience ( 10 years), which is twice the lifetime of CE5 units in Phase I. Most BOP upgrades for these systems were fundamentally the same as those used in the CE5s Phase I. The manufacture's predictions from existing fleet experience indicated that M5 units would meet the design goal of only two unplanned shut downs per year, and four (quarterly) scheduled, preventive maintenance visits by service personnel.

Table 2.11. Manufacturer-Rated CHP-FCS Performance Specifications in Phase II.

\begin{tabular}{ll}
\hline Fuel-Cell Parameters & Manufacturer-Rated FCS Performance Specifications \\
\hline Type & Phosphoric acid fuel cell (UTC Power Technology) \\
Operating Temperature & $160^{\circ} \mathrm{C}$ \\
FCS Fuel & Natural gas \\
Electrical Output & $5 \mathrm{kWe}$ \\
Heat Recovery Output & $5.5 \mathrm{kWth}$ \\
Electrical Efficiency & $36 \%(\mathrm{HHV})$ \\
Heat Recovery Efficiency & $40 \%(\mathrm{HHV})$ \\
Heat Stream Temperature & up to $65^{\circ} \mathrm{C}$ \\
\hline
\end{tabular}

The new product, ClearEdge M5 micro CHP-FCS, was released starting in summer of 2013. The new unit had a larger overall footprint of 62 inches wide $\times 36$ inches deep $\times 88$ inches tall (which was about double the size of the CE5 system), but this provided front access for all maintenance required. These new units could be placed adjacent to one another and back to back, which made them more amendable for commercial applications (see Figure 2.7). A summary of units upgraded with M5 technology is included in Table 2.12 (new unit numbers were assigned in this phase for identification purposes). 4 billion data points were recorded and analyzed between July 2013 and beginning of July 2014. 

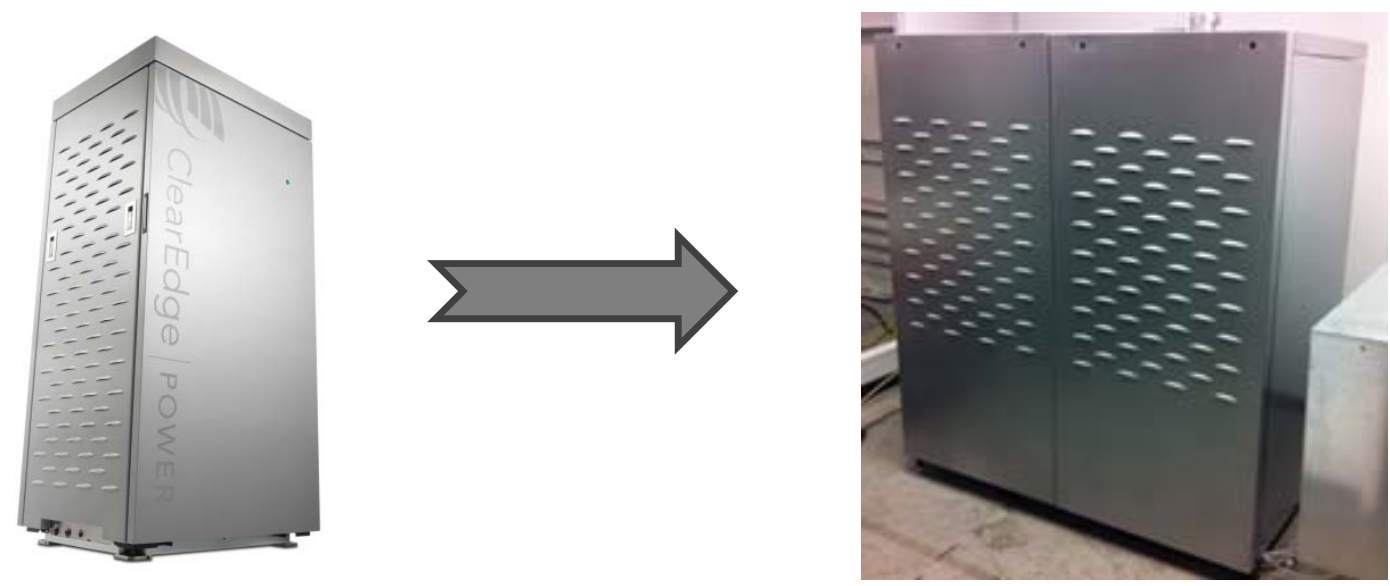

Figure 2.7. CE5 in Phase I Is Shown on the Left and M5 Installed During Phase II is Shown on the Right.

To replace CE5 systems with the new M5 units, ClearEdge proposed shutting down PNNL systems proactively and before they reached the end of their lifetime ${ }^{1}$. They recommended shutting down and replacing two units first, one at Roger's Garden and the other at Oakland Hills Country Club. These units were replaced in late July and August of 2013. Figure 2.8 shows the number of hours these systems were in operation ${ }^{2}$. All systems were eventually replaced except for those at Fresh and Easy. All 10 units replaced were operated for a total of about 44,000 hours and more than 4 billion data points were recorded and analyzed between July 2013 and beginning of July 2014.

Table 2.12. Summary of Building Type, Location, Number of Units, Unit Numbers, and Installation Dates (Phase II)

\begin{tabular}{|c|c|c|c|c|c|}
\hline Partner/Site & $\begin{array}{l}\text { Building } \\
\text { Type }\end{array}$ & Location & $\begin{array}{l}\text { Number } \\
\text { of Units }\end{array}$ & Unit \# & $\begin{array}{l}\text { Installation } \\
\text { Date }\end{array}$ \\
\hline \multirow{2}{*}{$\begin{array}{l}\text { Portland Community } \\
\text { College (PCC) }\end{array}$} & \multirow{2}{*}{ College } & \multirow{2}{*}{ Portland, OR } & \multirow{2}{*}{2} & SN11 & \multirow{2}{*}{$2 / 7 / 2014$} \\
\hline & & & & SN14 & \\
\hline \multirow{3}{*}{ Roger’s Garden } & \multirow{3}{*}{ Nursery } & \multirow{3}{*}{$\begin{array}{l}\text { Corona Del Mar, } \\
\text { CA }\end{array}$} & \multirow{3}{*}{3} & $\mathrm{P} 2$ & $7 / 26 / 2013$ \\
\hline & & & & SW15 & \multirow{2}{*}{$2 / 1 / 2014$} \\
\hline & & & & SW18 & \\
\hline \multirow{4}{*}{$\begin{array}{l}\text { Oakland Hills Country } \\
\text { Club }\end{array}$} & \multirow{4}{*}{ Recreation } & \multirow{4}{*}{ Oakland, CA } & \multirow{4}{*}{5} & SW1 & $12 / 27 / 2013$ \\
\hline & & & & SW2, SW3 & $1 / 3 / 2014$ \\
\hline & & & & SW6 & $1 / 13 / 2014$ \\
\hline & & & & P3 & 8/9/2013 \\
\hline Fresh \& Easy & Grocery & San Francisco, CA & 0 & N/A & N/A \\
\hline Total & & & 10 & & \\
\hline
\end{tabular}

\footnotetext{
${ }^{1}$ These unit replacements took place at no cost to the government. As a result, PNNL was not provided with cost information about the M5 and was not able to perform an additional economic analysis.

${ }^{2}$ PNNL does not have the exact date of shut down for these systems and hours of operation shown mostly represent number of hours for which data were collected and analyzed.
} 


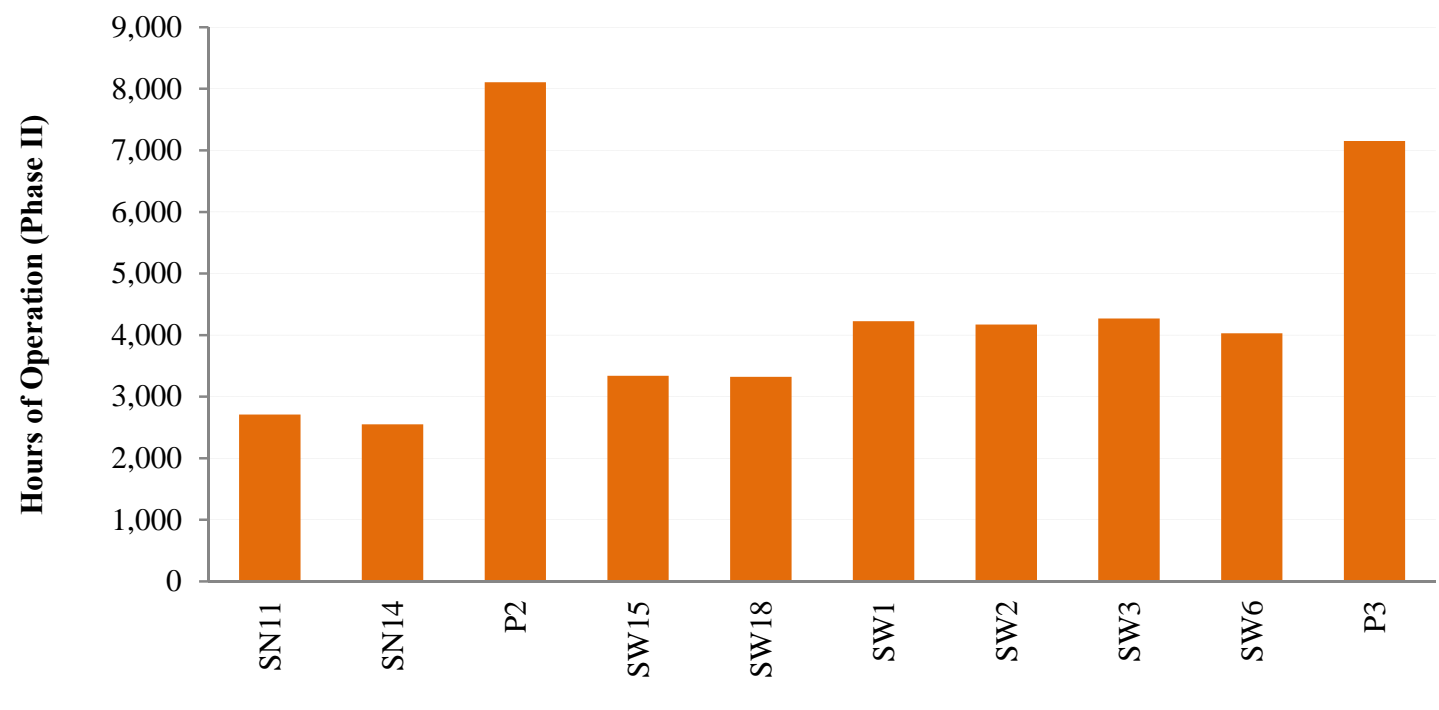

Unit Number

Figure 2.8. Total Number of Hours of Operation for Each M5 Unit Installed in Phase II

When Doosan purchased ClearEdge out of their bankruptcy in July 2014, all of the systems went offline and PNNL was not provided with any more data. These systems were still running when data collections went offline. Cell stacks were performing well at all systems and had not reached the end of their lifetime when PNNL data access was terminated. However, due to lack of maintenance and limitations with parts and manpower issues given the situation following ClearEdge Power's bankruptcy, the power set-point was degraded in some systems in the last month as time-series data indicate. Results of data analysis for system installed and monitored in Phase II of this demonstration are tabulated in Table 2.13. Time-series data for these 10 systems are included in Appendix B.

Table 2.13. Performance Evaluation of Systems Monitored in Phase II

\begin{tabular}{|c|c|c|c|c|c|c|c|}
\hline Unit \# & $\begin{array}{c}\text { Average Net } \\
\text { Electric } \\
\text { Power Output } \\
\text { [kWe] }\end{array}$ & $\begin{array}{c}\text { Average Net } \\
\text { Heat } \\
\text { Recovery* } \\
\text { [kWth] }\end{array}$ & $\begin{array}{c}\text { Temperature } \\
\text { To Site } \\
{\left[{ }^{\circ} \mathrm{C}\right]}\end{array}$ & $\begin{array}{c}\text { Average Net } \\
\text { System } \\
\text { Electric } \\
\text { Efficiency } \\
{[\%]}\end{array}$ & $\begin{array}{c}\text { Average Net } \\
\text { Heat Recovery } \\
\text { Efficiency* } \\
{[\%]}\end{array}$ & $\begin{array}{c}\text { Overall Net } \\
\text { System } \\
\text { Efficiency } \\
{[\%]}\end{array}$ & $\begin{array}{c}\text { Availability } \\
\mathbf{A}_{\mathbf{0}}^{* *}\end{array}$ \\
\hline SN11 & $4.3 \pm 1.0$ & $4.9 \pm 1.1$ & $45.3 \pm 6.3$ & $37.2 \pm 1.3$ & $42.2 \pm 1.5$ & $79.4 \pm 2.8$ & 91.8 \\
\hline SN14 & $4.7 \pm 0.5$ & $5.3 \pm 0.6$ & $41.6 \pm 3.9$ & $36.7 \pm 1.1$ & $41.6 \pm 1.3$ & $78.3 \pm 2.4$ & 86.4 \\
\hline P2 & $5.0 \pm 0.1$ & $5.6 \pm 0.1$ & $48.4 \pm 5.9$ & $34.8 \pm 0.3$ & $39.4 \pm 0.4$ & $74.2 \pm 0.7$ & 99.7 \\
\hline SW15 & $4.9 \pm 0.6$ & $5.6 \pm 0.7$ & $44.0 \pm 6.3$ & $34.7 \pm 1.4$ & $39.3 \pm 1.6$ & $74.0 \pm 3.0$ & 93.4 \\
\hline SW18 & $4.9 \pm 0.2$ & $5.6 \pm 0.2$ & $53.4 \pm 7.8$ & $35.7 \pm 0.5$ & $40.5 \pm 0.6$ & $76.2 \pm 1.1$ & 92.9 \\
\hline SW1 & $4.7 \pm 0.4$ & $5.3 \pm 0.5$ & $53.2 \pm 3.5$ & $34.8 \pm 1.1$ & $39.4 \pm 1.2$ & $74.2 \pm 2.3$ & 95.2 \\
\hline SW2 & $4.7 \pm 0.5$ & $5.3 \pm 0.6$ & $53.0 \pm 3.6$ & $35.6 \pm 0.8$ & $40.4 \pm 0.9$ & $76.0 \pm 1.6$ & 97.6 \\
\hline SW3 & $5.0 \pm 0.2$ & $5.6 \pm 0.2$ & $53.4 \pm 2.7$ & $36.6 \pm 2.0$ & $41.5 \pm 2.3$ & $78.1 \pm 4.3$ & 100.0 \\
\hline SW6 & $4.8 \pm 0.2$ & $5.4 \pm 0.3$ & $52.5 \pm 3.2$ & $36.4 \pm 0.6$ & $41.3 \pm 0.7$ & $77.7 \pm 1.3$ & 99.9 \\
\hline P3 & $4.7 \pm 0.6$ & $5.4 \pm 0.7$ & $39.6 \pm 5.3$ & $35.1 \pm 1.5$ & $39.8 \pm 1.7$ & $75.0 \pm 3.2$ & 91.7 \\
\hline
\end{tabular}

Notes: Data Analysis (net system electric efficiency) is based on HHV.

* Net heat recovery data are calculated values, derived from real-time measured values.

** Availability $\left(A_{o}\right)$ quantifies the system operating (at or above $1 \mathrm{~kW}$ ) time when compared to the total time since commissioning. 
Results of performance evaluation for all CHP-FCS installed, operated, and monitored in Phase II are summarized in Table 2.14 (averages for all 10 units). Table 2.14 shows how the results of data analysis compare with the manufacturer's rated performance specification. Over the duration of the operating time, the average electric power output of systems monitored was slightly lower than $5 \mathrm{kWe}$, which was the rated electrical power output specified by the manufacturer. The average net electric efficiency, average net heat recovery efficiency and the overall net efficiency of all systems (on average) were very consistent and near the manufacturer's rated values. System availability however is lower than expected on average, but this value was mainly pulled down because of lack of maintenance at some sites in the last month as time-series data indicate.

Table 2.14. Micro-CHP-FCS Performance Summary in Phase II

\begin{tabular}{|c|c|c|}
\hline \multicolumn{3}{|c|}{ Total Time M5 Systems Were Monitored } \\
\hline Performance Indicators & $\begin{array}{l}\text { Stated } \\
\text { Value }\end{array}$ & Jul. 2013 to Jul. 2014 \\
\hline Number of Operating Units & -- & 10 \\
\hline Average Net Electric Power Output (kWe) & 5.0 & $4.8 \pm 0.4$ \\
\hline Average Net Heat Recovery ${ }^{(a)}(\mathrm{kWt})$ & 5.5 & $5.4 \pm 0.5$ \\
\hline Temperature to Site $\left({ }^{\circ} \mathrm{C}\right)$ & Up to 65 & $42.9 \pm 4.8$ \\
\hline Average Net System Electric Efficiency ${ }^{(\mathrm{b})}(\%)$ & 36 & $35.8 \pm 1.1$ \\
\hline Average Net Heat Recovery Efficiency ${ }^{(\mathrm{b})}(\%)$ & 40 & $40.5 \pm 1.2$ \\
\hline Overall Net System Efficiency $^{(\mathrm{b})}(\%)$ & 76 & $76.3 \pm 2.3$ \\
\hline Availability $\mathrm{A}_{\mathrm{o}}(\%)$ & & 94.8 \\
\hline
\end{tabular}

\subsection{System Performance Comparison - Phase I vs. Phase II}

Results of data analysis for CE5 models installed in Phase I and M5 units in Phase II indicate improvement in electrical power output (from 4.1 to $4.9 \mathrm{kWe}$ ), heat generated (from 4.7 to $5.4 \mathrm{kWth}$ ), and availability (from $94 \%$ to $95 \%$ ). The net system electric efficiency, net heat recovery efficiency, and overall system efficiency increased on average as shown in 
Table 2.15. The water temperature was however reduced from $51^{\circ} \mathrm{C}$ to $43^{\circ} \mathrm{C}\left(123^{\circ} \mathrm{F}\right.$ to $\left.106^{\circ} \mathrm{F}\right)$. This was because the water temperature set-point was reduced and it can be controlled depending on the site demand.

Figure 2.9 illustrates total operating hours for the CE5 vs. M5 models. It should be noted that M5 units had a higher life expectancy of 80,000 hours which is twice the life expectancy of CE5 systems. However, PNNL data access to M5 units was terminated prematurely before they reached the end of their life. As a result, the total number of hours these units were monitored and data were collected are less than CE5 systems. However, the length of each time period mentioned in Technical Assessment - Phase I (summarized in Table 2.10) is relatively more comparable with the time period in Phase II. For example, after BOP upgrades, 8 CE5 systems ran for about 12 months from July 2012 to June 2013. Two M5 units ran for about the same 12 month time period from July 2013 to June 2014. 
Table 2.15. Summary of Performance Evaluation of System in Phase I vs. Phase II

\begin{tabular}{|c|c|c|c|}
\hline & & CE4 (Phase I) & M5 (Phase II) \\
\hline Performance Indicators & $\begin{array}{l}\text { Stated } \\
\text { Value }\end{array}$ & Oct. 2011 to Jul. 2013 & Jul. 2013 to Jul. 2014 \\
\hline Number of Operating Units & -- & 15 & 10 \\
\hline Average Net Electric Power Output (kWe) & 5.0 & $4.1 \pm 0.2$ & $4.8 \pm 0.4$ \\
\hline Average Net Heat Recovery ${ }^{(a)}(\mathrm{kWt})$ & 5.5 & $4.6 \pm 0.3$ & $5.4 \pm 0.5$ \\
\hline Temperature to Site $\left({ }^{\circ} \mathrm{C}\right)$ & Up to 65 & $51.1 \pm 5.0$ & $42.9 \pm 4.8$ \\
\hline $\begin{array}{l}\text { Average Net System Electric Efficiency }{ }^{(b)} \\
(\%)\end{array}$ & 36 & $33.1 \pm 2.4$ & $35.8 \pm 1.1$ \\
\hline $\begin{array}{l}\text { Average Net Heat Recovery Efficiency }{ }^{(\mathrm{b})} \\
(\%)\end{array}$ & 40 & $37.5 \pm 2.7$ & $40.5 \pm 1.2$ \\
\hline Overall Net System Efficiency ${ }^{(\mathrm{b})}(\%)$ & 76 & $70.7 \pm 5.2$ & $76.3 \pm 2.3$ \\
\hline Availability $\mathrm{A}_{\mathrm{o}}(\%)$ & & 93.5 & 94.8 \\
\hline \multicolumn{4}{|c|}{$\begin{array}{l}\text { a. The average heat recovery values are calculated by the manufacturer, and do not represent a measured value } \\
\text { b. Efficiencies are based on HHV }\end{array}$} \\
\hline
\end{tabular}

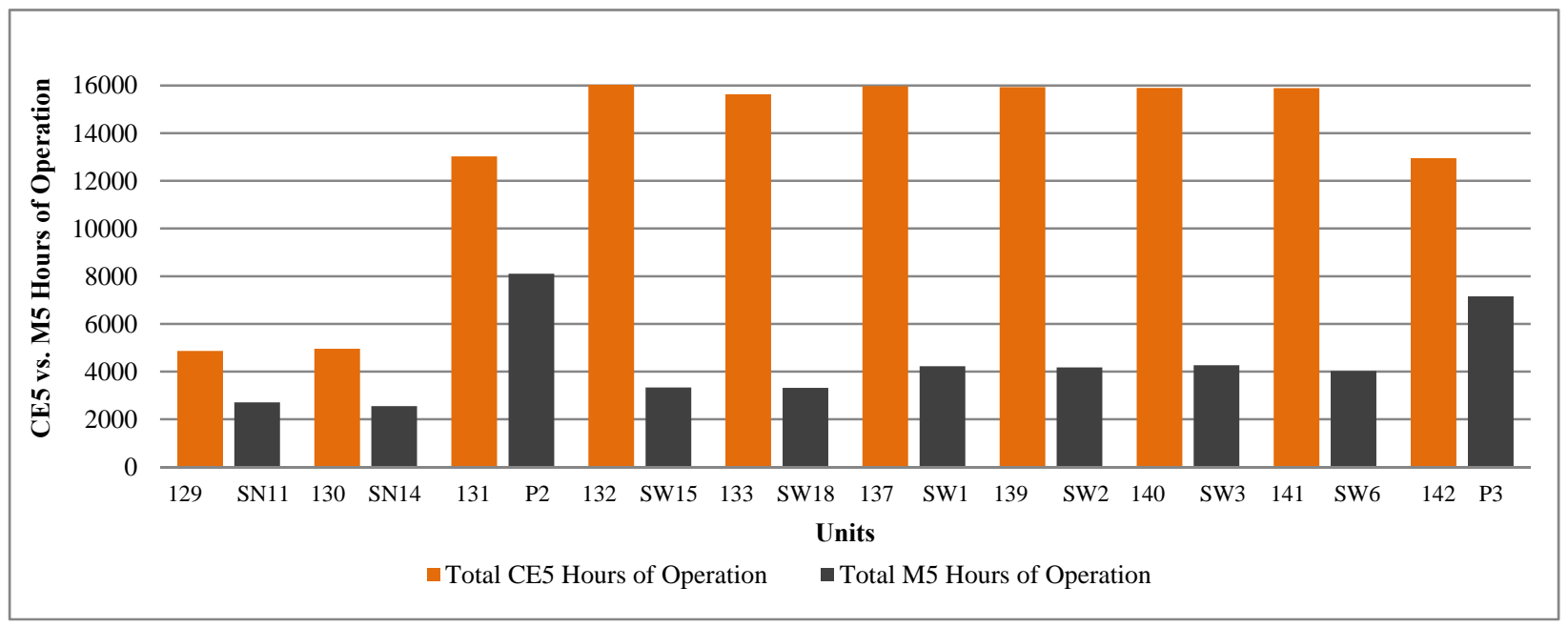

Figure 2.9. Comparing Hours of Operations of CE5 vs. M5 Units

The average electric power outputs of CE5 CHP-FCSs are compared with those of M5 models for the 10 units that were replaced with M5 model in Phase II and shown in Figure 2.10. Although the net electric power outputs of M5 systems increased when compared to those of CE5 (on average for the time period systems were monitored), the average standard deviation is much higher for some systems (see 129 vs. SN11 in Figure 2.10). Time-series data (see Appendix B) indicate that this unit was due for maintenance but due to lack of manpower in the last couple of months of data collection (May and June 2014), electric power set-point was reduced as a remedy, but this does not seem to have been sufficient and the system was still having some issues. Therefore, the standard deviation of net electric power out has increased. 


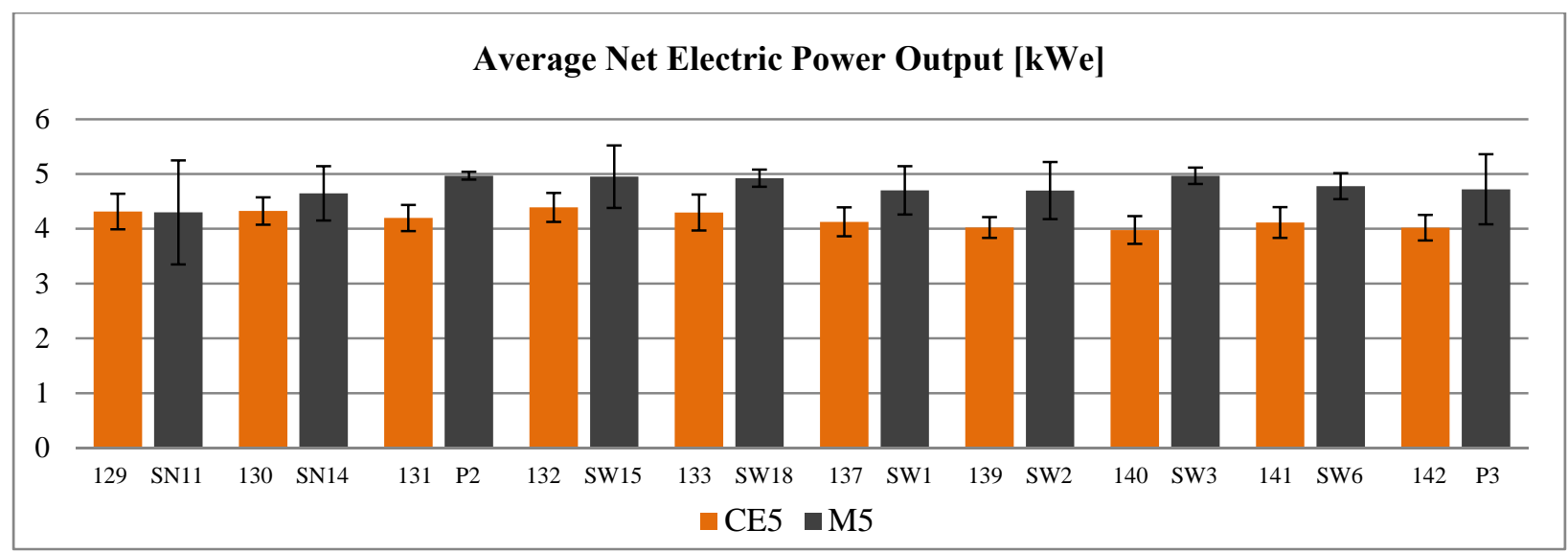

Figure 2.10. Average Net Electric Power Output (kWe) of CE5 vs. M5 Models

Similarly, the averages of net system electric efficiency, net heat recovery, net heat recovery efficiency, overall net system efficiency, temperature of water sent to site, and system availability are depicted respectively in Figure 2.11, Figure 2.12, Figure 2.13, Figure 2.14, Figure 2.15, and Figure 2.16. It should be noted that because systems were installed at different times, averages shown are over the time each unit was in operation. Therefore, the lengths of data analysis are not necessarily the same from system A in Phase I to system B in Phase II nor from system B in Phase II to another system in the same phase. Yet, they provide good results to evaluate performance of these systems when compared to each other. As it is shown, the average standard deviations for net electric efficiency of all systems are relatively lower in systems installed in Phase II.

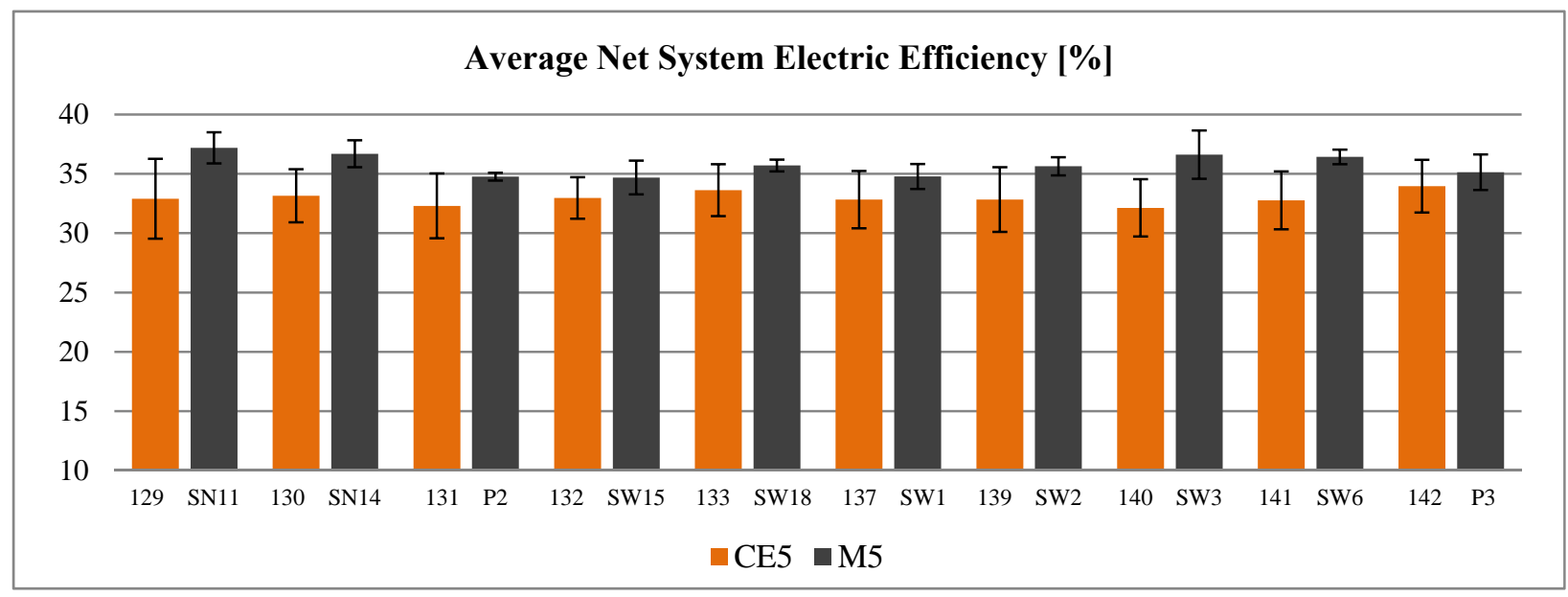

Figure 2.11. Average Net System Electric Power Efficiency [\%] of CE5 vs. M5 Models 


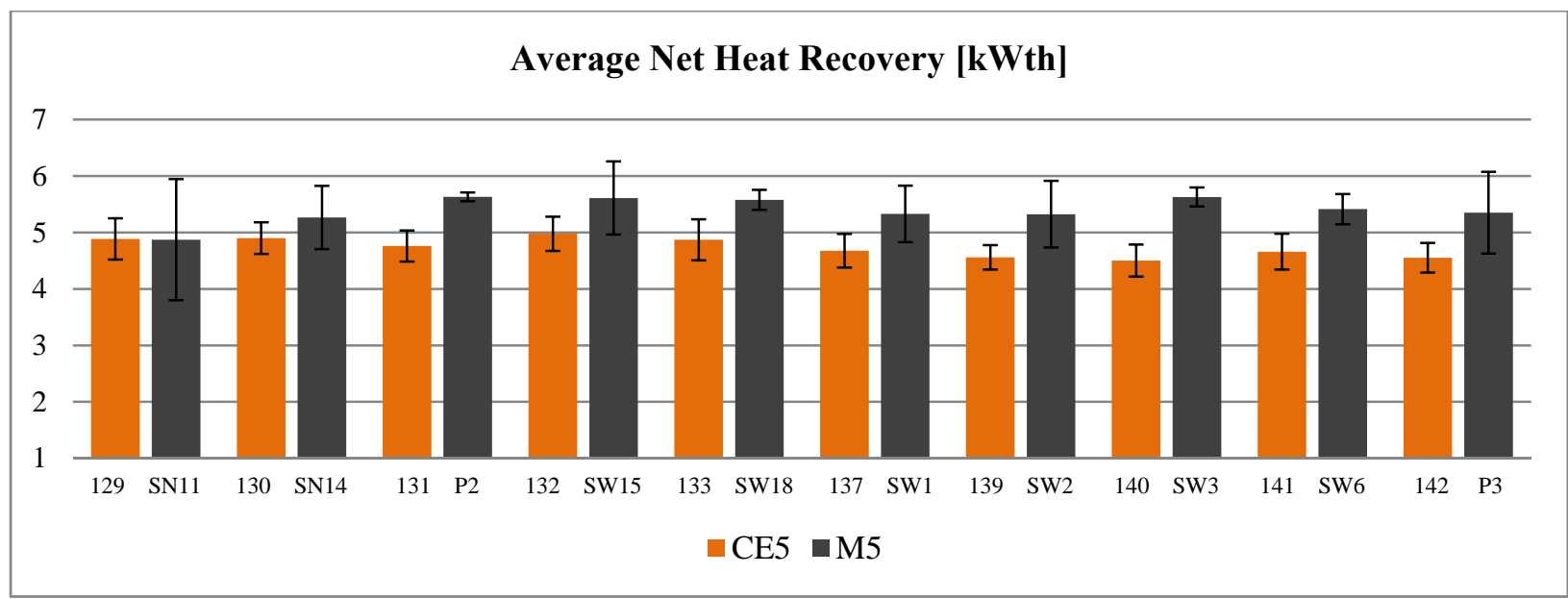

Figure 2.12. Average Net Heat Recovery (kWth) of CE5 vs. M5 Models

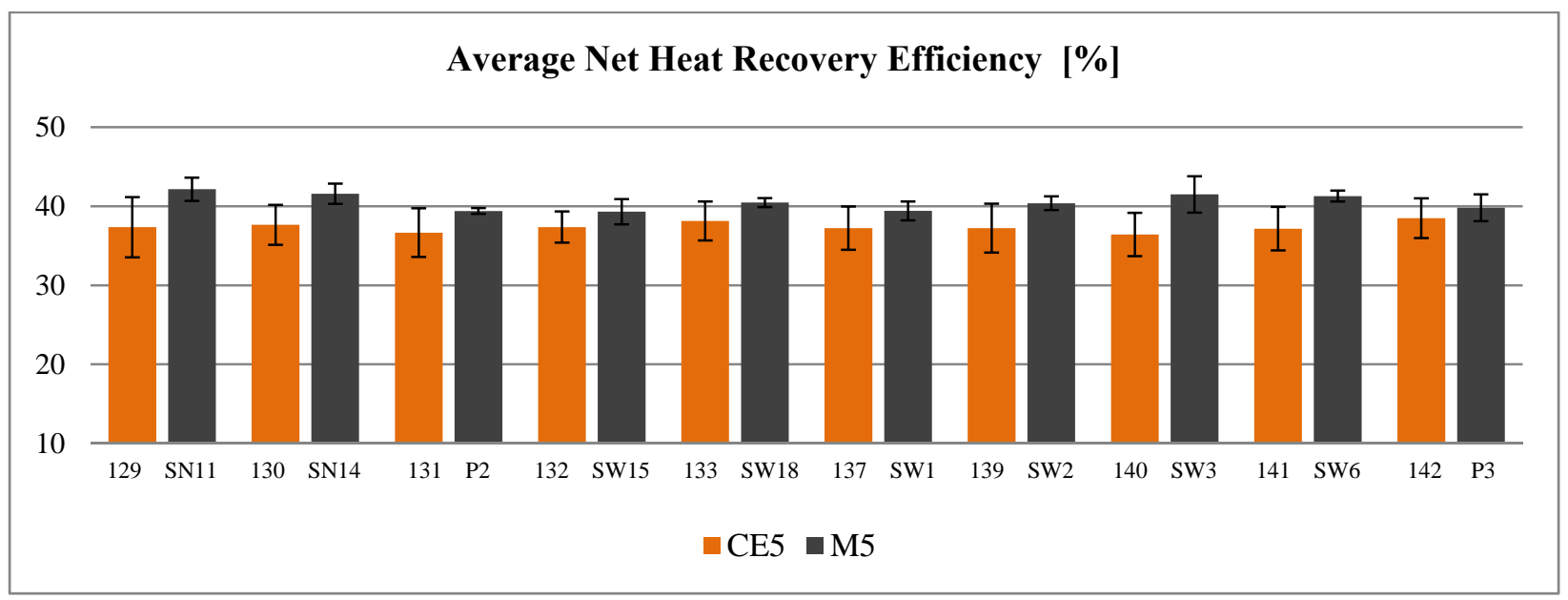

Figure 2.13. Average Net Heat Recovery Efficiency [\%] of CE5 vs. M5 Models

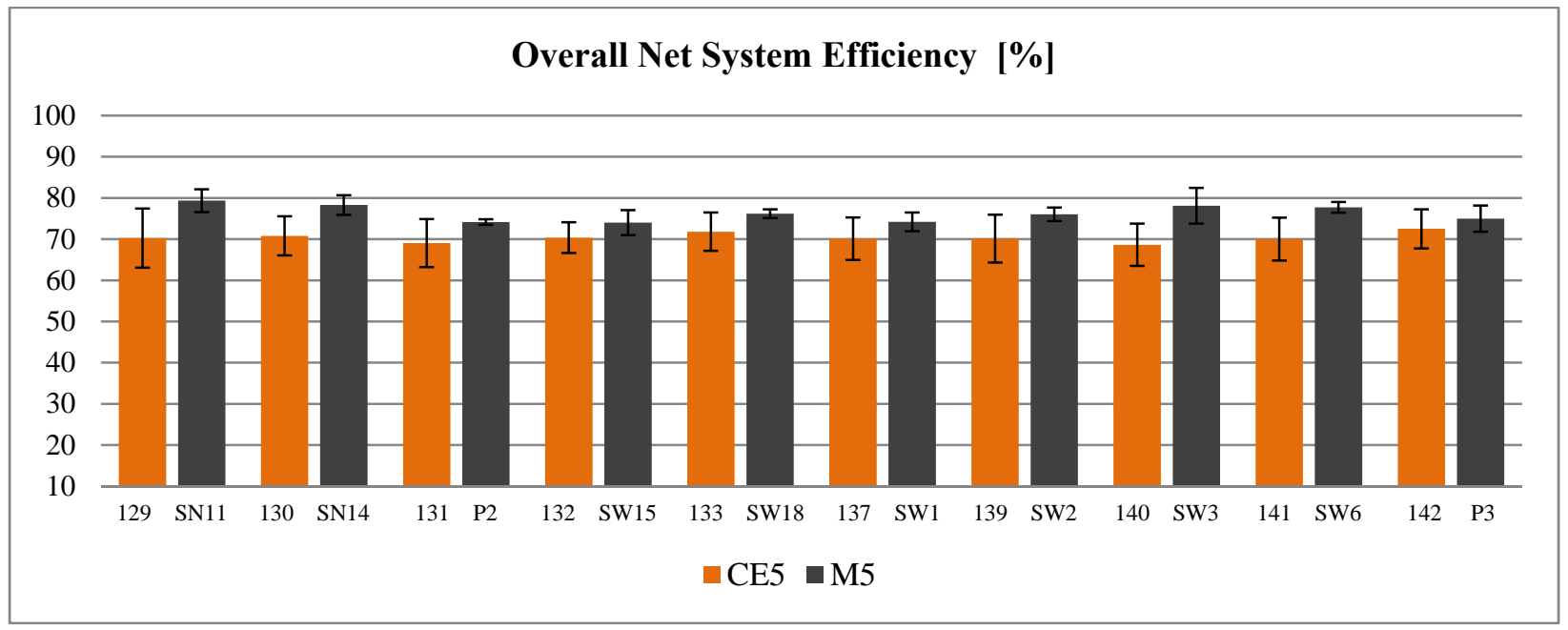

Figure 2.14. Overall Net System Efficiency [\%] of CE5 vs. M5 Models 


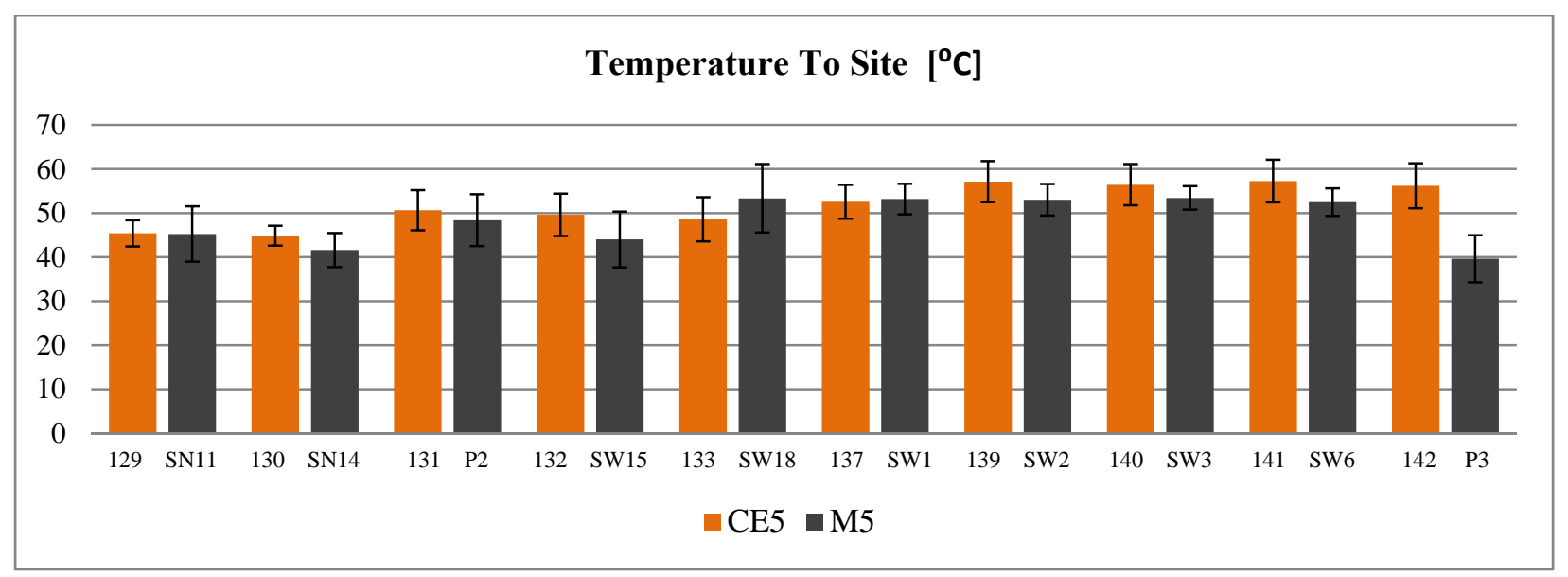

Figure 2.15. Temperature of Water Sent to Site $\left[{ }^{0} \mathrm{C}\right]$ for CE5 vs. M5 Models

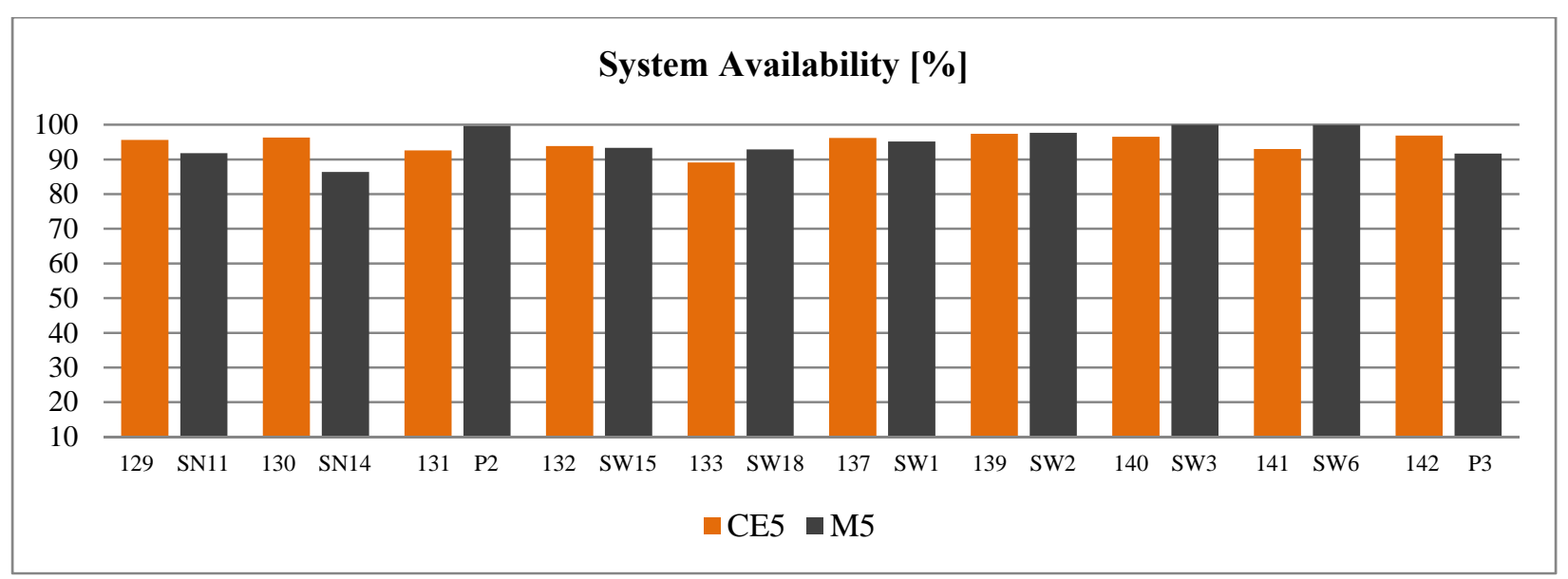

Figure 2.16. Percentage of System Availability in CE5 Models vs. M5

Figure 2.19 shows how the net electric power output of one of the CE5 systems (unit 131 at Roger's Garden) in Phase I compares with the net electric power output of the M5 (P2 installed at the same location) over time. Although the net electric power output seems to be consistent in CE5 until the end of April 2013, degradation in the net electric efficiency and the overall system efficiency (shown in Figure 2.18 and Figure 2.19 respectively) indicate that the gas input of the system had been increased to keep the net power output consistent and reliable. Then, a stack replacement had taken place (around mid-October 2012) to boost up system efficiency to the value specified by the manufacturer. The red dots in timeseries data plots indicate expected (i.e., that of the manufacturer) rated value of performance indicators and the black line shows an average value over the time period shown.

On the other hand, both the net electric power output of the M5 system (Figure 2.17), net electric efficiency (Figure 2.18) and overall efficiency of this system (Figure 2.19) are consistent indicating the gas input had not been manipulated to sustain the reliability of the net electric power output of the system. Beginning November 2013, some maintenance took place, but the overall average efficiency of the system is not that far off from manufacturer's rated value (i.e., the distance between the black line and the red dotted line). 

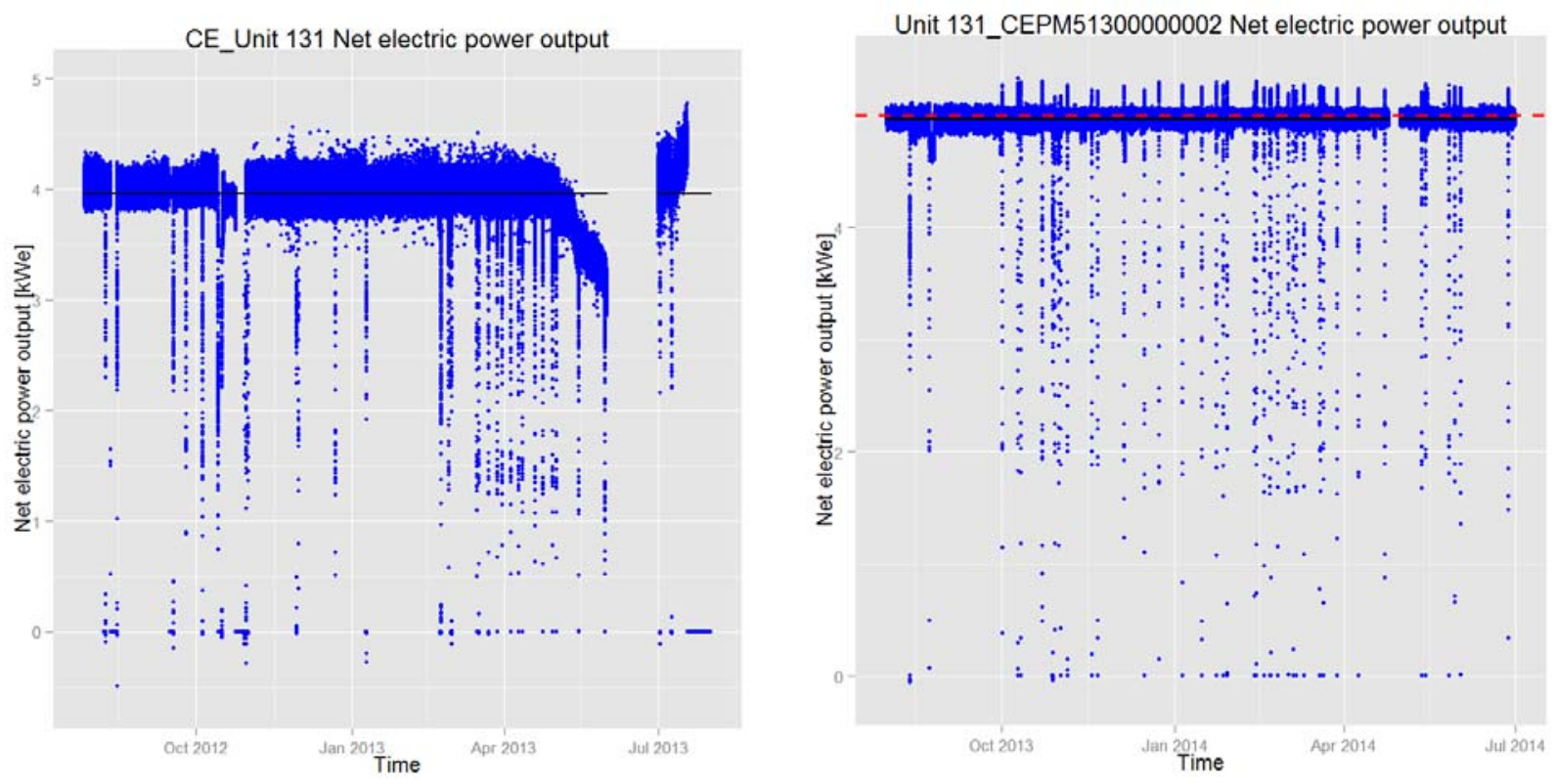

Figure 2.17. Comparison of Net Electric Power Output of CE5 after BOP in Phase I Shown on the Left and M5 in Phase II Shown on the Right
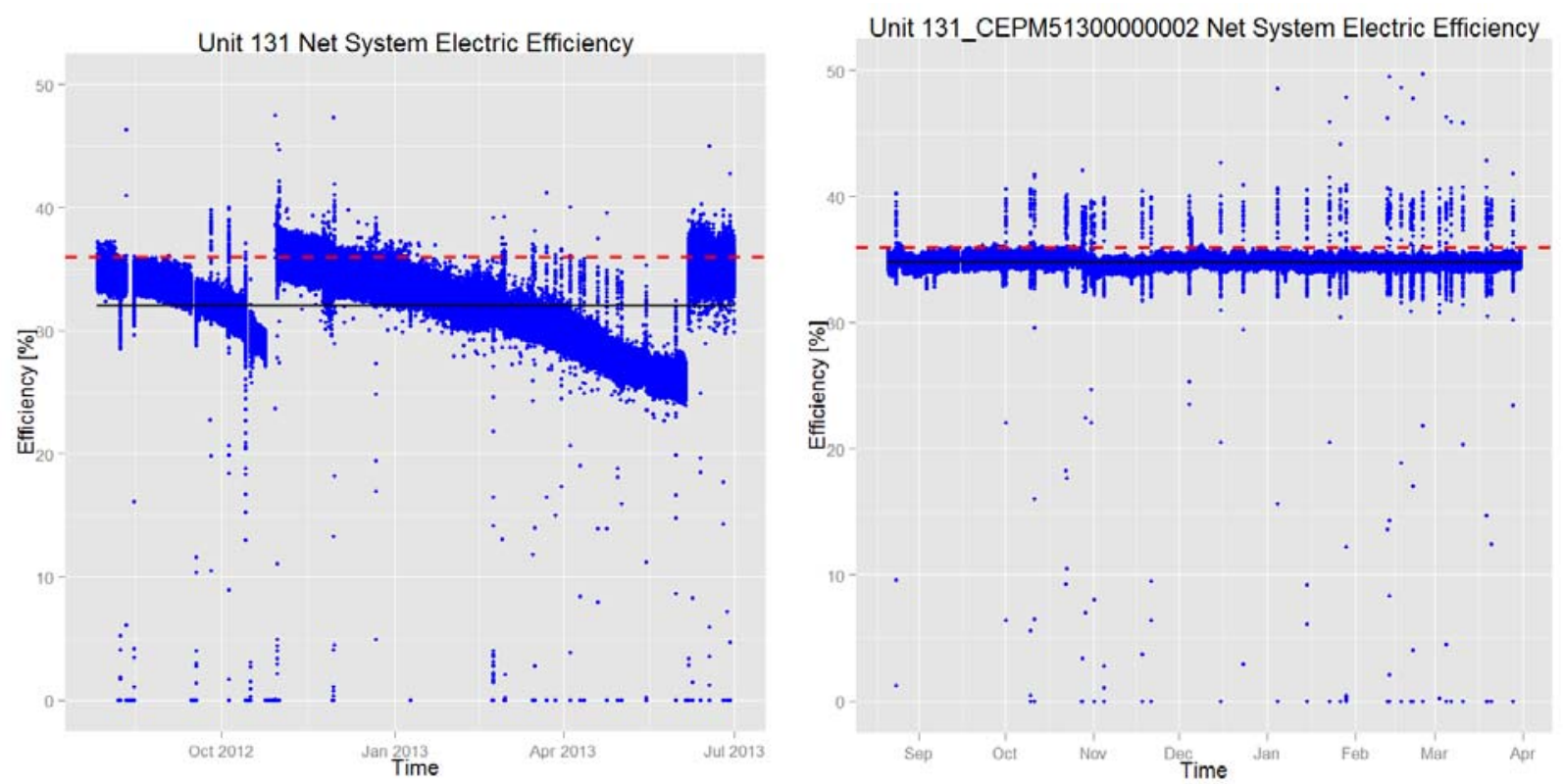

Figure 2.18. Comparison of Net Electric Efficiency in CE5 after BOP in Phase I Shown on the Left and M5 in Phase II Shown on the Right

Results of time-series data also show that degradation of the net electric system efficiency and total system efficiency (Figure 2.19) were much greater in CE5's compared to M5's. For instance, the standard deviation of overall system efficiency unit 131 reduced from 5.8 to 0.7 . This means the M5 unit was degraded $88 \%$ less than its peer CE5 unit in the mean time between shut downs required for maintenance. 

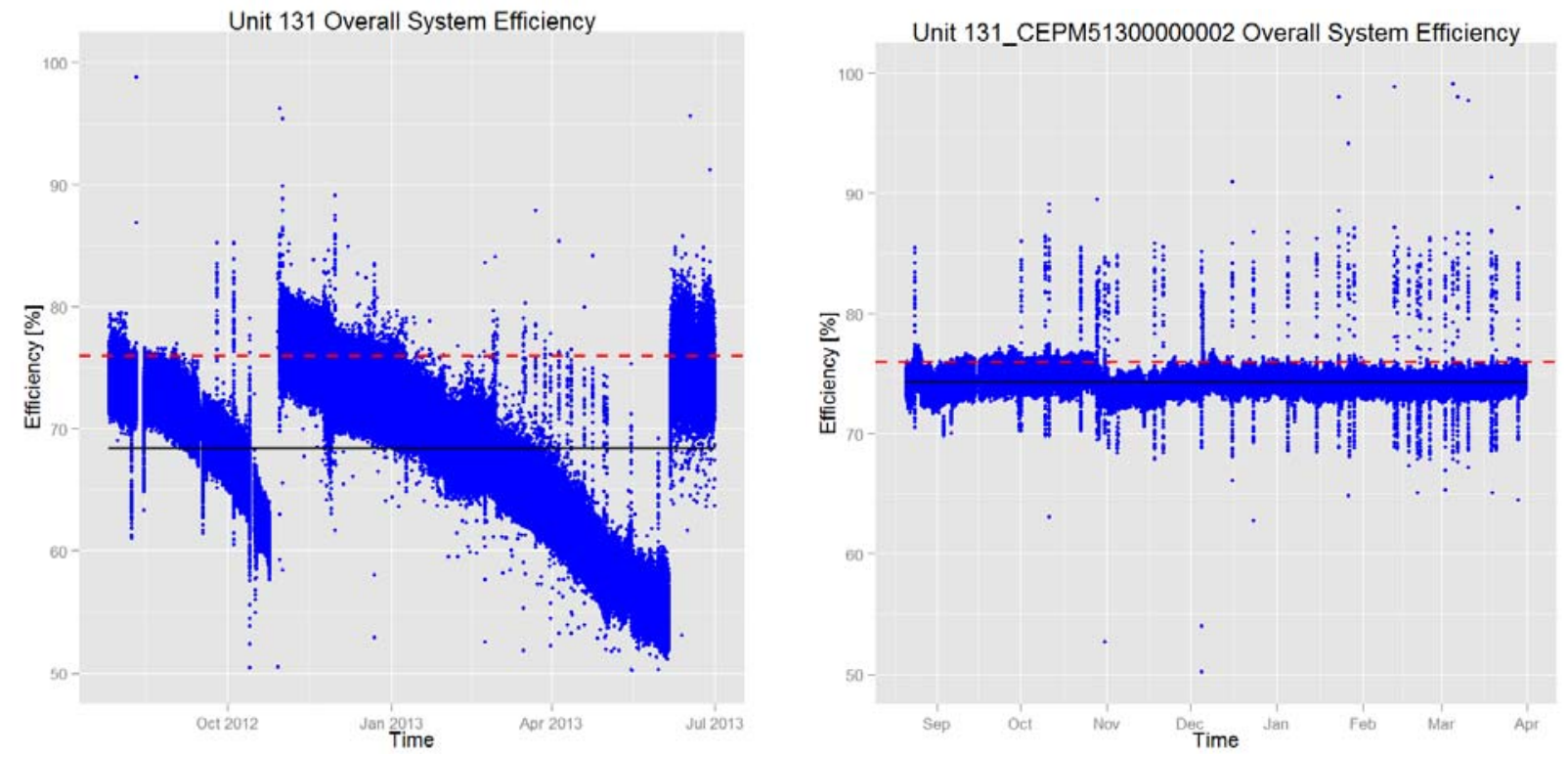

Figure 2.19. Comparison of System Overall Efficiency of CE5 after BOP in Phase I Shown on the Left and M5 in Phase II Shown on the Right

Distributions of net electric power output (Figure 2.20) and net electric power efficiency (Figure 2.21) of $\mathrm{CE} 5^{1}$ and $\mathrm{M} 5^{2}$ models provide good indication of power generation stability, consistency and reliability of M5 systems in Phase II when compared to electric power output performance of this unit (131/P2) in Phase I.

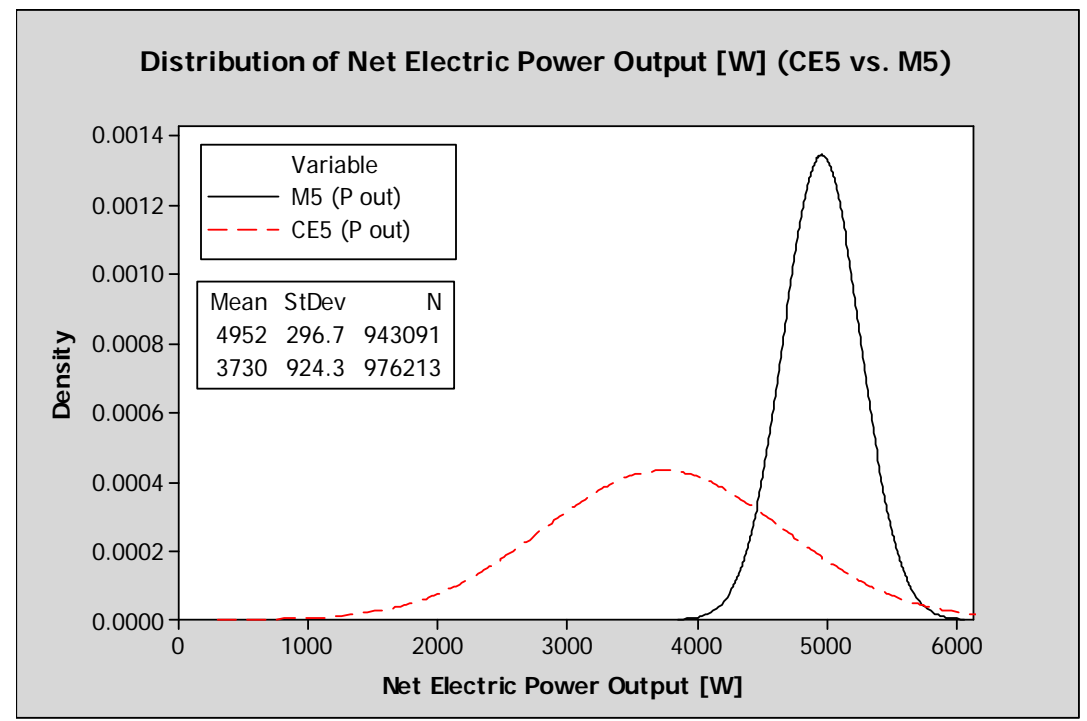

Figure 2.20. Distribution of Net Electric Power Output [W] of CE5 (Unit 131) vs. that of M5 (Unit P2) (as an example)

\footnotetext{
${ }^{1}$ CE5 data used in the distributions provided contain data after BOP in CE5s (from July 2012 to June 2013).

${ }^{2}$ M5 data used in the distributions provided include performance data from beginning of August 2013 to the end of June 2014 (end of data collection).
} 
Distribution of Net Electric Power Efficinecy (CE5 vs. M5)

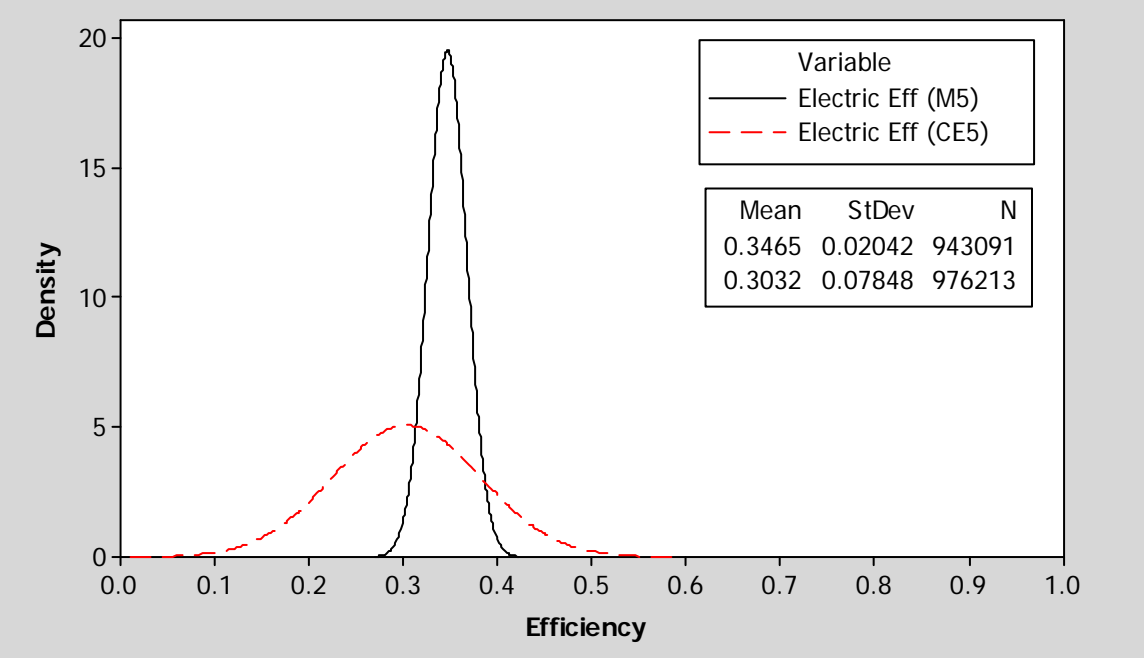

Figure 2.21. Distribution of Net Electric Power Efficiency of CE5 (Unit 131) vs. that of M5 (Unit P2) (as an example)

Distribution curves provided in this section include both run time to shut down and time to restart (i.e., when system had no generation). This would provide better representation of performance of each system in about one year (i.e., 11 months for each system shown) indicating M5 units needed less maintenance and they were down for shorter period of time during their operating hours. In Figure 2.21, the net electric power efficiency of CE5 is about 30\% and that of M5 is nearly 35\%. However, the standard deviation of electric power efficiency of CE5 is about four times higher than that of M5 on average.

\subsection{Electricity and Heat Utilization}

Electricity utilization data were collected for Roger's Garden and Fresh \& Easy during Phase I. Box plots in Figure 2.22 show the minimum, maximum, and average electric demand of each building. The bar plots in the same figure (in green) show the capacity of CHP-FCSs installed and the dotted red lines represent the amount of average electricity utilization from September 2012 to August 2013 for Roger's Garden and Fresh and Easy buildings. The total electricity generated even at maximum system capacity at each site was less than half of the minimum electricity demand of the building. Results show that $100 \%$ of the CHP-FCSs electricity generated was utilized by each building between September 2012 and August 2013. 


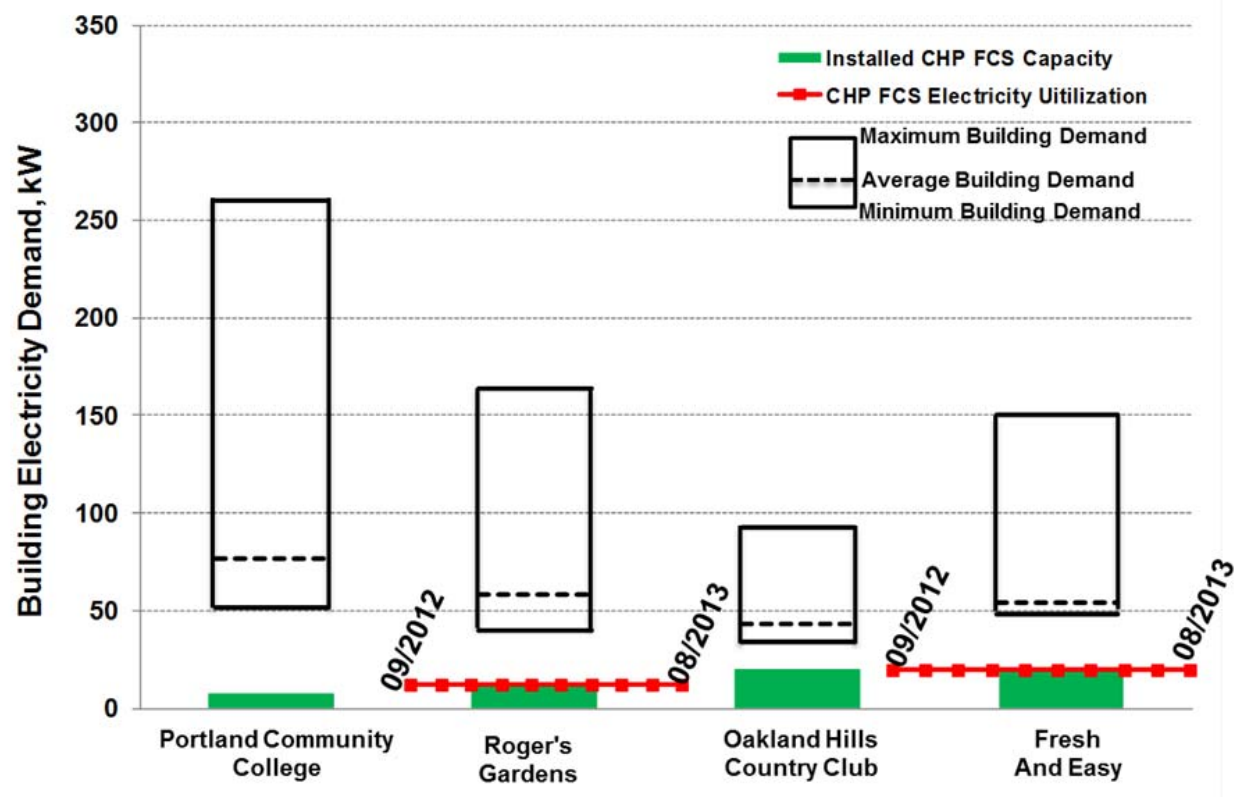

Figure 2.22. Summary of Buildings’ Electricity Demand and Utilization

Heat utilization data was also collected for Roger's Garden and Fresh \& Easy. Box plots in Figure 2.23 show building's minimum, maximum, and average heat demand. Heat demand for Roger's Garden was found to be constant (maximum = minimum = average). The bar plots (in green) in the same figure show heat generating capacity of CHP-FCSs installed.

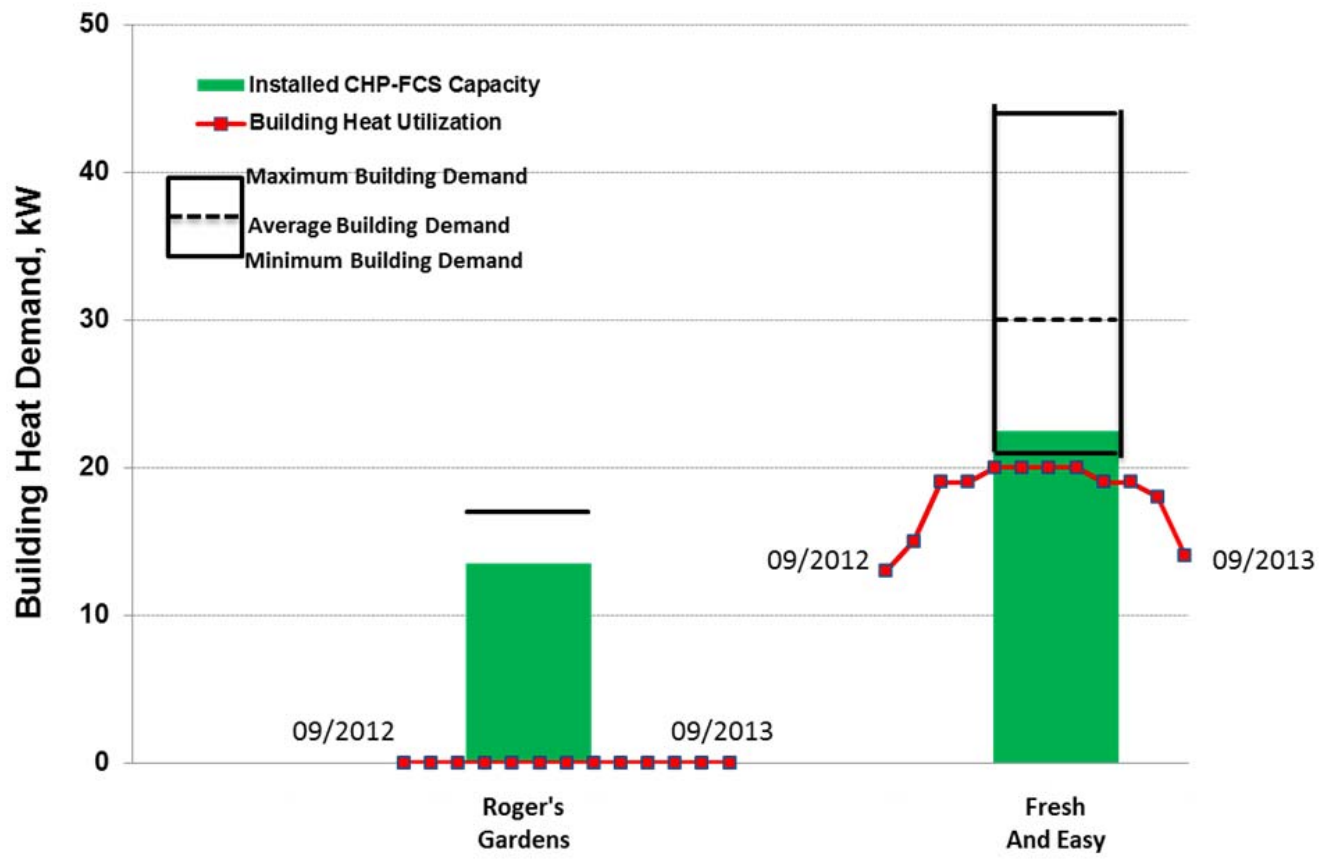

Figure 2.23. Summary of Buildings’ Heat Demand 
The average heat utilization per month is also depicted in Figure 2.23 (the red dotted lines) for Fresh and Easy and Roger's Garden from September 2012 to September 2013. As it is shown in the graph, the heat utilization at Roger's Garden was constantly zero during the data collection period. This means there was no heat utilization at Roger's Garden site. Being a nursery in Southern California, Roger's Garden did not use the heat that was being produced by the CHP-FC systems. As a result, the heat monitoring equipment at Roger's Garden was scheduled to be removed and installed at Oakland Hills Tennis Club. Most of the heat generated by the five units at Fresh \& Easy site was utilized from September 2012 to July 2013. End of July 2013, one unit was shut down to be replaced with M5 and the other four were taken down end of August. Therefore, heat utilization was reported to be zero from that time on.

\subsection{Summary of Shutdowns}

In the first Phase of the project, only general causes of shut downs were provided to PNNL. These included: premature part failure, intentional/preventive maintenance, site/facilities, and human error. Figure 2.24 shows the total number of events based on these four shut-down categories.

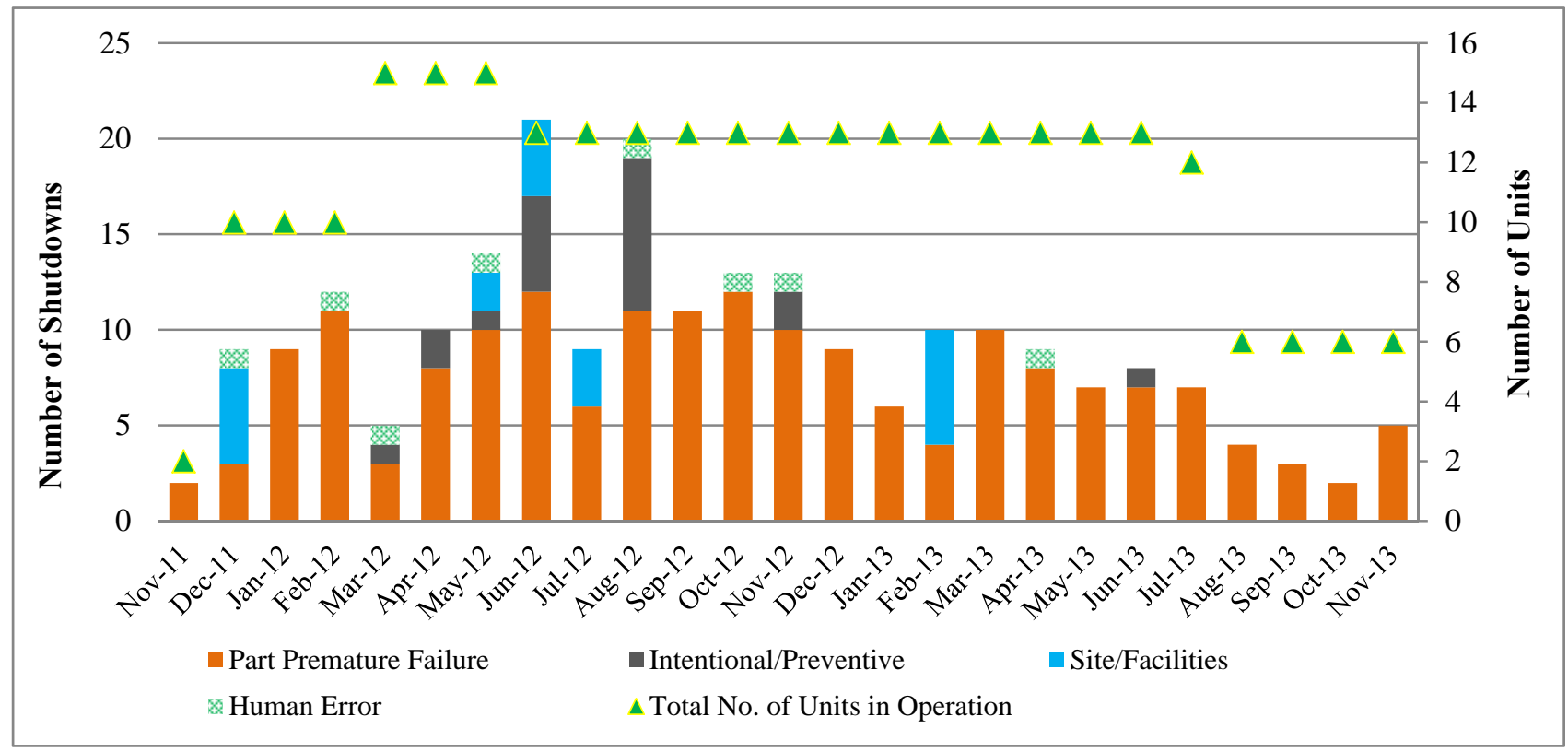

Figure 2.24. Summary of Shutdowns and their Causes in Phase I

In Phase II, in addition to the general cause of shut downs, some root causes of failures were also provided by ClearEdge. A summary of failures reported in Phase II are listed in Table 2.16. Runtime to shut down and time to restart are also shown in this table. 
Table 2.16. Monthly Failures, Runtime to Shut Down, and Duration of Shut Down Reported for Each Unit

\begin{tabular}{|c|c|c|c|c|}
\hline Unit \# & Date & Root Cause of Shutdown & $\begin{array}{l}\text { Runtime } \\
\text { To } \\
\text { Shutdown } \\
\text { [hr] }\end{array}$ & $\begin{array}{l}\text { Time To } \\
\text { Restart } \\
\text { [hr] }\end{array}$ \\
\hline $\mathrm{P} 2$ & $8 / 13 / 2013$ & Improperly seated pin (poor electrical connection). & 436 & 10 \\
\hline $\mathrm{P} 2$ & $10 / 27 / 2013$ & $\begin{array}{l}\text { Planned CSA removal for seal rework upgrade (not a CSA } \\
\text { failure). }\end{array}$ & 1808 & 10 \\
\hline P3 & $10 / 1 / 2013$ & Loose connection at in-rush current switch & 1326 & 66 \\
\hline P3 & $10 / 6 / 2013$ & Crack in FPS insulation. & 57 & 106 \\
\hline P3 & $10 / 13 / 2013$ & CSA EOL - 1,442 hrs. & 59 & 14 \\
\hline P3 & $1 / 6 / 2014$ & Inaccurate steam pressure sensor reading. & 2015 & 48 \\
\hline P3 & $1 / 28 / 2014$ & Inaccurate RTD sensor reading - damaged connector. & 468 & 13 \\
\hline SW1 & $1 / 30 / 2014$ & AC Module failure (suspected). & 818 & 93 \\
\hline SW6 & $1 / 15 / 2014$ & Poor connection at DB45 connector. & 195 & 17 \\
\hline SW6 & $1 / 27 / 2014$ & Leak internal to SPA. & 267 & 24 \\
\hline P3 & $2 / 22 / 2014$ & Faulty inverter (inverter fan failed). & 590 & 84 \\
\hline SW1 & $2 / 18 / 2014$ & AC Module failure. & 349 & 23 \\
\hline SW2 & $2 / 26 / 2014$ & Loose solder cup connection at APS FT sensor. & 1282 & 35 \\
\hline P3 & $3 / 11 / 2014$ & $\begin{array}{l}\text { Inaccurate steam pressure sensor reading (faulty PT or } \\
\text { loose connector). }\end{array}$ & 331 & 26 \\
\hline SW1 & $3 / 29 / 2014$ & $\begin{array}{l}\text { Cross-threaded connector resulted in moisture and } \\
\text { corrosion at PT connection. }\end{array}$ & 915 & 43 \\
\hline SW2 & $3 / 25 / 2014$ & $\begin{array}{l}\text { Faulty water tank level switch signal or below spec drain } \\
\text { rate. }\end{array}$ & 624 & 24 \\
\hline SW1 & $4 / 23 / 2014$ & Faulty burner blower - replaced. & 552 & 24 \\
\hline SW2 & $4 / 21 / 2014$ & $\begin{array}{l}\text { Faulty water tank level switch signal or below spec drain } \\
\text { rate - faulty component replaced. }\end{array}$ & 614 & 38 \\
\hline P3 & $5 / 1 / 2014$ & Faulty burner blower. & 1203 & 24 \\
\hline P3 & $5 / 13 / 2014$ & Faulty burner blower. & 269 & 45 \\
\hline P3 & $5 / 16 / 2014$ & Faulty burner blower. & 26 & 139 \\
\hline P3 & $5 / 29 / 2014$ & Poor response from grid disturbance. & 164 & 1 \\
\hline P3 & $5 / 30 / 2014$ & Software setting. & 21 & 1 \\
\hline SN11 & $5 / 13 / 2014$ & Unknown electrical. & 1802 & 69 \\
\hline P3 & $6 / 11 / 2014$ & Poor response from grid disturbance. & 291 & 1 \\
\hline SN11 & $6 / 17 / 2014$ & Faulty in-rush relay. & 776 & 67 \\
\hline SN11 & $6 / 21 / 2014$ & Unknown electrical. & 31 & 36 \\
\hline SN11 & $6 / 24 / 2014$ & Unknown electrical. & 18 & 34 \\
\hline SN11 & 6/30/2014 & Unknown electrical - (DC/DC converter) replaced. & 122 & 1 \\
\hline SW15 & $6 / 13 / 2014$ & Thermal management system - water in oil system. & 3166 & 99 \\
\hline SW15 & $6 / 18 / 2014$ & Thermal management system - water in oil system. & 20 & 118 \\
\hline SW18 & $6 / 7 / 2014$ & $\begin{array}{l}\text { Thermal management system - water in oil system - faulty } \\
\text { internal HEX. }\end{array}$ & 3024 & 235 \\
\hline
\end{tabular}


Table 2.17 shows how the number of faults and system shut downs compare between CE5 unis in Phase I and M5 units in Phase II for their total operating hours (Figure 2.9 shows how total operating hours compare). Both CE5 and M5 systems had an average of 2.6 shut downs per month per unit.

Table 2.17. Total Failures Affecting CE5 vs. M5 Units.

\begin{tabular}{|c|c|c|c|c|c|c|c|c|}
\hline \multirow[t]{2}{*}{ Unit Number } & \multicolumn{2}{|c|}{$\begin{array}{c}\text { Part Premature } \\
\text { Failure }\end{array}$} & \multicolumn{2}{|c|}{$\begin{array}{l}\text { Intentional / } \\
\text { Preventive }\end{array}$} & \multicolumn{2}{|c|}{ Site/Facilities } & \multicolumn{2}{|c|}{ Human Error } \\
\hline & CE5 & M5 & CE5 & M5 & CE5 & M5 & CE5 & M5 \\
\hline 129-SN11 & 5 & 5 & 0 & 0 & 1 & 0 & & 0 \\
\hline $130-\mathrm{SN} 14$ & 4 & 0 & 0 & 0 & 1 & 0 & & 0 \\
\hline 131-P2 & 13 & 2 & 3 & 0 & 1 & 0 & 1 & 0 \\
\hline 132-SW15 & 20 & 2 & 4 & 0 & 0 & 0 & & 0 \\
\hline 133-SW18 & 24 & 1 & 4 & 0 & 0 & 0 & & 0 \\
\hline 137-SW1 & 12 & 4 & 0 & 0 & 2 & 0 & & 0 \\
\hline 139-SW2 & 15 & 3 & 0 & 0 & 3 & 0 & 1 & 0 \\
\hline 140-SW3 & 11 & 0 & 0 & 0 & 2 & 0 & & 0 \\
\hline 141-SW6 & 15 & 2 & 1 & 0 & 3 & 0 & & 0 \\
\hline 142-P3 & 10 & 13 & 0 & 0 & 3 & 0 & 1 & 0 \\
\hline 147 & 12 & 0 & 1 & 0 & 0 & 0 & & 0 \\
\hline 153 & 14 & 0 & 1 & 0 & 1 & 0 & 1 & 0 \\
\hline 161 & 9 & 0 & 2 & 0 & 1 & 0 & 2 & 0 \\
\hline 162 & 5 & 0 & 2 & 0 & 1 & 0 & & 0 \\
\hline 163 & 16 & 0 & 2 & 0 & 1 & 0 & 2 & 0 \\
\hline
\end{tabular}

Figure 2.25 illustrates how the mean runtime to shut down of CE5 units compare with that of M5 units for the total time they were in operation. There were a total of 229 scheduled and unscheduled shut downs reported for CE5 units in Phase I and 32 unscheduled shut downs for M5 units in Phase II. The mean runtime to shut down is comparable for both units, 835 hours for CE5 and 745 for M5 units.

The time to restart (e.g., repair time) was reported for 120 CE5 shut downs out of the 231 documented by ClearEdge. These data were manually recorded by ClearEdge. Therefore, they are incomplete and subject to error. The histograms of these are shown in Figure 2.26 for both CE5 and M5 systems. The average time to repair was 28 hours for CE5 and 49 hours for M5. However time-series data (see Figure 2.20) show that the standard deviation of net electric output of CE5 was much larger than that of M5. This is because during the repair time, the net electric power was recorded as zero. This made the distribution of electric power output of CE5 to be much wider than that of M5 units. Therefore, at least for unit 131 vs P2 (in Figure 2.20), the mean time to repair of CE5 cannot be less than that of M5. This indicates that mean time to repair data recorded manually for CE5 units are subject to error. 


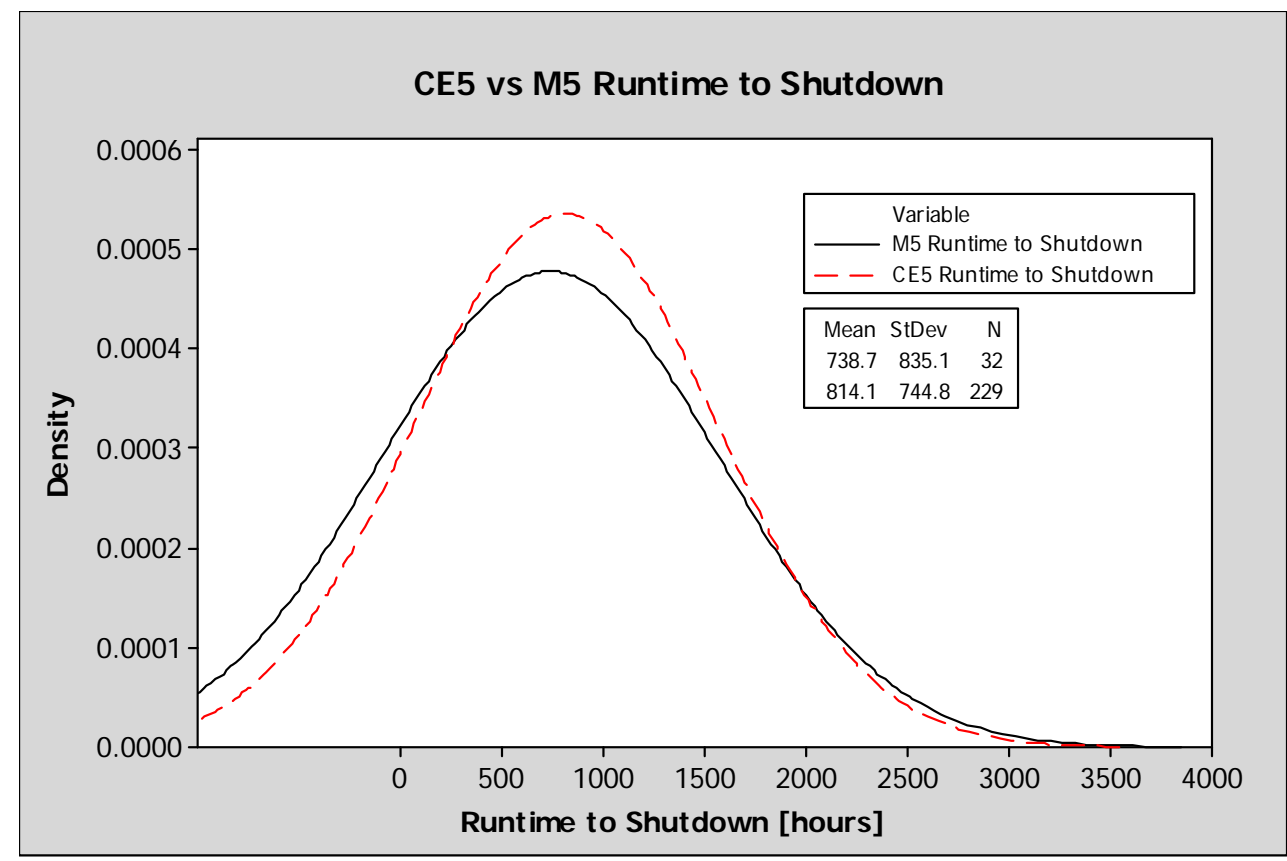

Figure 2.25. Meantime between Failures (MTBF) in Phase I (CE5) vs. Phase II (M5)
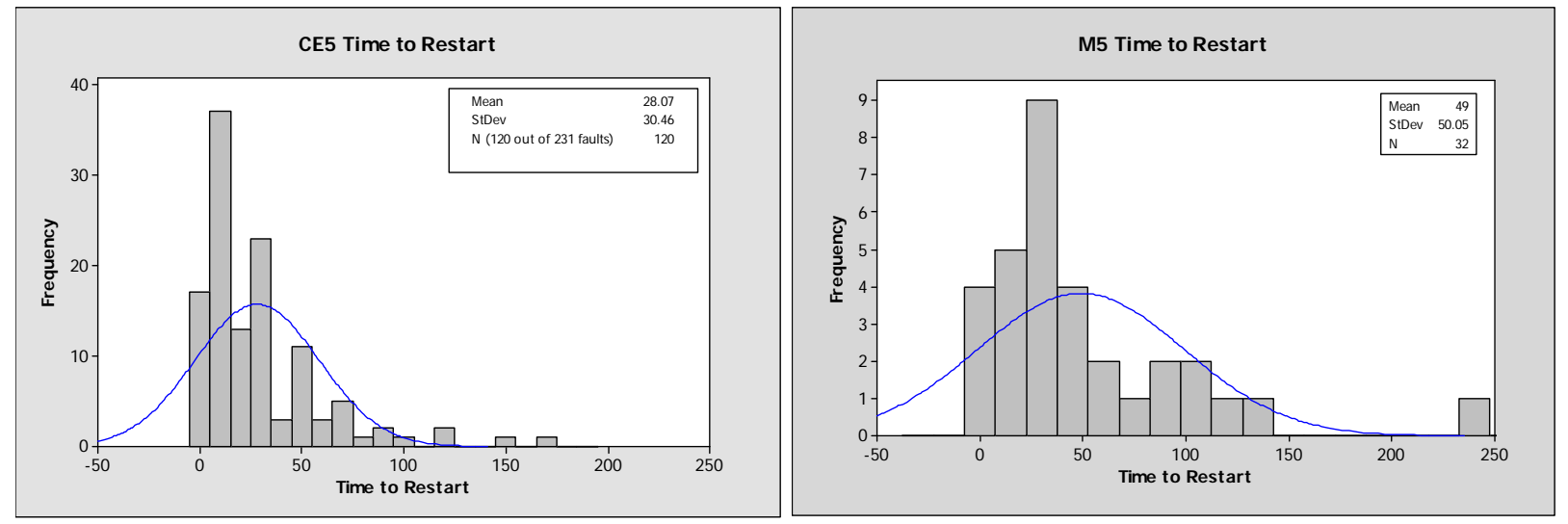

Figure 2.26. Histograms of Time to Restart Comparison for CE5 vs. M5 Systems.

\subsection{Performance Comparison of CE5 and M5 Models with DOE Technical Targets}

DOE has set preliminary technical targets for $1-10 \mathrm{kWe}$ stationary CHP-FCS ${ }^{1}$. DOE 2015 targets are tabulated in Table 2.18. For example, for a residential $10 \mathrm{kWe}$ CHP system, the technical targets are: an electrical generation efficiency of $42.5 \%$, total energy efficiency of $87.5 \%$, and durability in excess of 40,000 hours, and system availability at $98 \%$.

The average performance of CE5 and M5 systems are also tabulated in Table 2.18. The comparison shows that both the electrical efficiency and total energy efficiency of systems monitored were improved by about $8 \%$ on average. Taking CE5 unit 131 as an example and comparing its performance after BOP

\footnotetext{
${ }^{1}$ http://energy.gov/eere/fuelcells/distributedstationary-fuel-cell-systems
} 
upgrades with the net electric and total efficiencies of the Phase 2 system (M5 unit P2) at Roger's Garden show that these efficiencies had improved by about $11 \%$ in one year ${ }^{1}$.

Table 2.18. Summary of DOE Preliminary Technical Targets for 1-10 kWe CHP-FCS Operating on Natural Gas

\begin{tabular}{lcc|c}
\hline Performance Indicators & 2015 & CE5 (Average) & M5 (Average) \\
\hline Electrical Efficiency at Rated Power & $42.5 \%$ & $33.1 \%$ & $35.8 \%$ \\
CHP Energy Efficiency & $87.5 \%$ & $70.7 \%$ & $76.3 \%$ \\
Operating Lifetime & $40,000 \mathrm{~h}$ & 40,000 & 80,000 \\
& & (Expected) & (Expected) \\
System availability & $98 \%$ & $93.5 \%$ & $94.8 \%$ \\
\hline
\end{tabular}

Comparing the average net electrical efficiency with the DOE target shows that it is about $19 \%$ away from that of DOE target (about the same in case of unit 131/P2) and the net efficiency of the system should be improved by nearly $15 \%$ on average (about $18 \%$ for unit $131 / \mathrm{P} 2$ ) to reach the DOE target. The system availability increased by $1 \%$ on average (5\% in case of unit $131 / \mathrm{P} 2$ ) and it is $3 \%$ off from DOE target (better than DOE target in case of unit 131/P2). The operating lifetime of systems cannot be truly compared because M5 systems were taken down before they reach the end of their life.

\footnotetext{
${ }^{1} \mathrm{P} 2$ unit was one of the two M5 units that were monitored for one year. Therefore, it makes it more reasonable to compare its performance directly with its CE5 peer, which ran for the same period of time after BOP.
} 


\subsection{Conclusions}

The results of this analysis indicate that systems installed in the second phase of this demonstration performed much better in terms of availability, consistency in generation, and reliability. The average net electrical power output increased from 4.1 to $4.9 \mathrm{kWe}$, net heat recovery from 4.7 to $5.4 \mathrm{kWth}$, and system availability improved from $94 \%$ to $95 \%$. The average net system electric efficiency, average net heat recovery efficiency, and overall net efficiency of the system increased respectively from $33 \%$ to $36 \%$, from $38 \%$ to $41 \%$, and from $71 \%$ to $76 \%$. The temperature of water sent to site however reduced by about $16 \%$ from $51{ }^{\circ} \mathrm{C}$ to $43{ }^{\circ} \mathrm{C}$. This was a control strategy and the temperature can be controlled depending on building heat demands.

More importantly, the number of shut downs and maintenance events required to keep the systems running at the manufacturer's rated performance specifications were substantially reduced by about 76\% (for 8 to 10 units running over a one-year period). From July 2012 to June 2013, there were eight CE5 units in operation and a total of 134 scheduled and unscheduled shut downs took place. From July 2013 to June 2014, between 2 to 10 units were in operation and only 32 shut downs were reported (all unscheduled). On average, the numbers of shut downs reported per unit per month were 0.8 for CE5 systems and 0.46 for M5 units. This is about $42 \%$ reduction in number of maintenances required to keep systems running at manufacture's rated performance. Results of time-series data also show that degradation of the net electric system efficiency and total system efficiency were much greater in CE5s compared to M5's. For instance, the standard deviation of overall system efficiency for one of the CE5 units reduced from 5.8 to 0.7 . This means the M5 unit was degraded 88\% less than its peer CE5 unit in the mean time between shut downs required for maintenance.

Comparing the performance of systems monitored with DOE 2015 technical targets for small CHP systems (an electrical generation efficiency of $42.5 \%$, total energy efficiency of $87.5 \%$, and durability in excess of 40,000 hours, and system availability at $98 \%$ ) show that improvements are required to reach the DOE technical targets. The electrical efficiency should be increased by $19 \%$, the total system efficiency by nearly $15 \%$, and the system availability by $3 \%$. 



\subsection{References}

1. Colella WG and J Alsup. 2010. Fuel Cell Site Recommendation Report. SAND2010-5593P, Sandia National Laboratories, Albuquerque, New Mexico.

2. Colella WG. 2011. "Initial Deployment and Independent Testing of Micro-combined Heat and Power Fuel Cell Systems in Light Commercial Buildings.” Proceedings of the European Fuel Cell Conference, Rome, Italy.

3. O’Hayre R, SW Cha, WG Colella, and FB Prinz. 2009. Fuel Cell Fundamentals. Second edition, pp. 351-370, 451-482, John Wiley \& Sons, Inc., Hoboken, New Jersey. 

Appendix A

Time-Series Performance of CE5 Units in Phase I 



\section{Appendix A}

\section{Time-Series Performance Data for CE5 Units in Phase I}

\section{A.1 Net Electric Power Output}

The following plots show tine series data for the net electric power output of each CE5 unit before BOP in Phase I. All data analysis is based on HHV. Red dotted line is the manufacturer stated performance for each parameter. The beginning time and ending time is different for each unit because they were gradually installed from September 2011 to March 2012.
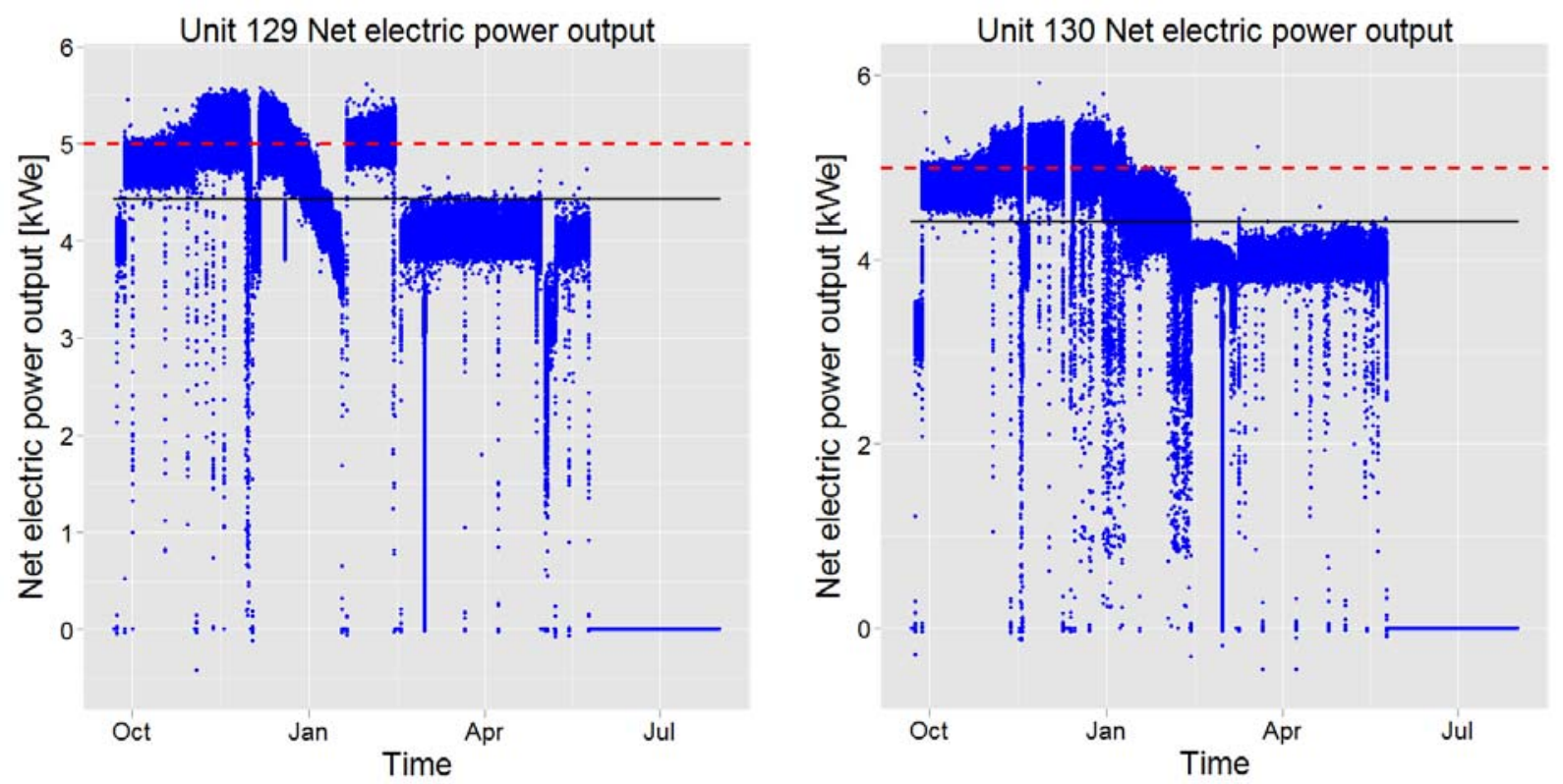

Figure A.1. Net Electric Power Output of Units 129 and 130 from October 2011 to July 2012 

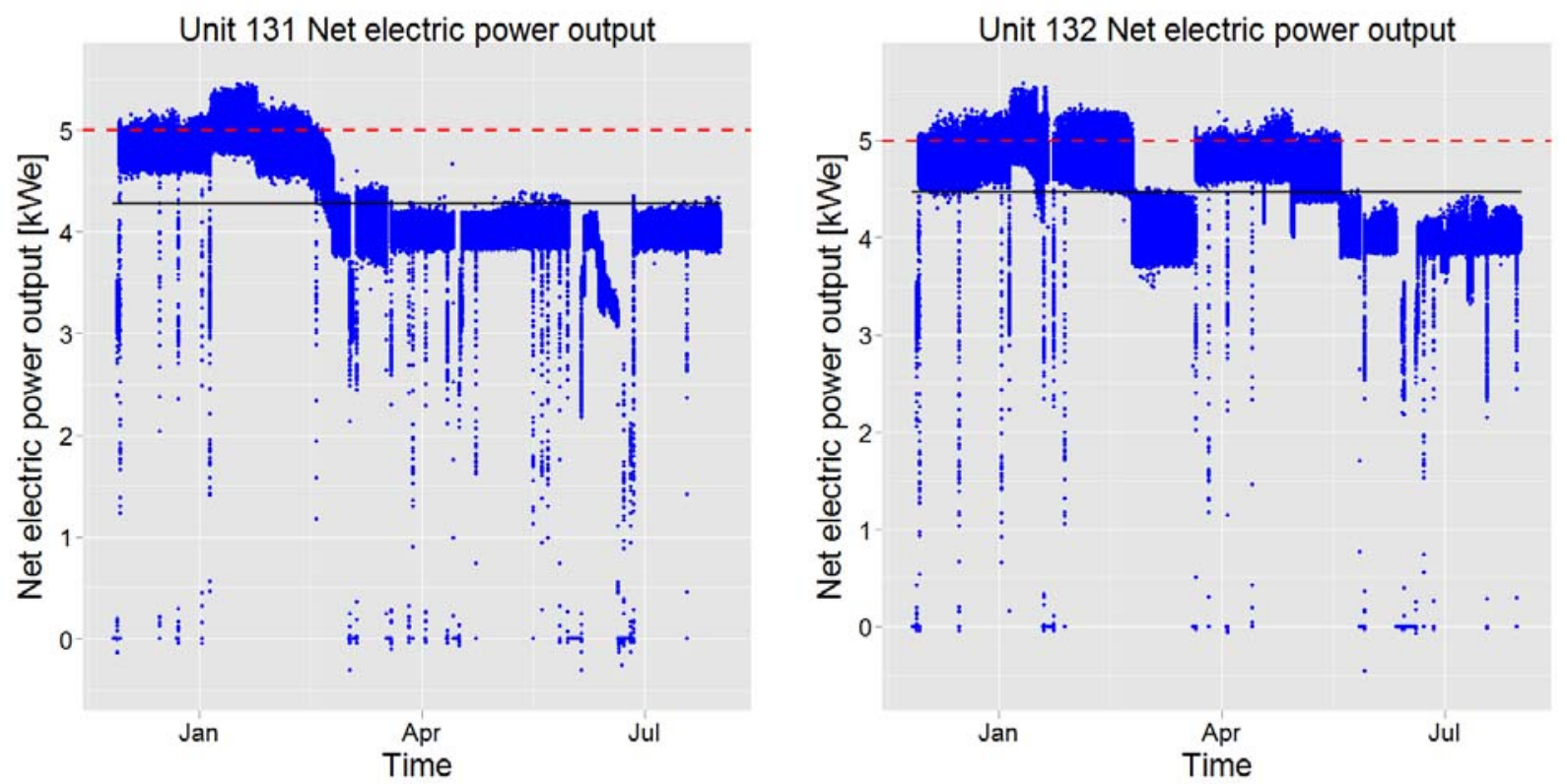

Figure A.2. Net Electric Power Output of Units 131 and 132 running from December 2011 to July 2012
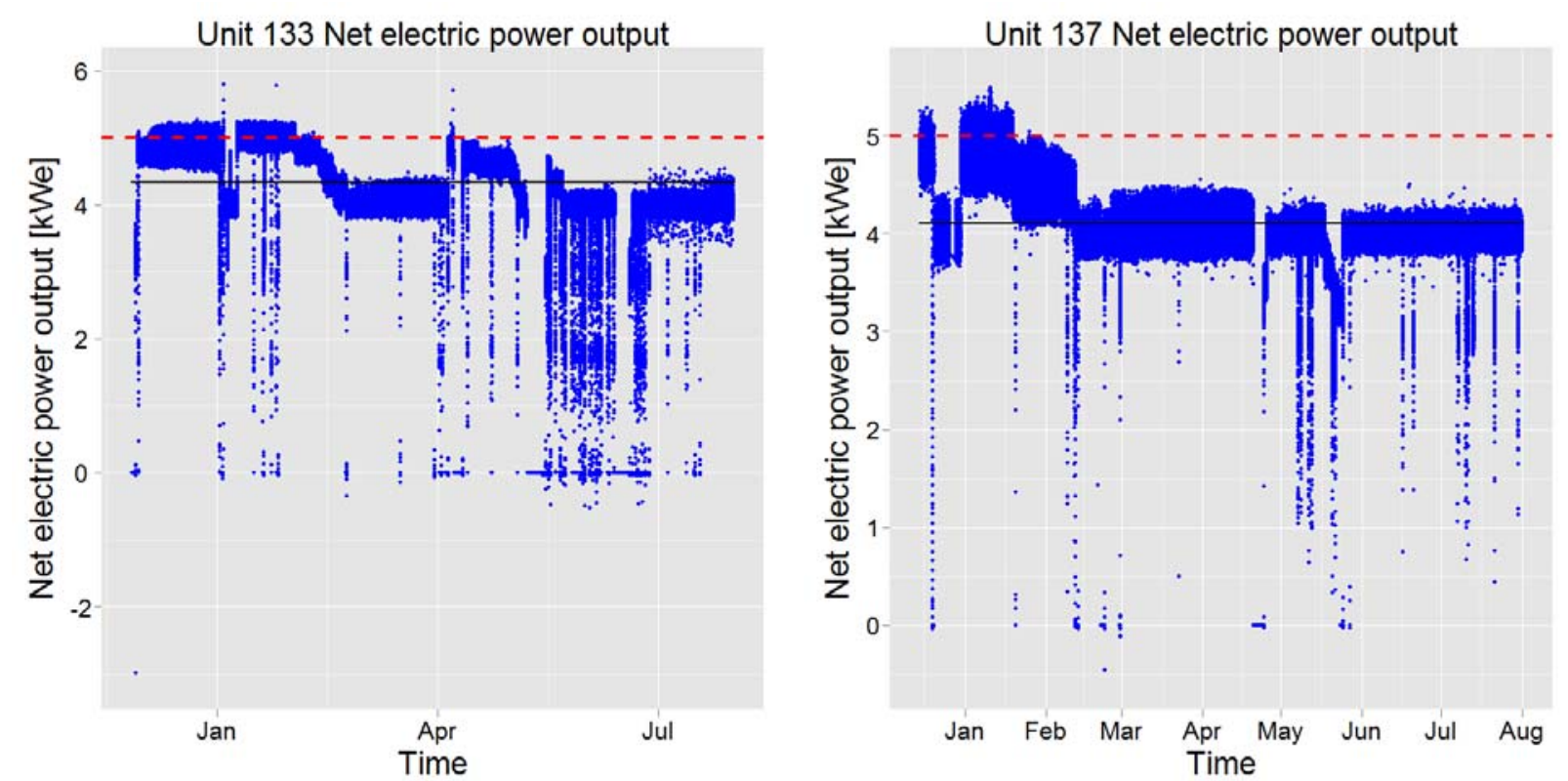

Figure A.3. Net Electric Power Output of Units 133 and 137 running from December 2011 through July 2012 

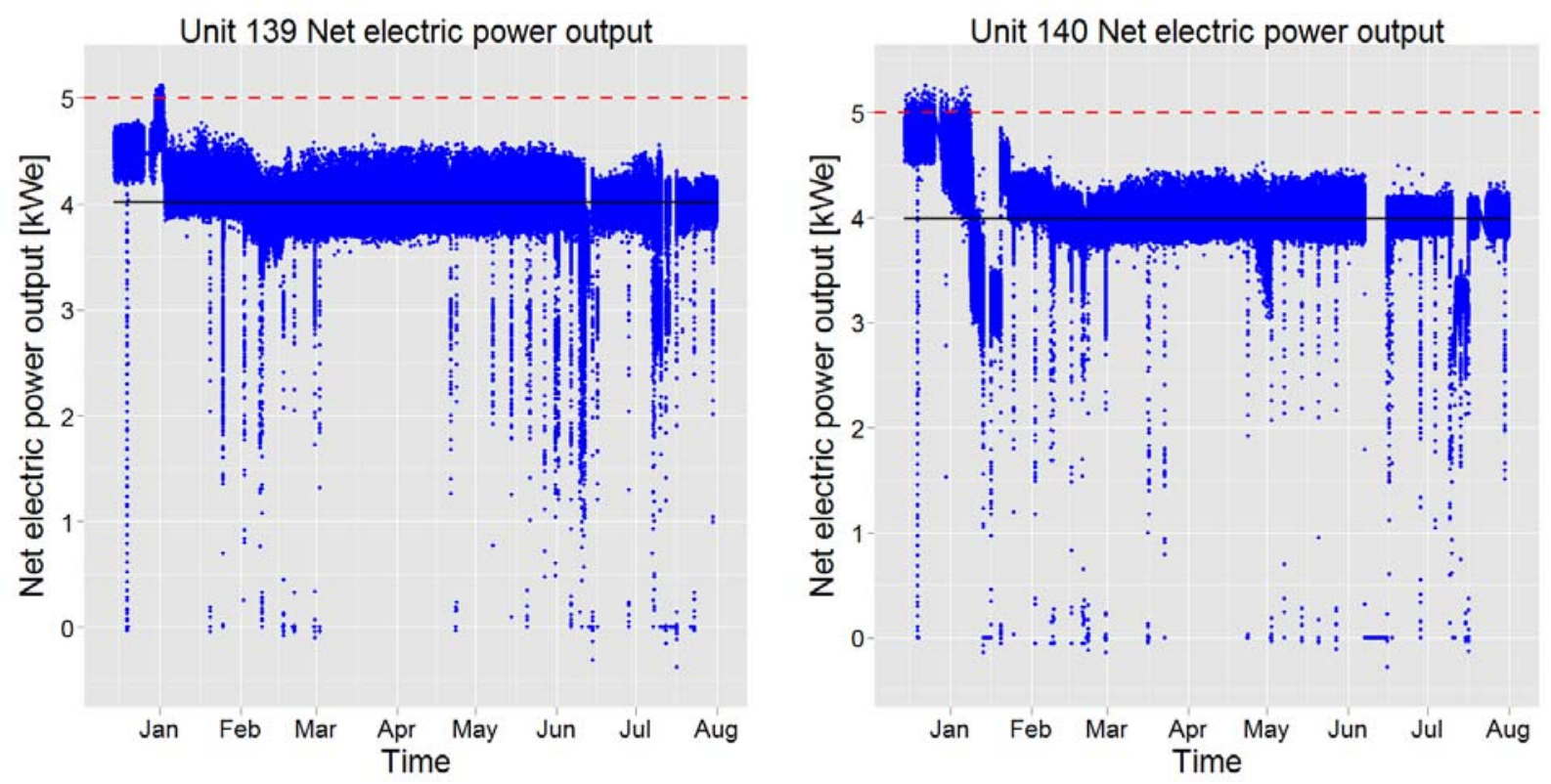

Figure A.4. Net Electric Power Output of Units 139 and 140 running from December 2011 through July 2012
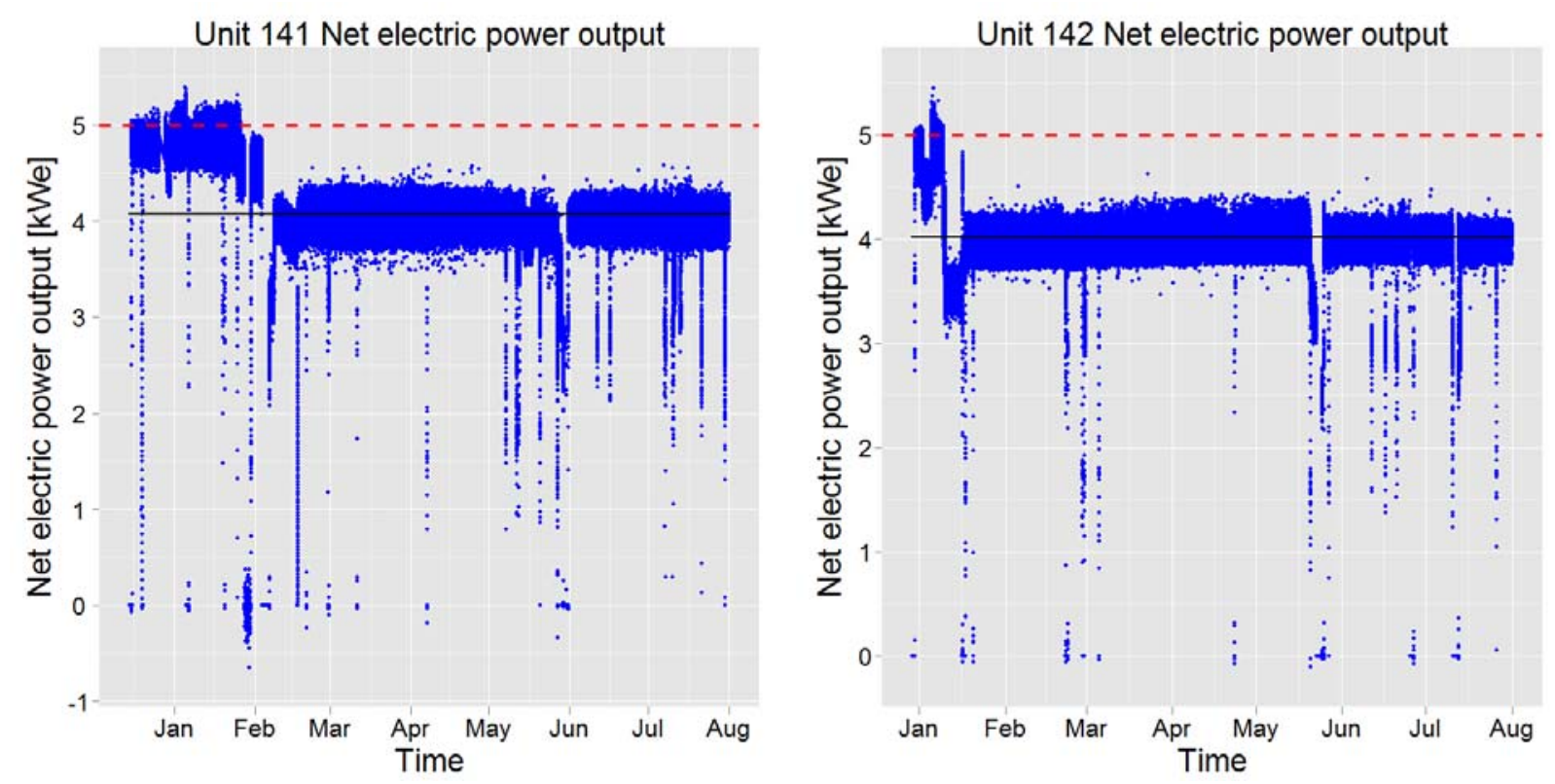

Figure A.5. Net Electric Power Output of Units 141 and 142 running from December 2011 through July 2012 

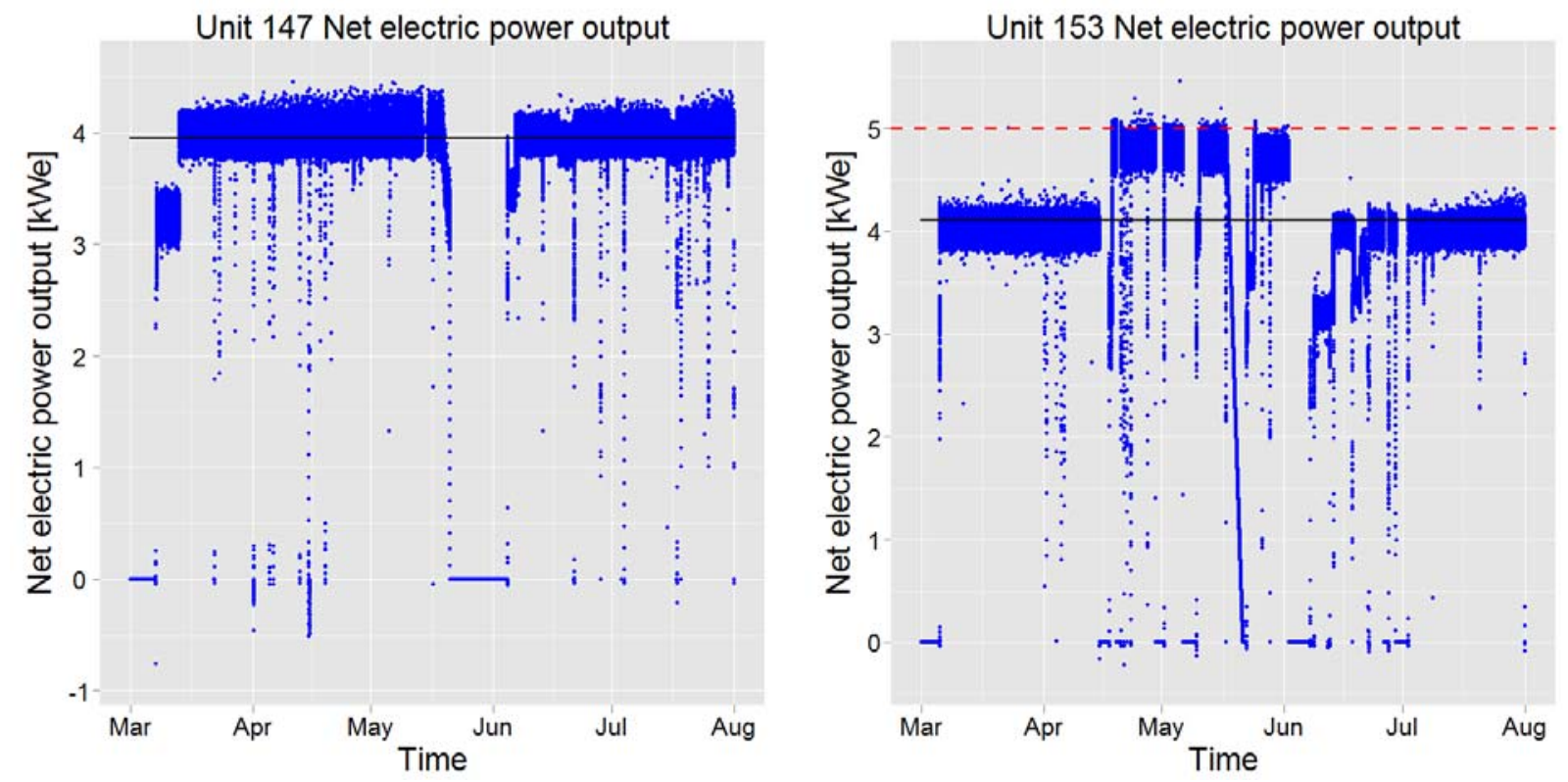

Figure A.6. Net Electric Power Output Of Units 147 and 153 running from March 2012 through July 2012
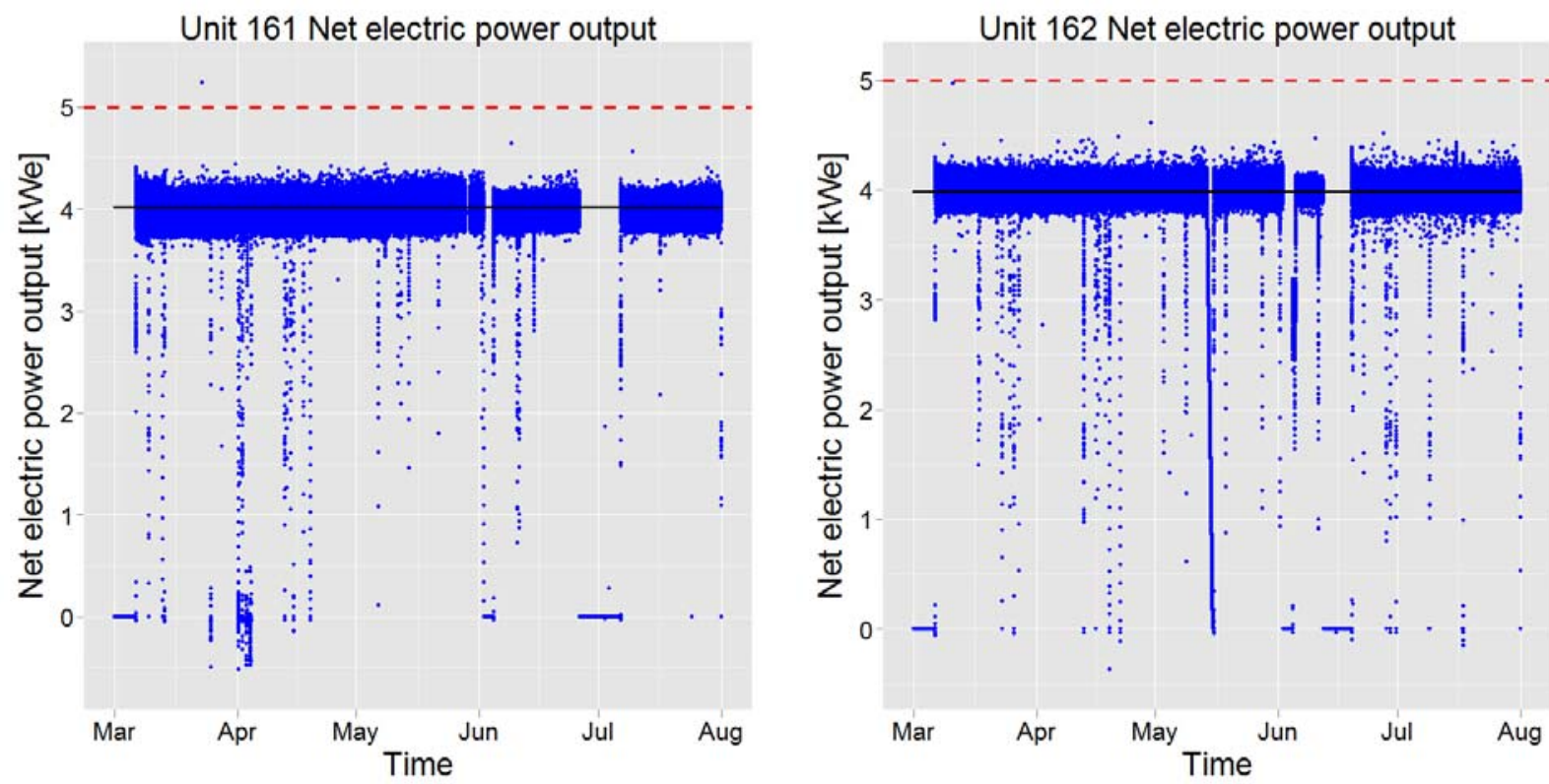

Figure A.7. Net Electric Power Output of Units 161 and 162 running from March 2012 through July 2012 


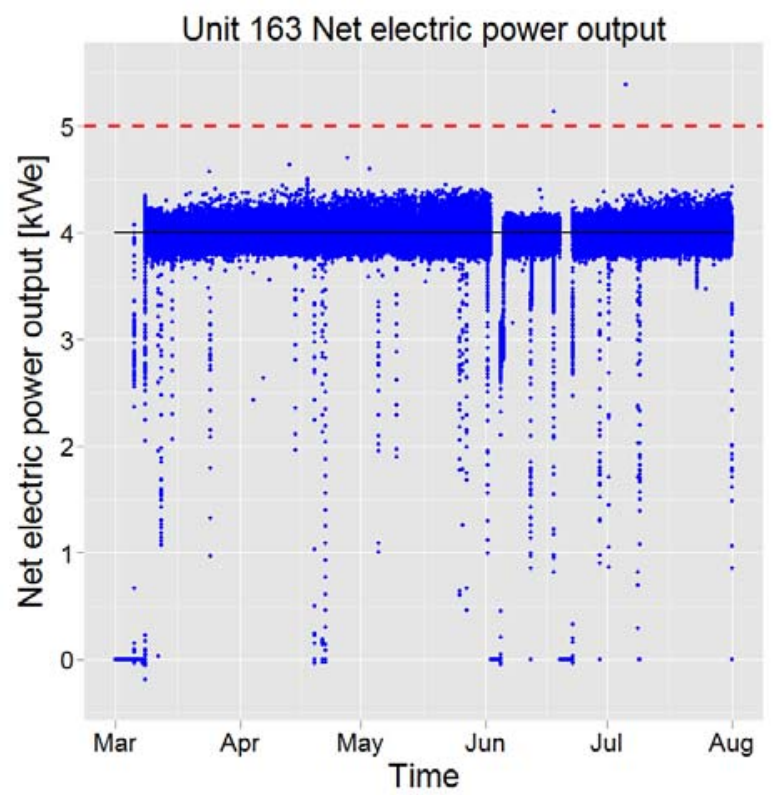

Figure A.8. Net Electric Power Output of Unit 163 from March 2012 through July 2012

\section{A.2 Net System Electric Efficiency}

The following plots show time series data for the net system electric efficiency of each CE5 unit in Phase I (before BOP).
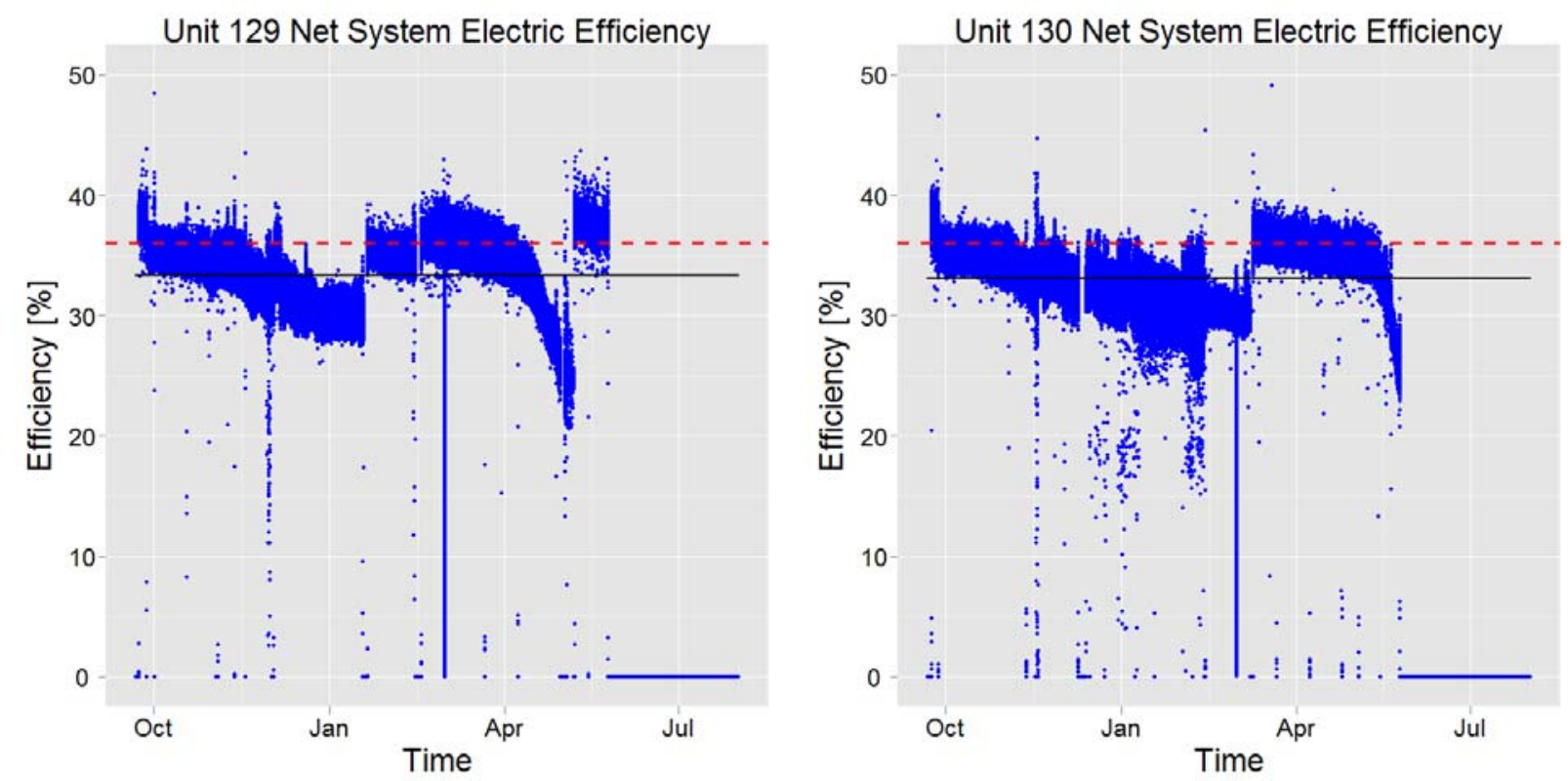

Figure A.9. Net System Electric Efficiency of Units 129 and 130 from December 2011 through July 2012 

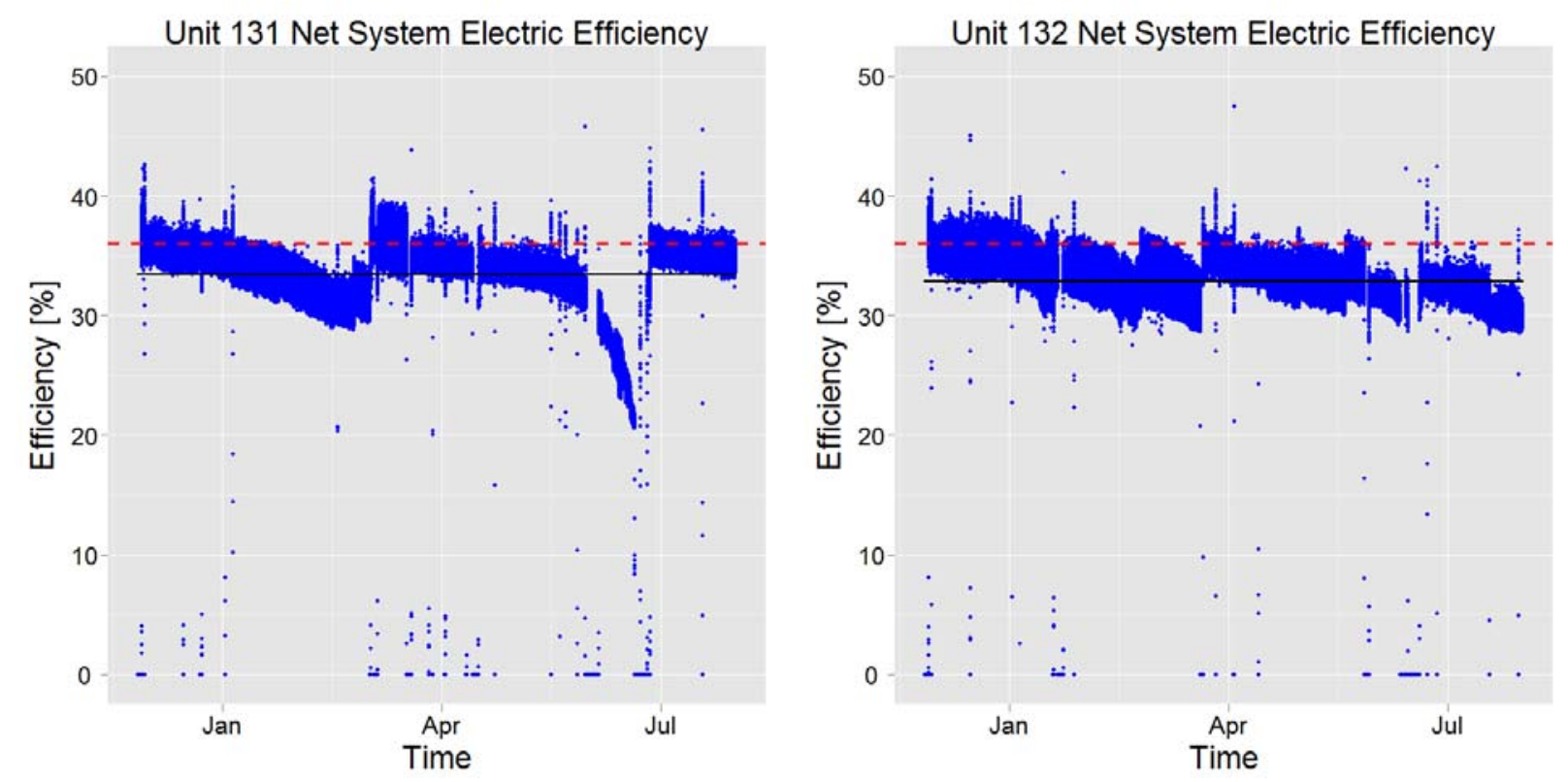

Figure A.10. Net System Electric Efficiency of Units 131 and 132 from December 2011 through July 2012
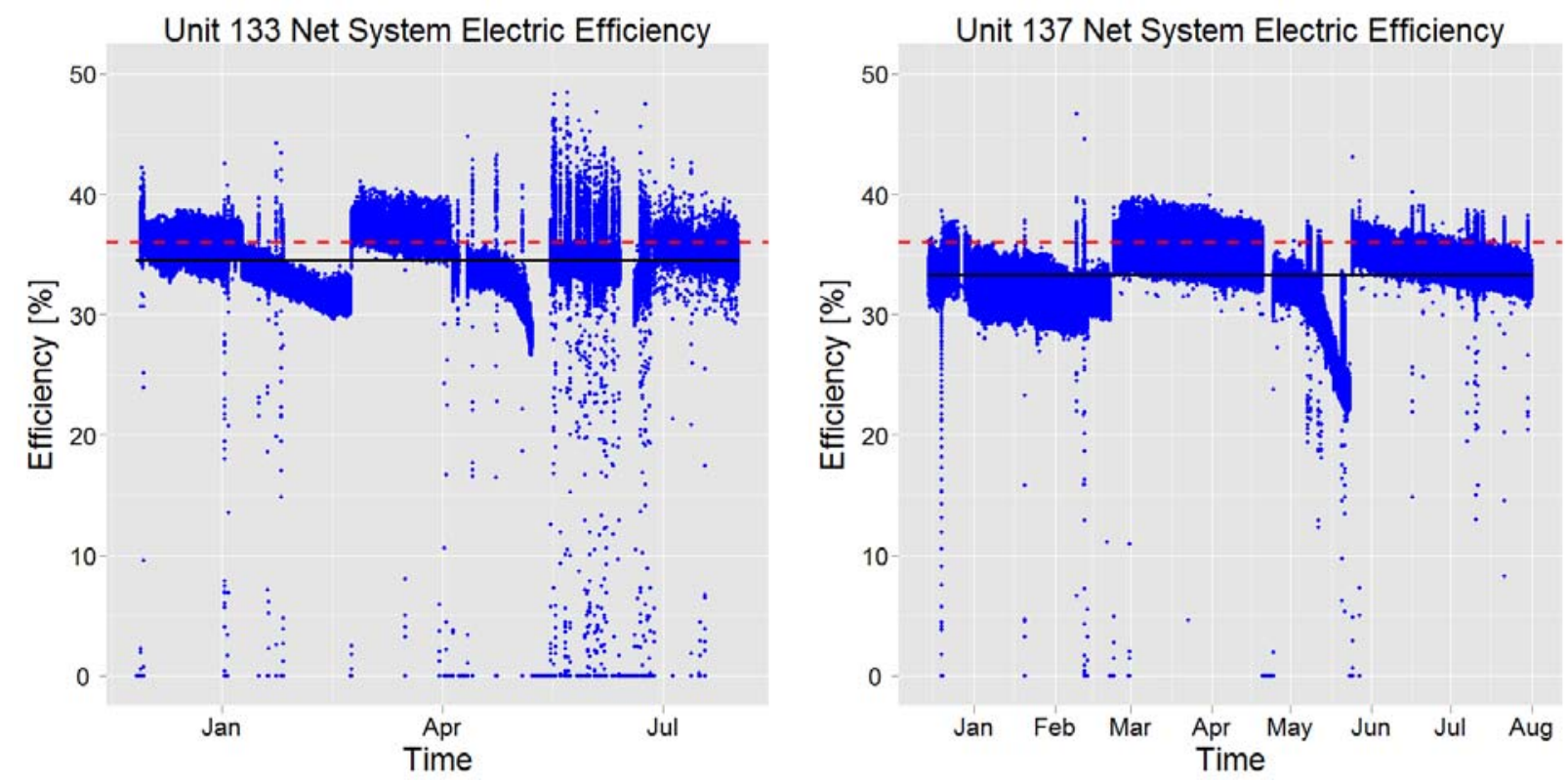

Figure A.11. Net System Electric Efficiency of Units 133 and 137 from December 2011 through July 2012 

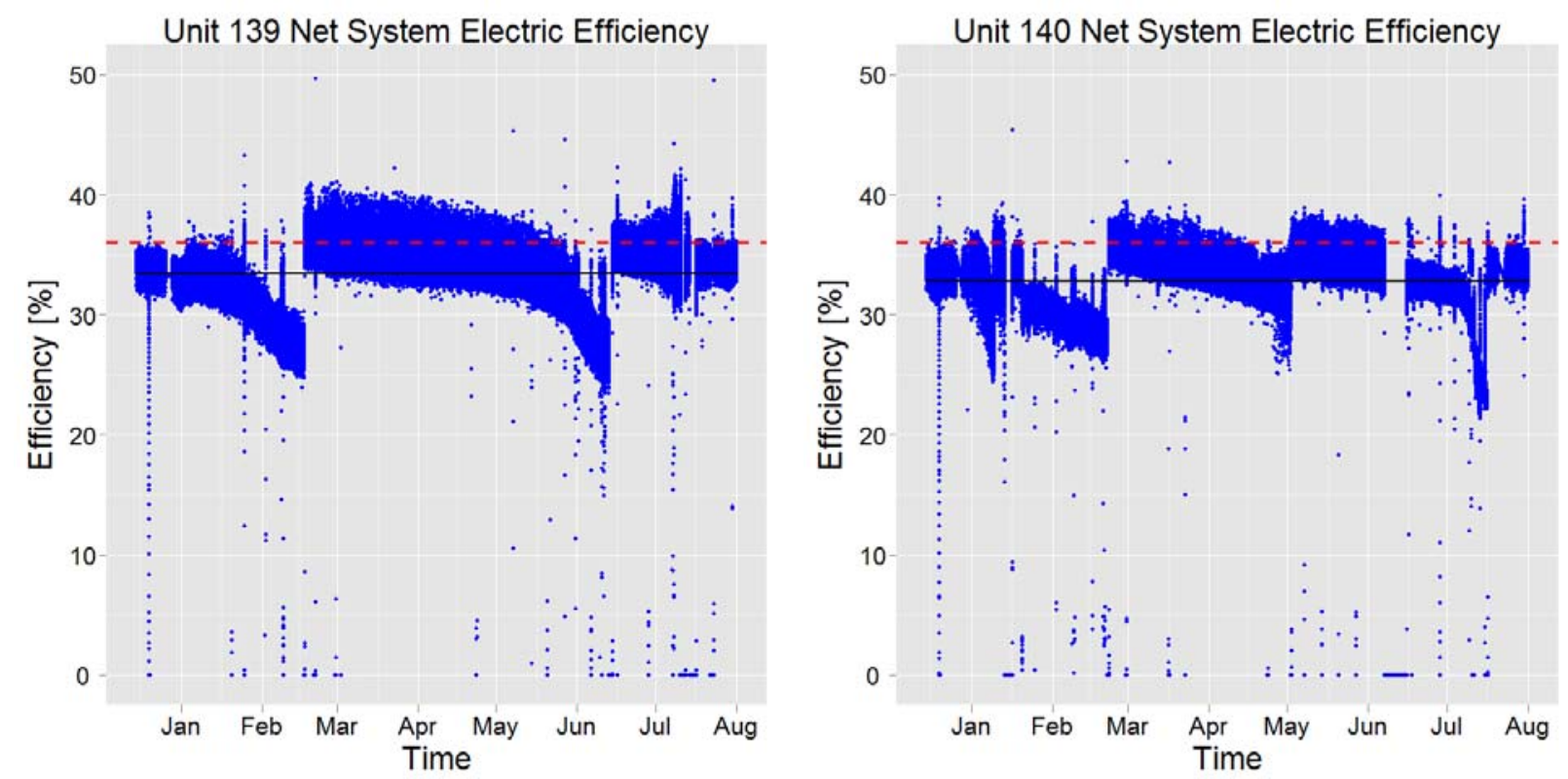

Figure A.12. Net System Electric Efficiency of Units 139 and 140 from December 2011 through July 2012
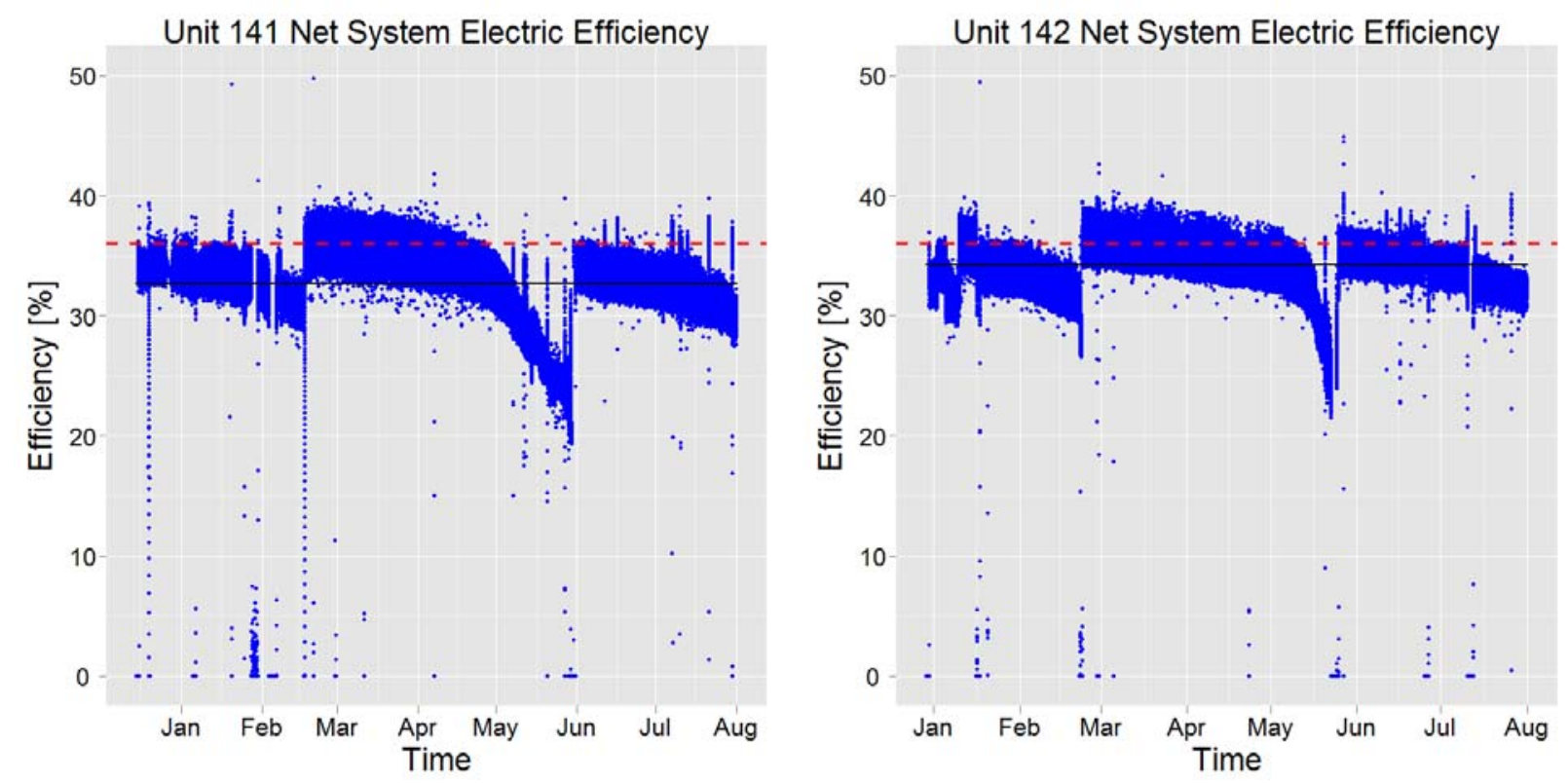

Figure A.13. Net System Electric Efficiency of Units 141 and 152 from December 2011 through July 2012 

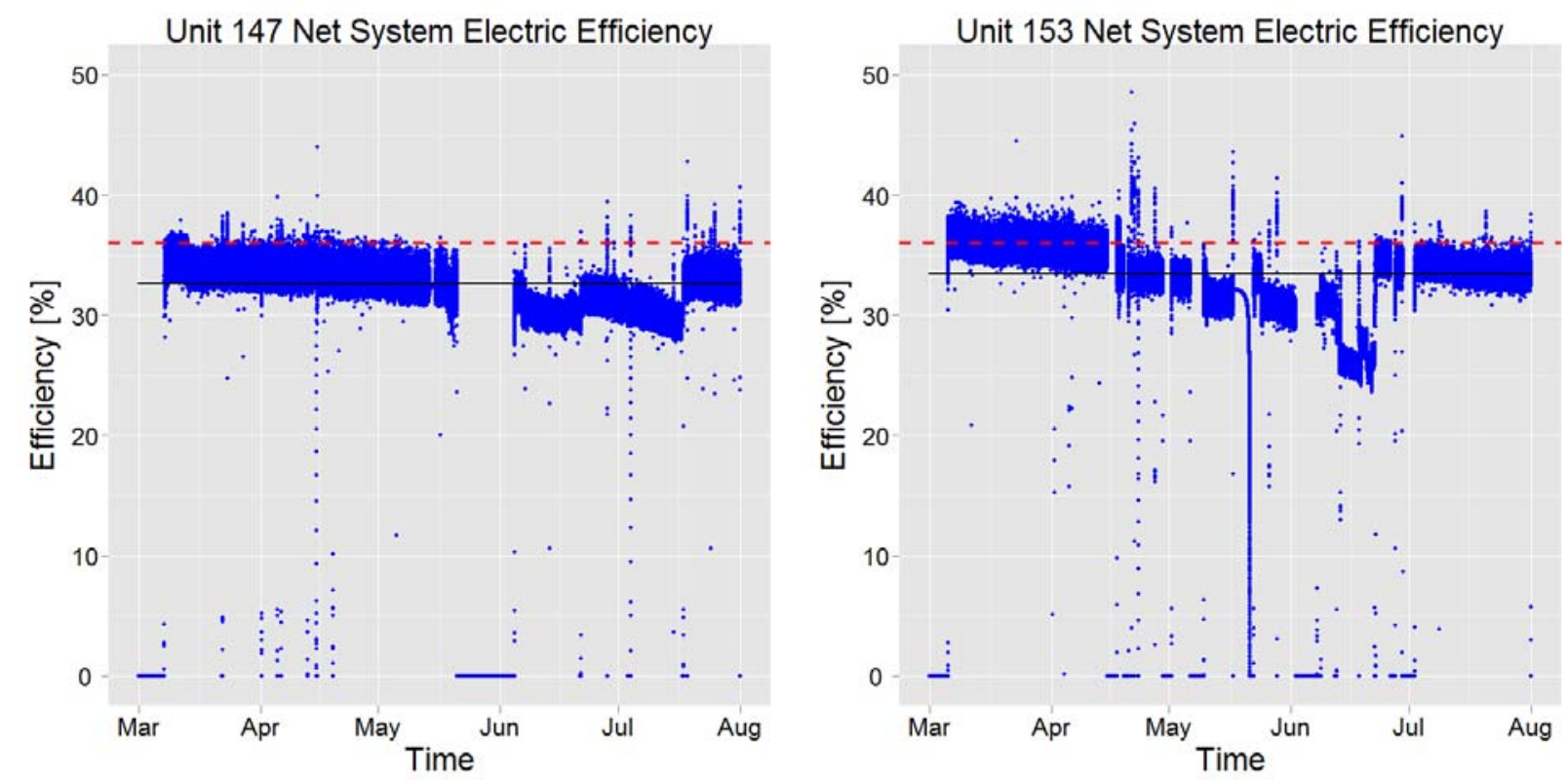

Figure A.14. Net System Electric Efficiency of Units 147 and 153 from March 2012 through July 2012
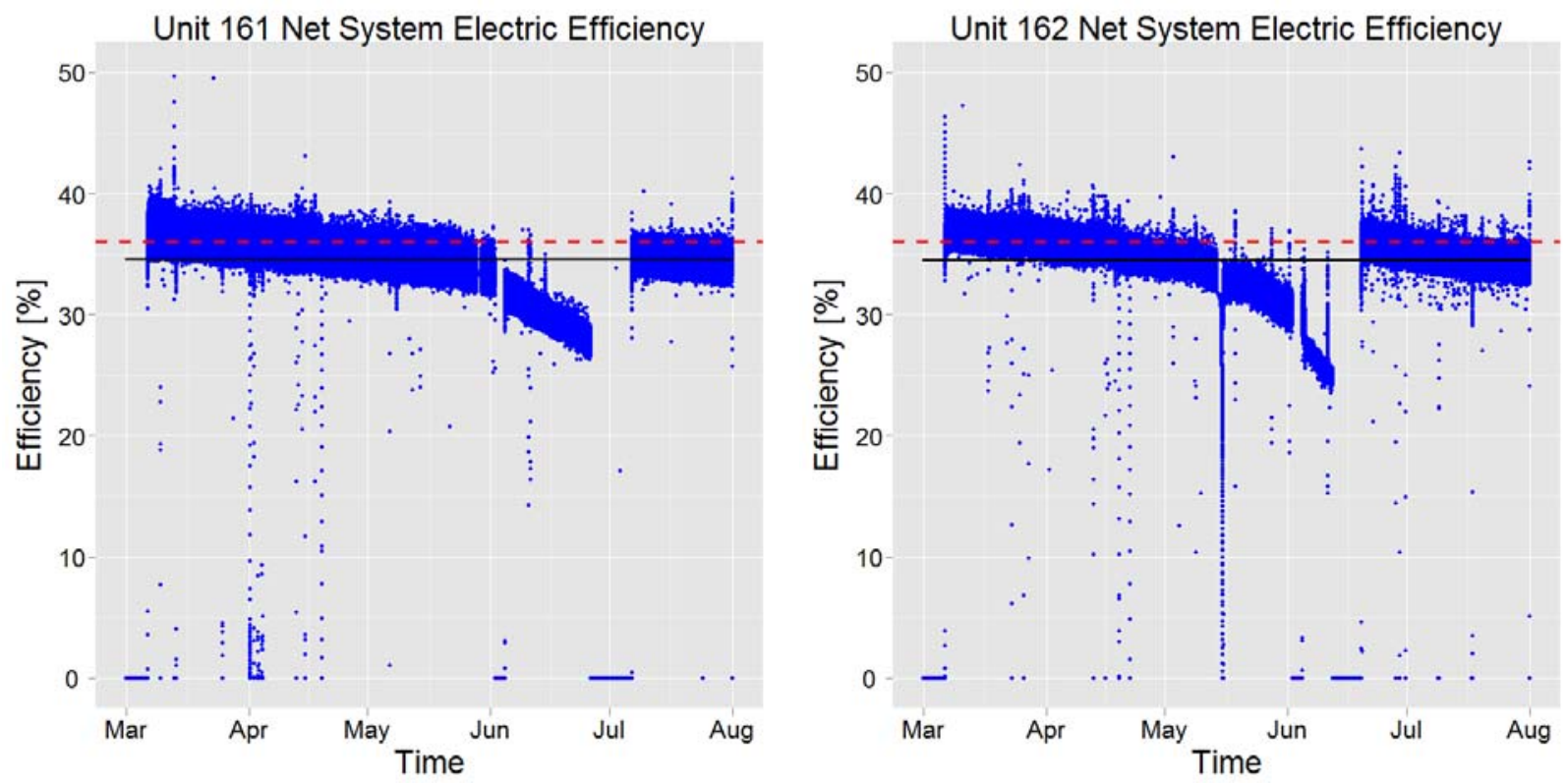

Figure A.15. Net System Electric Efficiency of Units 161 and 162 from March 2012 through July 2012 


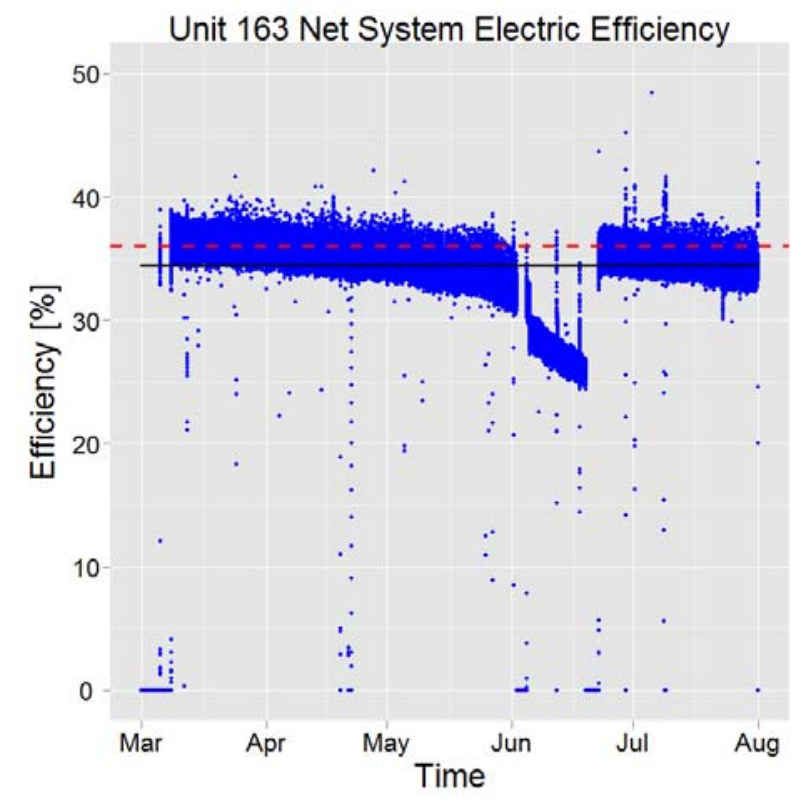

Figure A.16. The Net System Electric Efficiency of Unit 163 from March 2012 through July 2012 

Appendix B

Time-Series Performance Data for M5 Units in Phase II 



\section{Appendix B}

\section{Time-Series Performance Data for M5 Units in Phase II]}

\section{B.1 Net Electric Power Output}
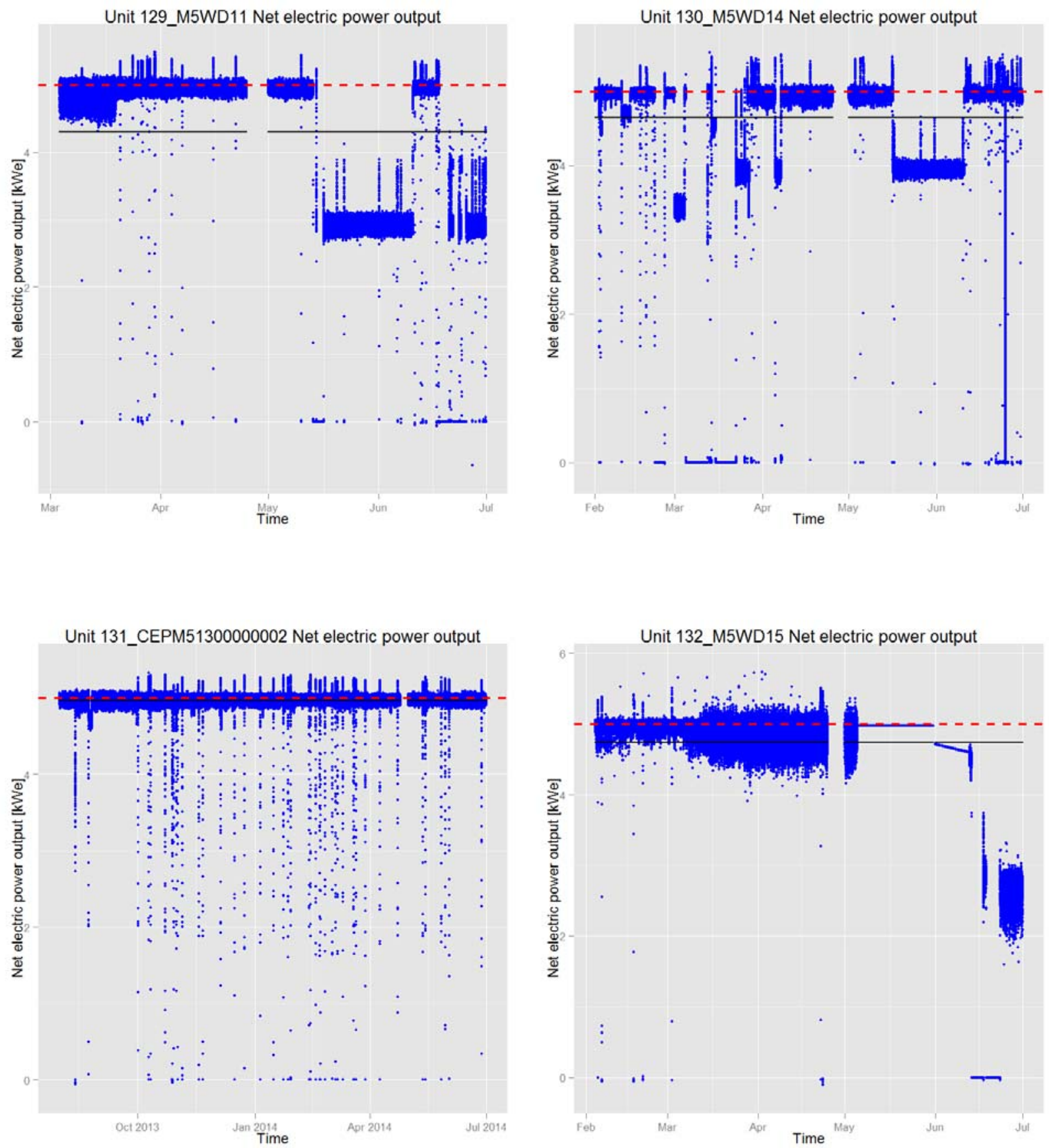

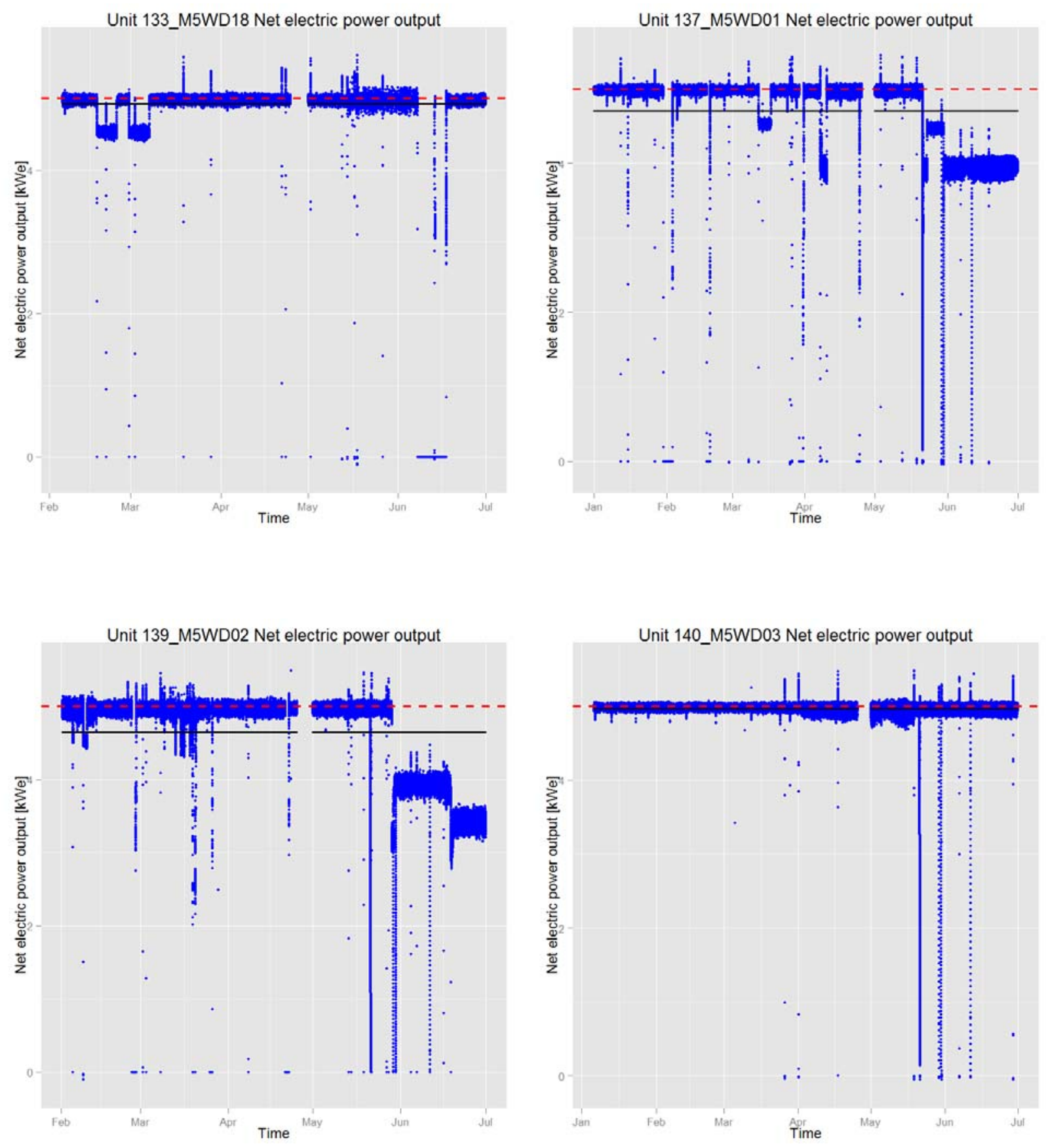

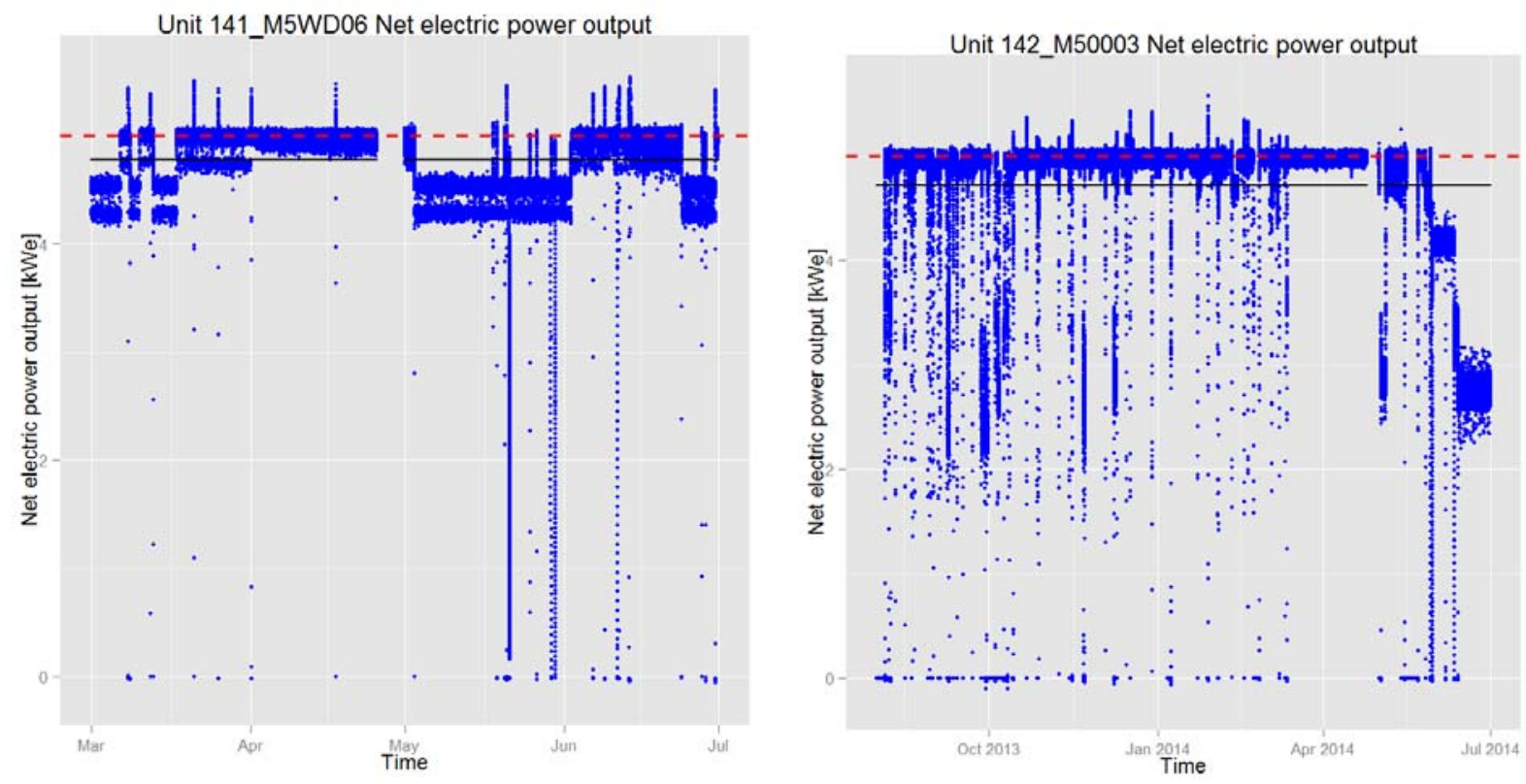

\section{B.2 The Net System Electric Efficiency}
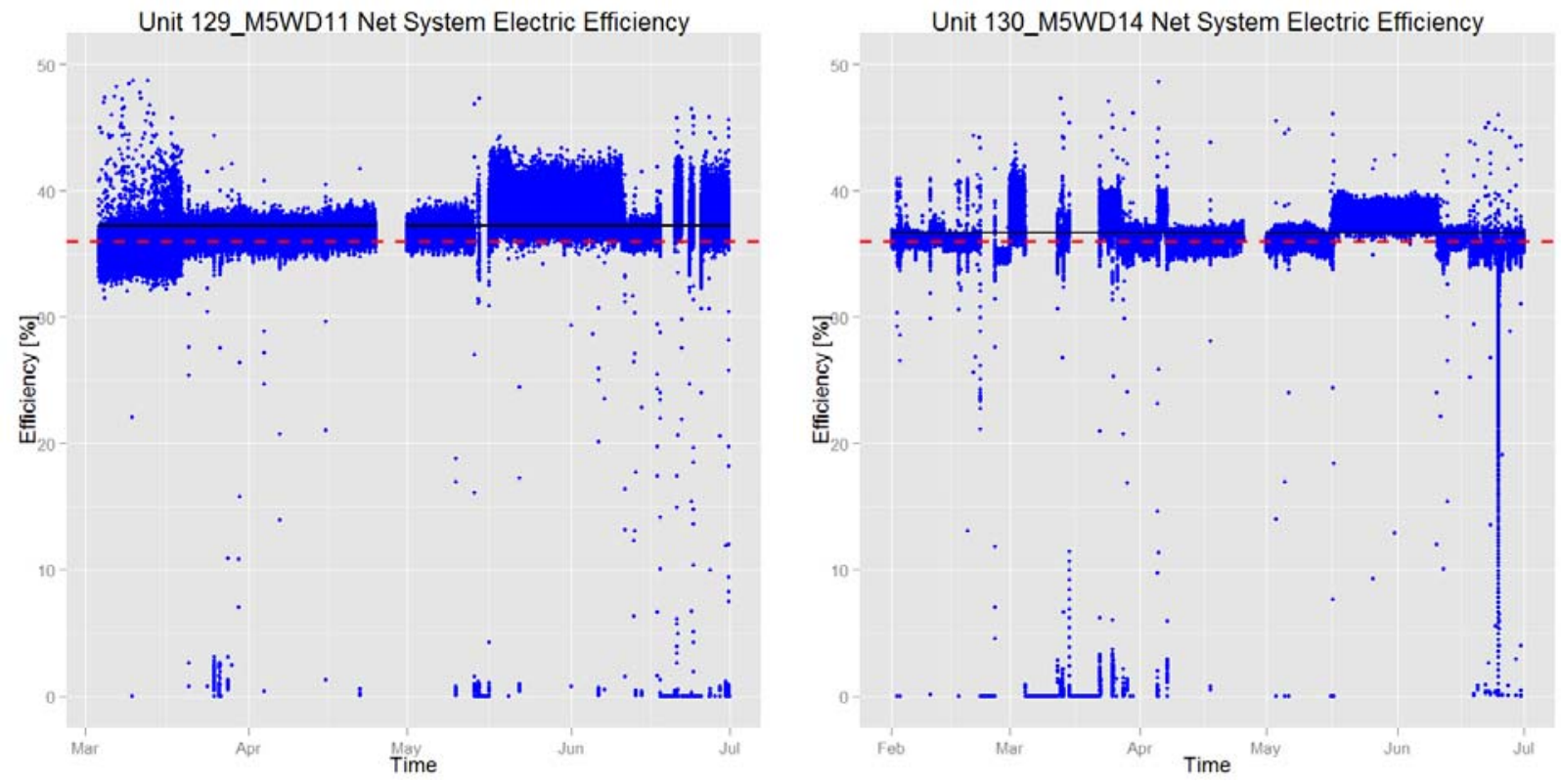

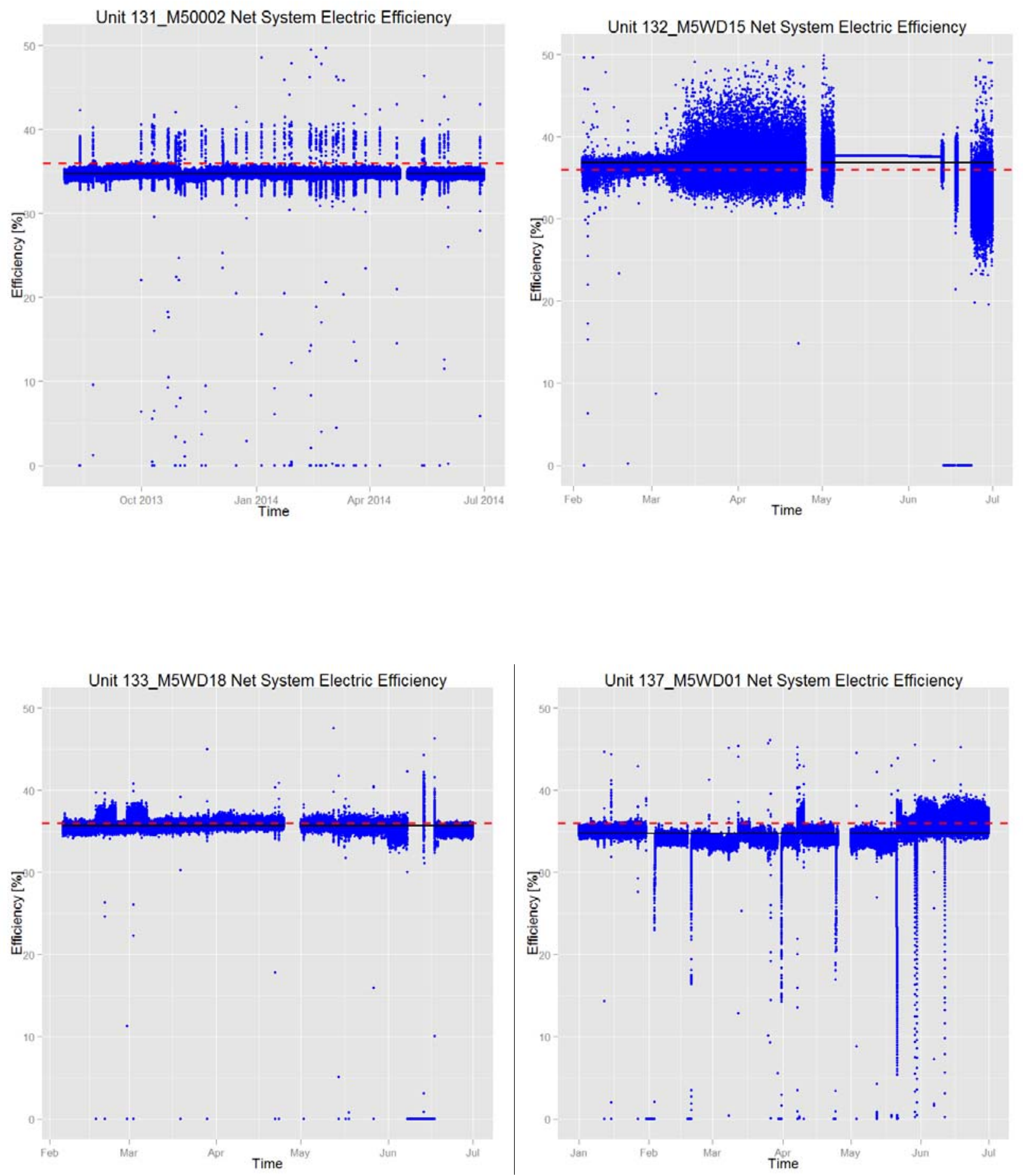

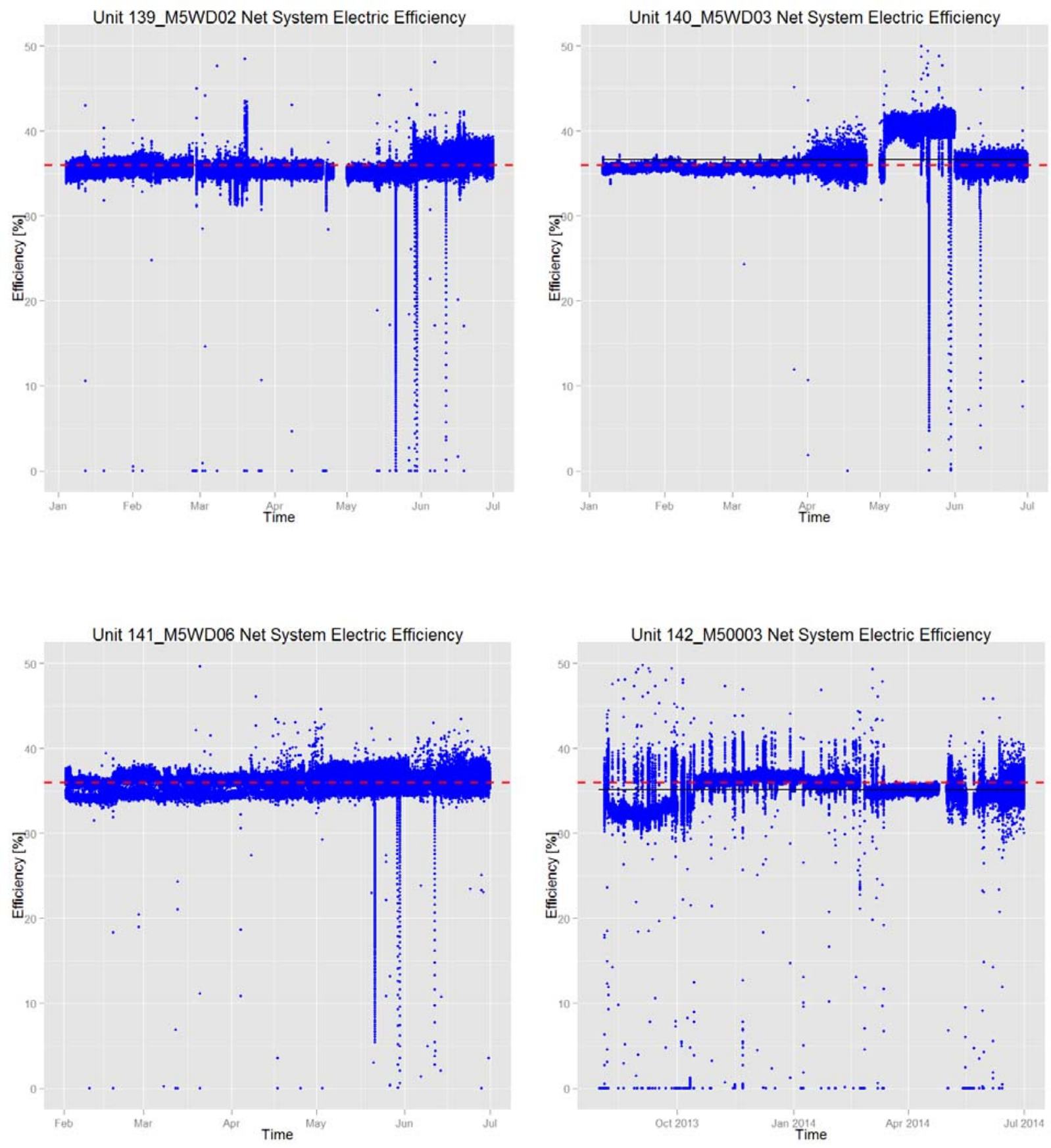


\section{B.3 The Net Heat Recovery for External Heating}
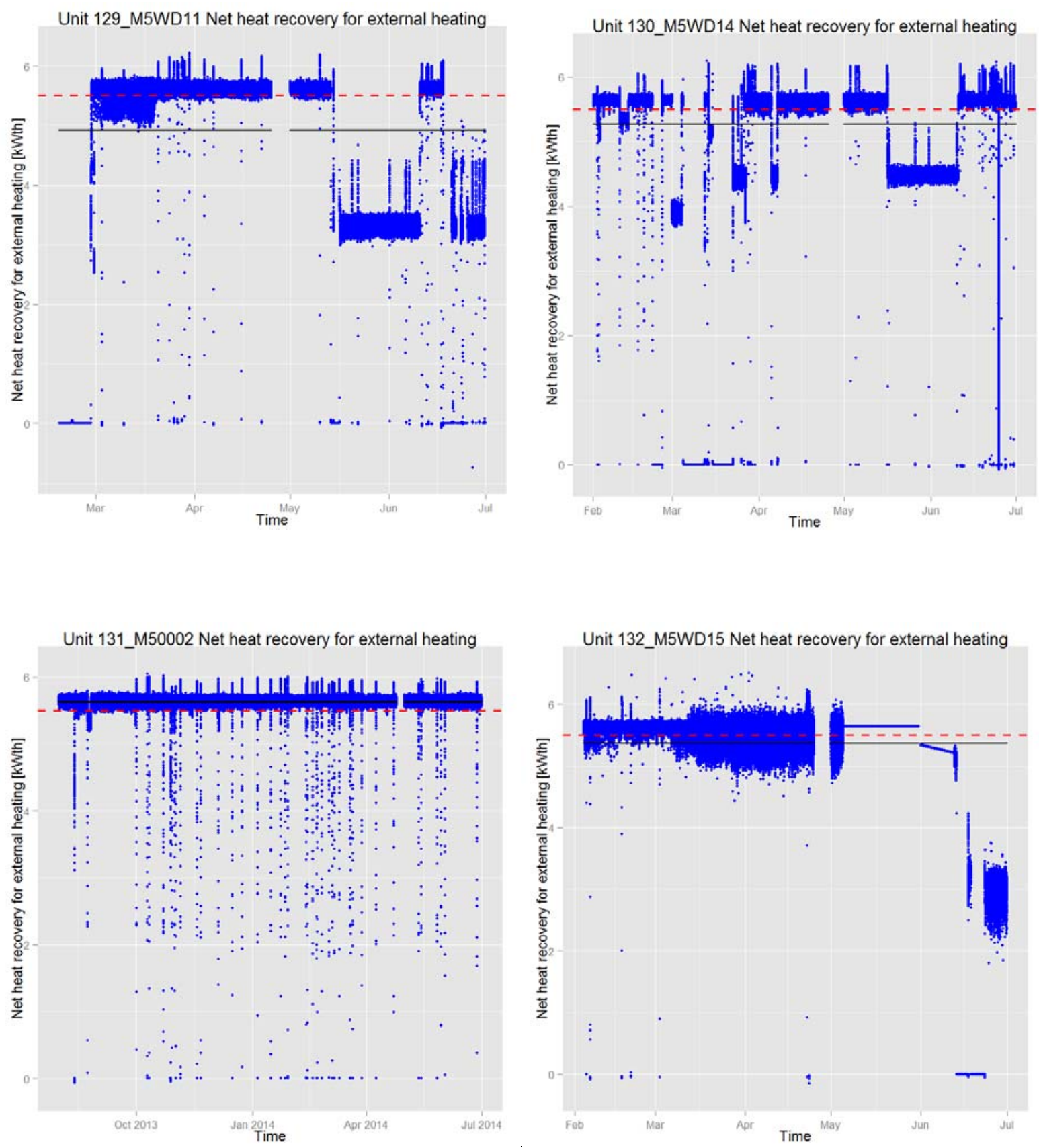

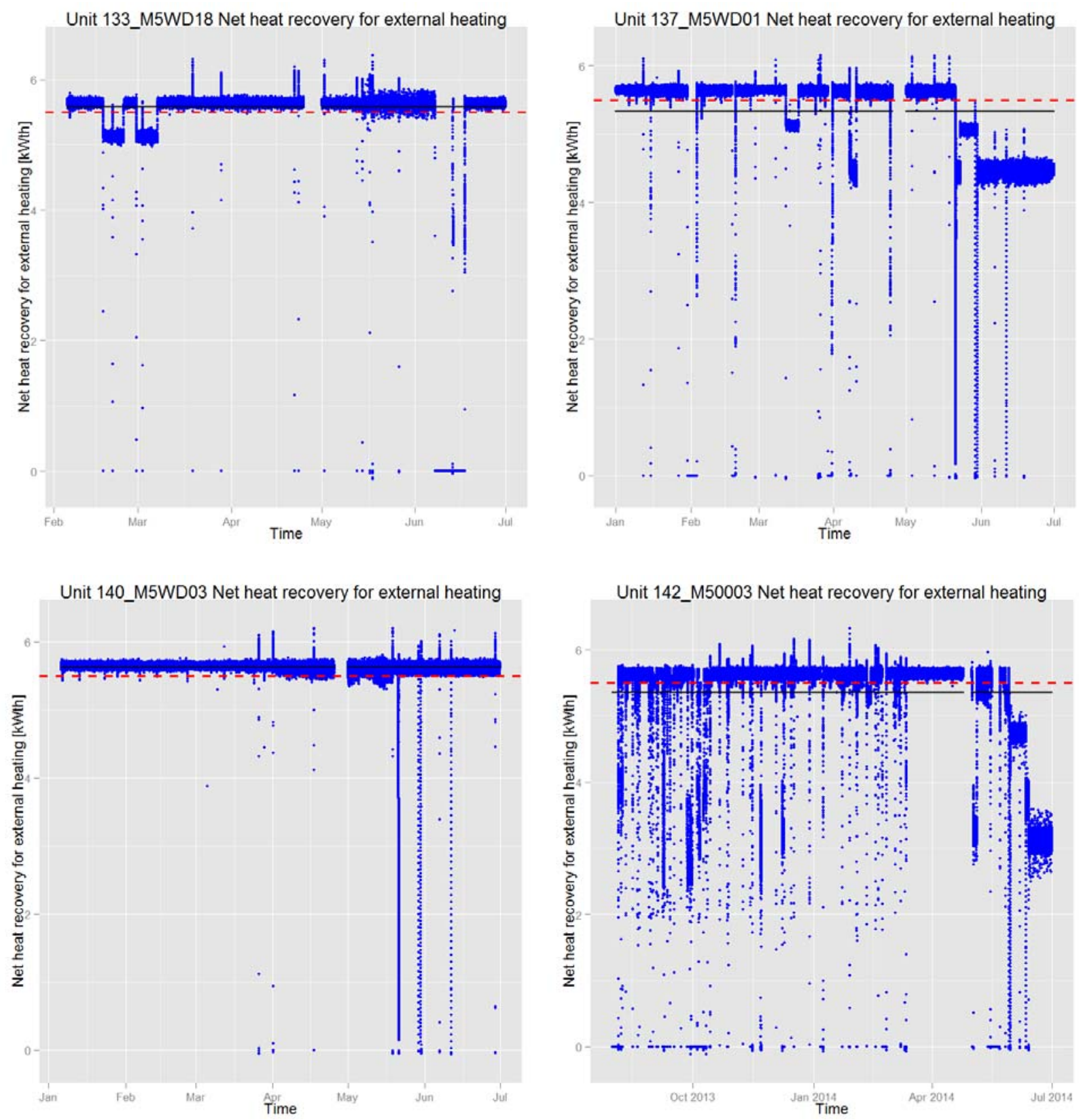


\section{B.4 Net Heat Recovery Efficiency}
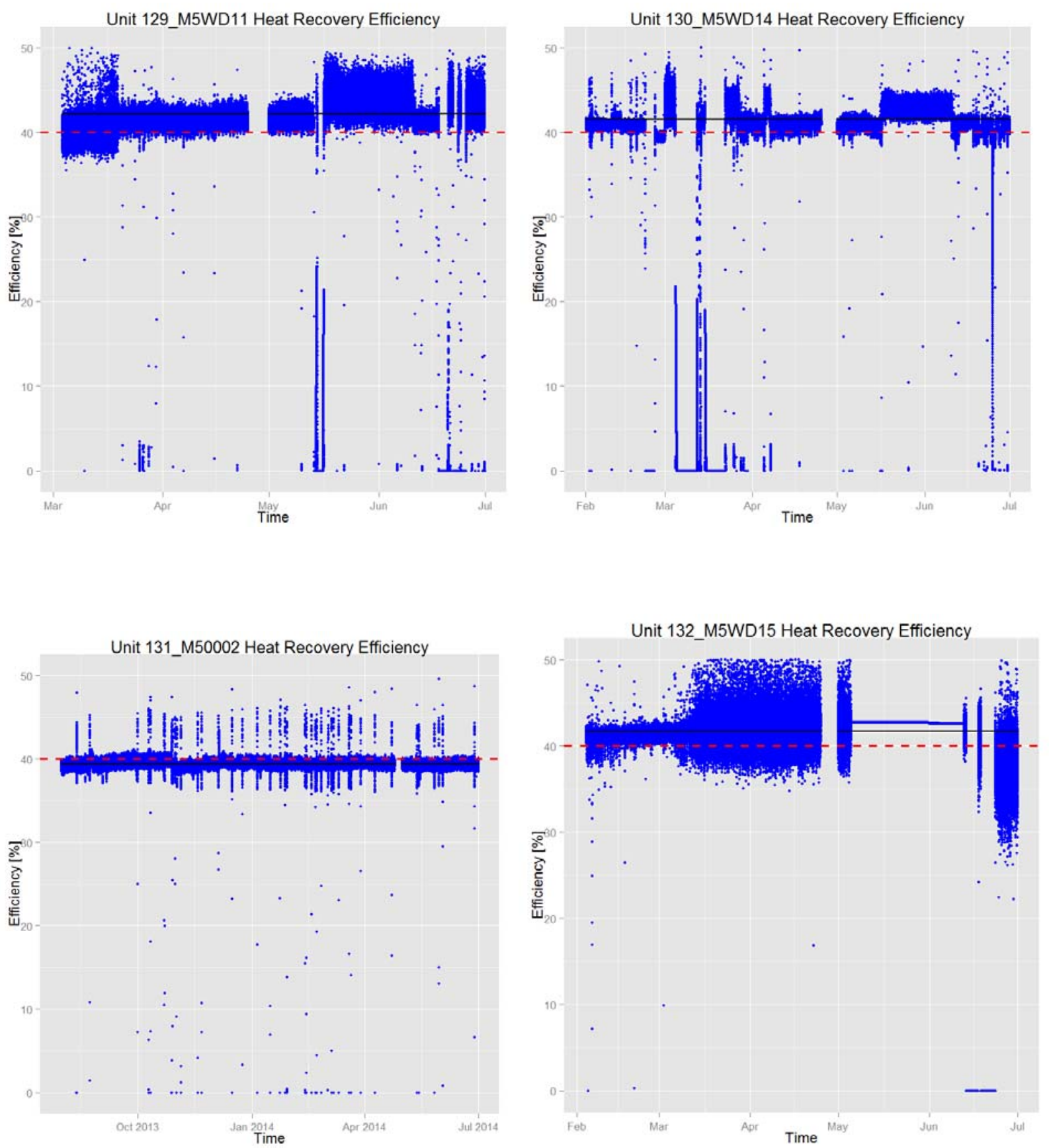

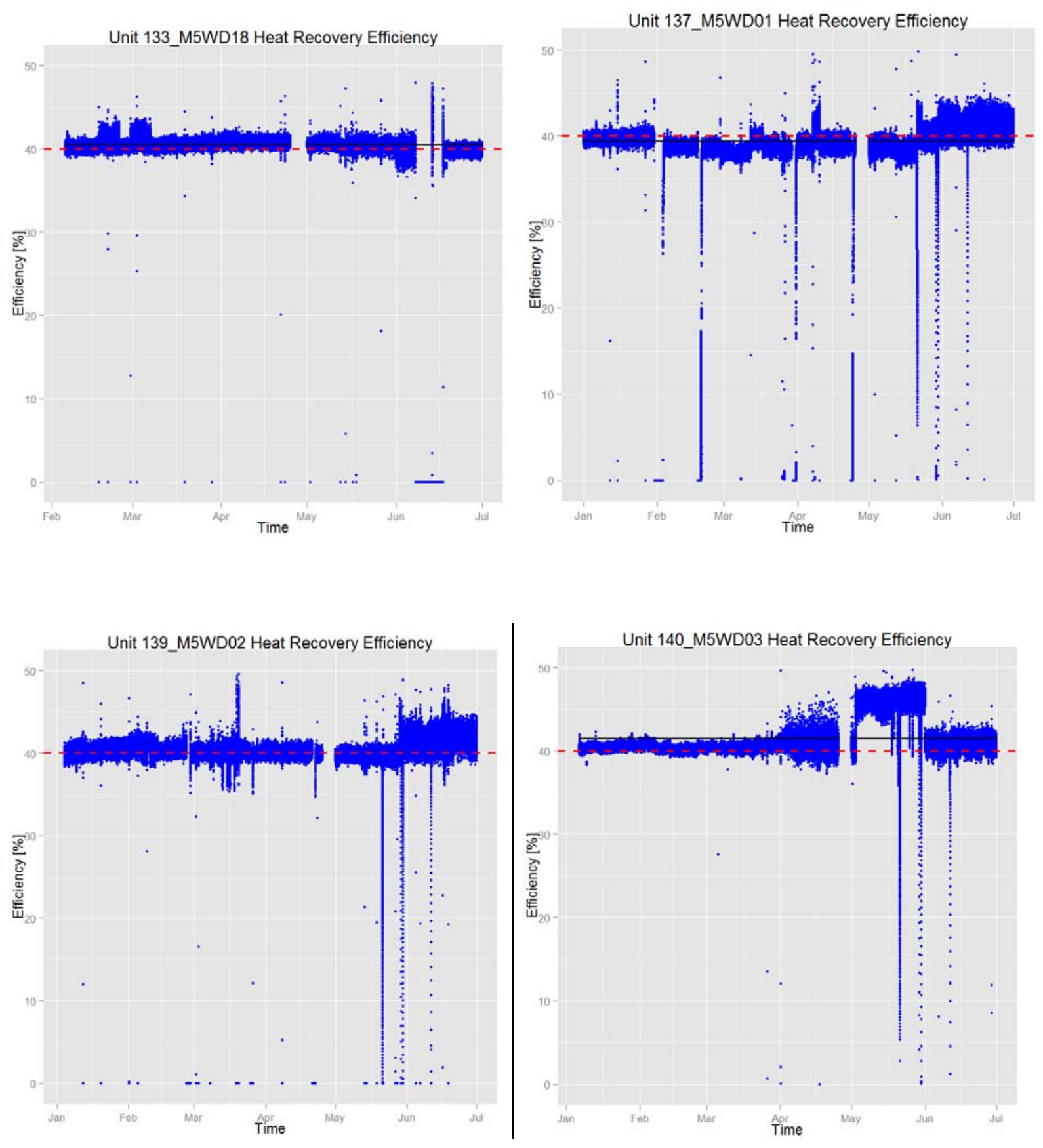

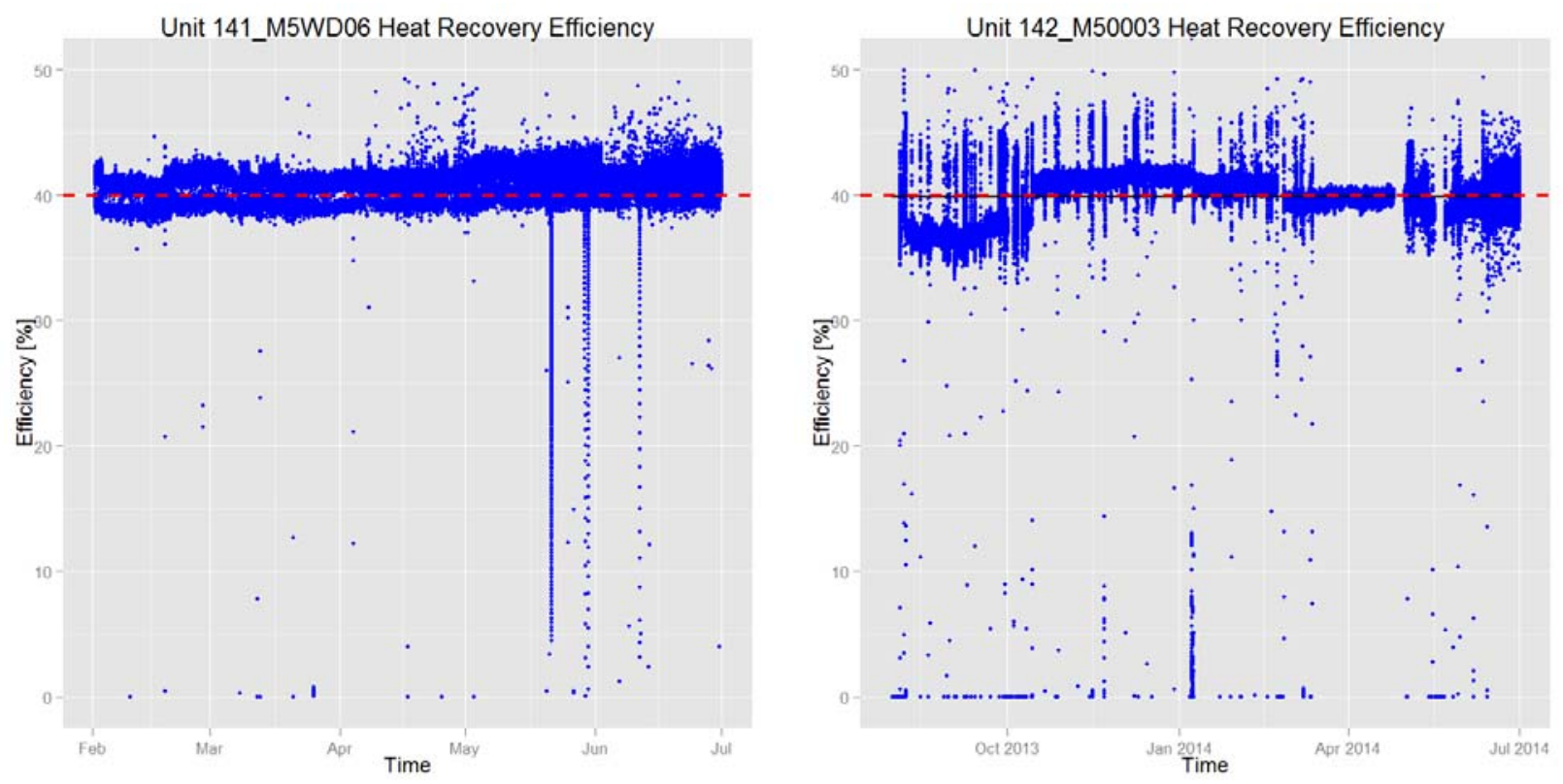

\section{B.5 The Overall System Efficiency}
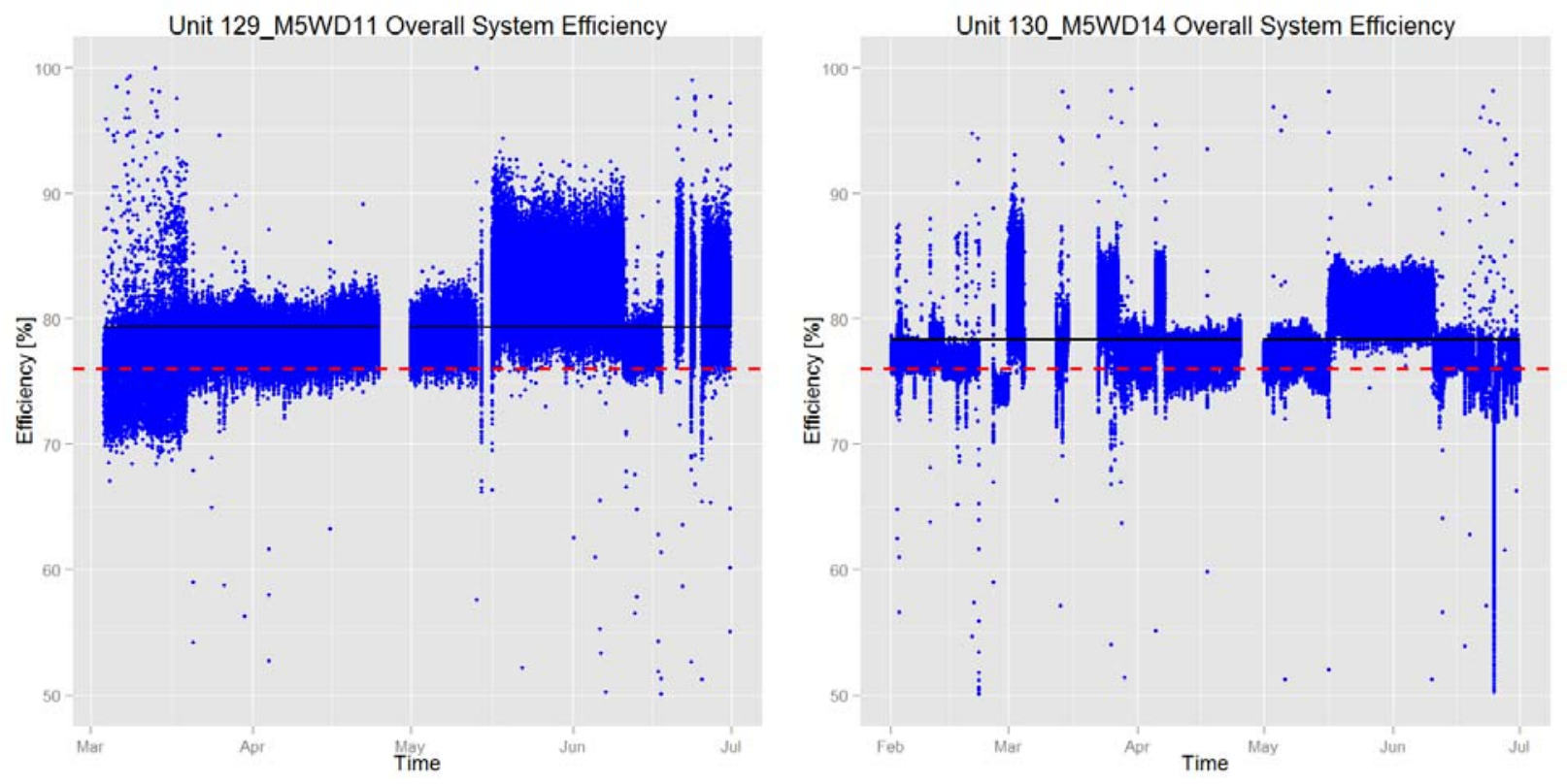

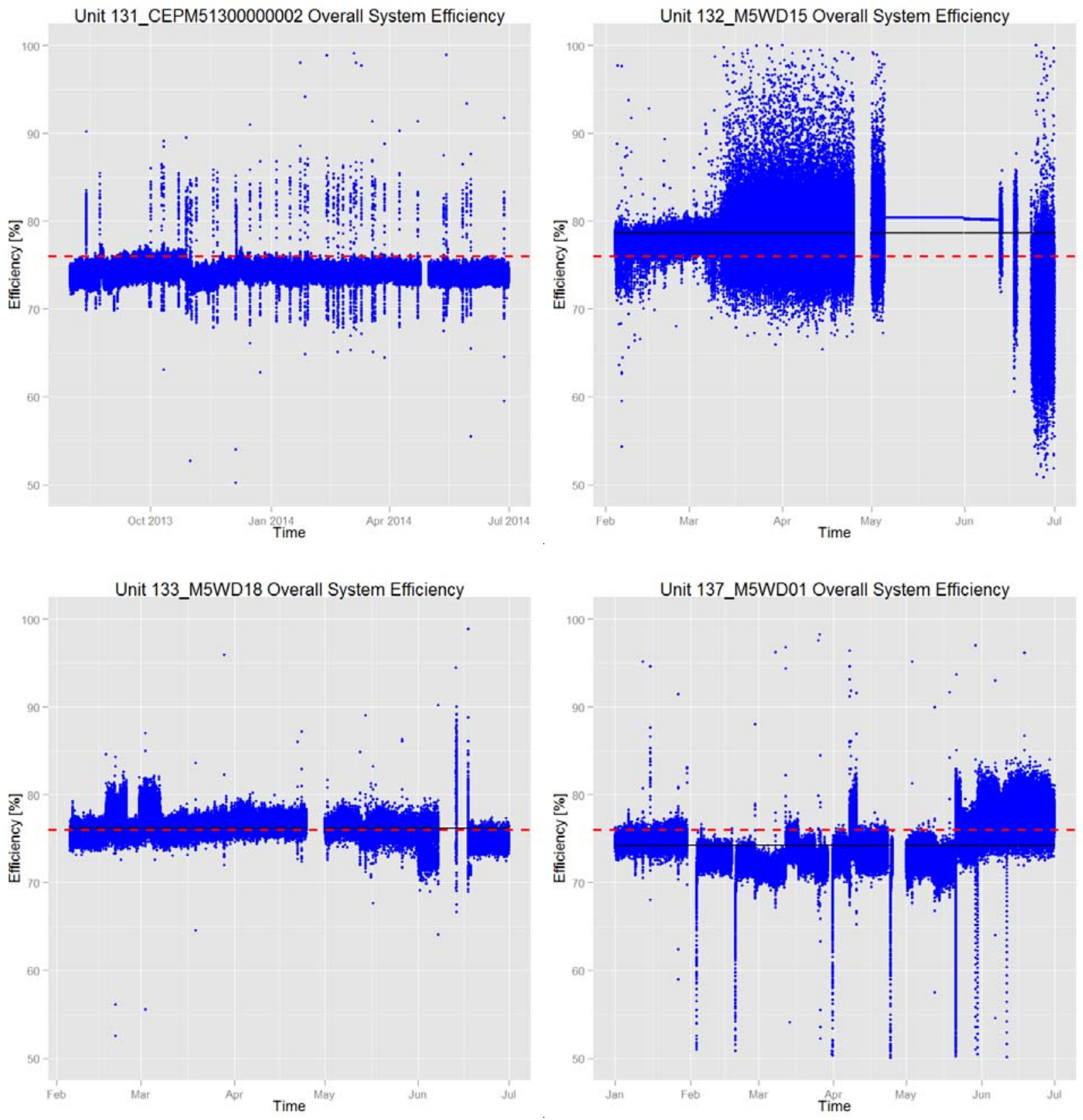

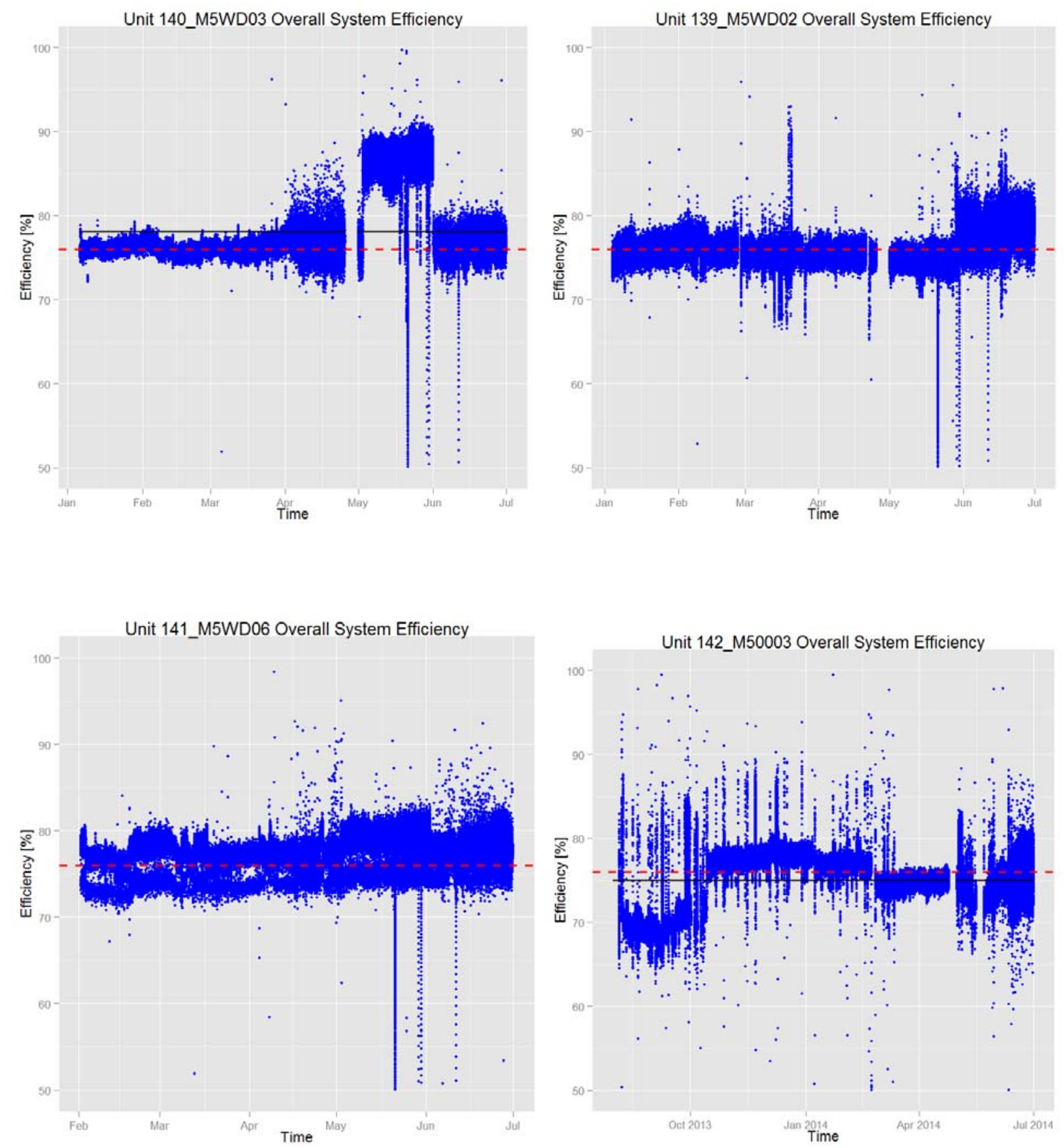


\section{B.6 Temperature of Water Sent to Site}
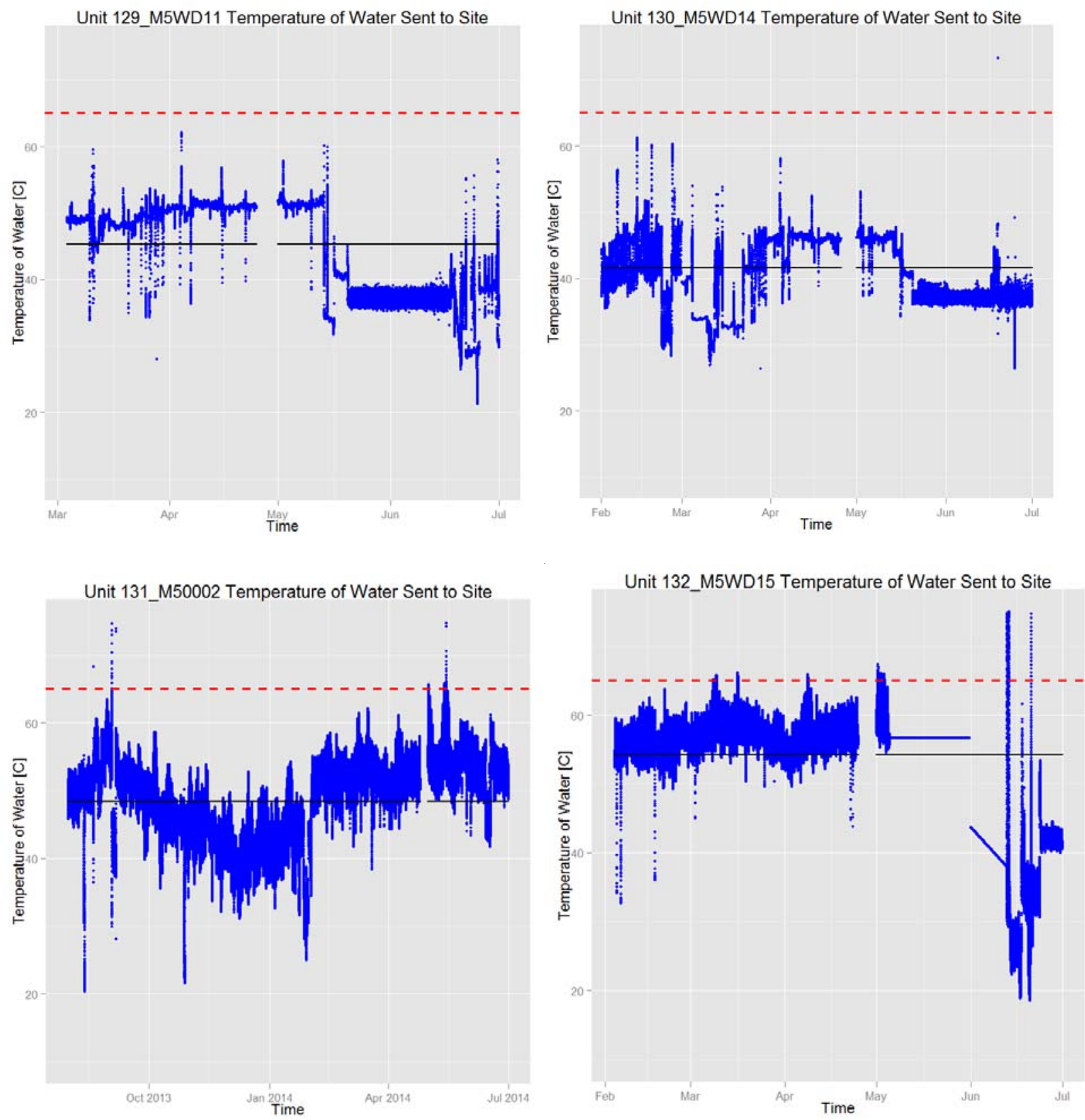

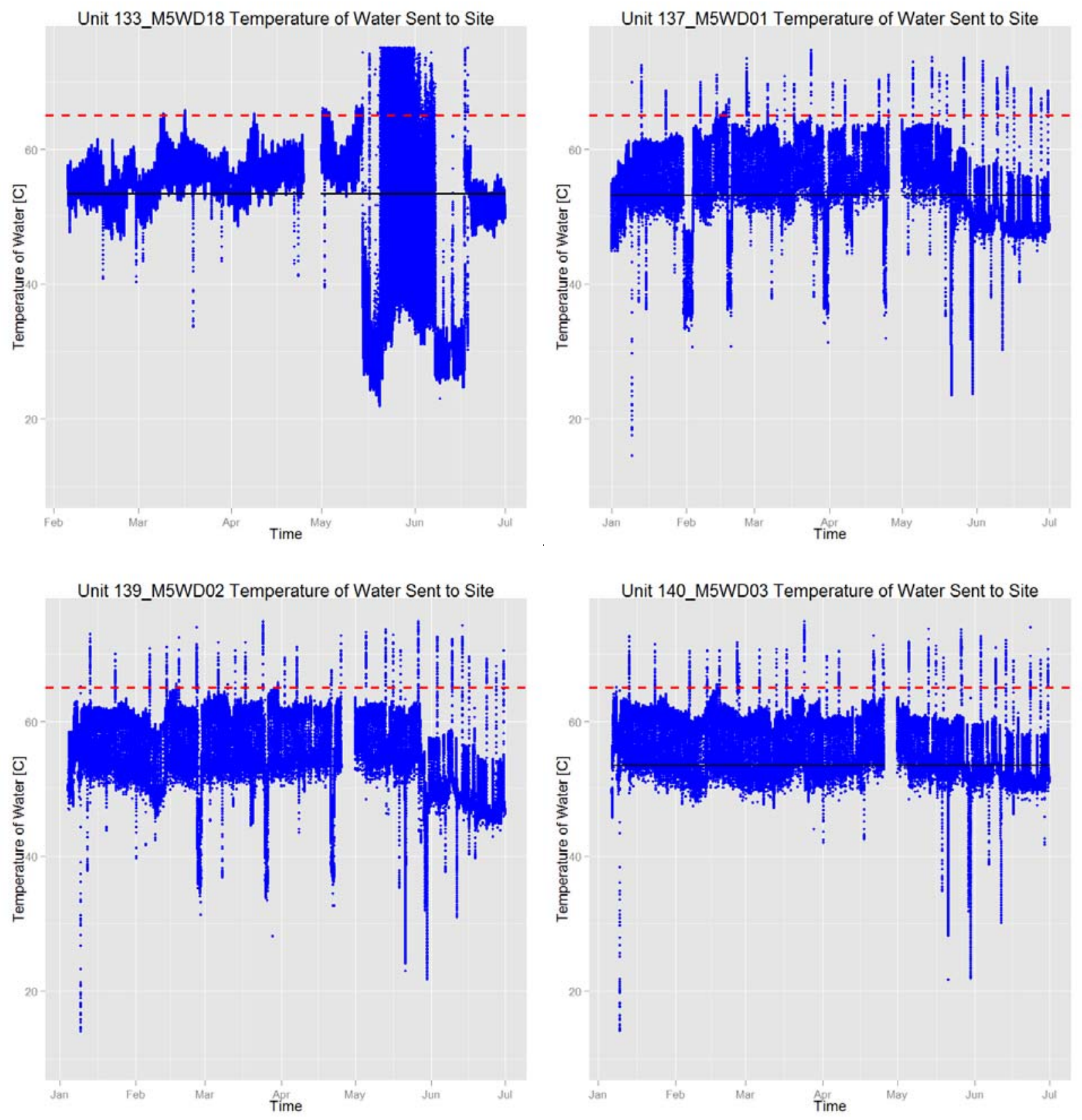

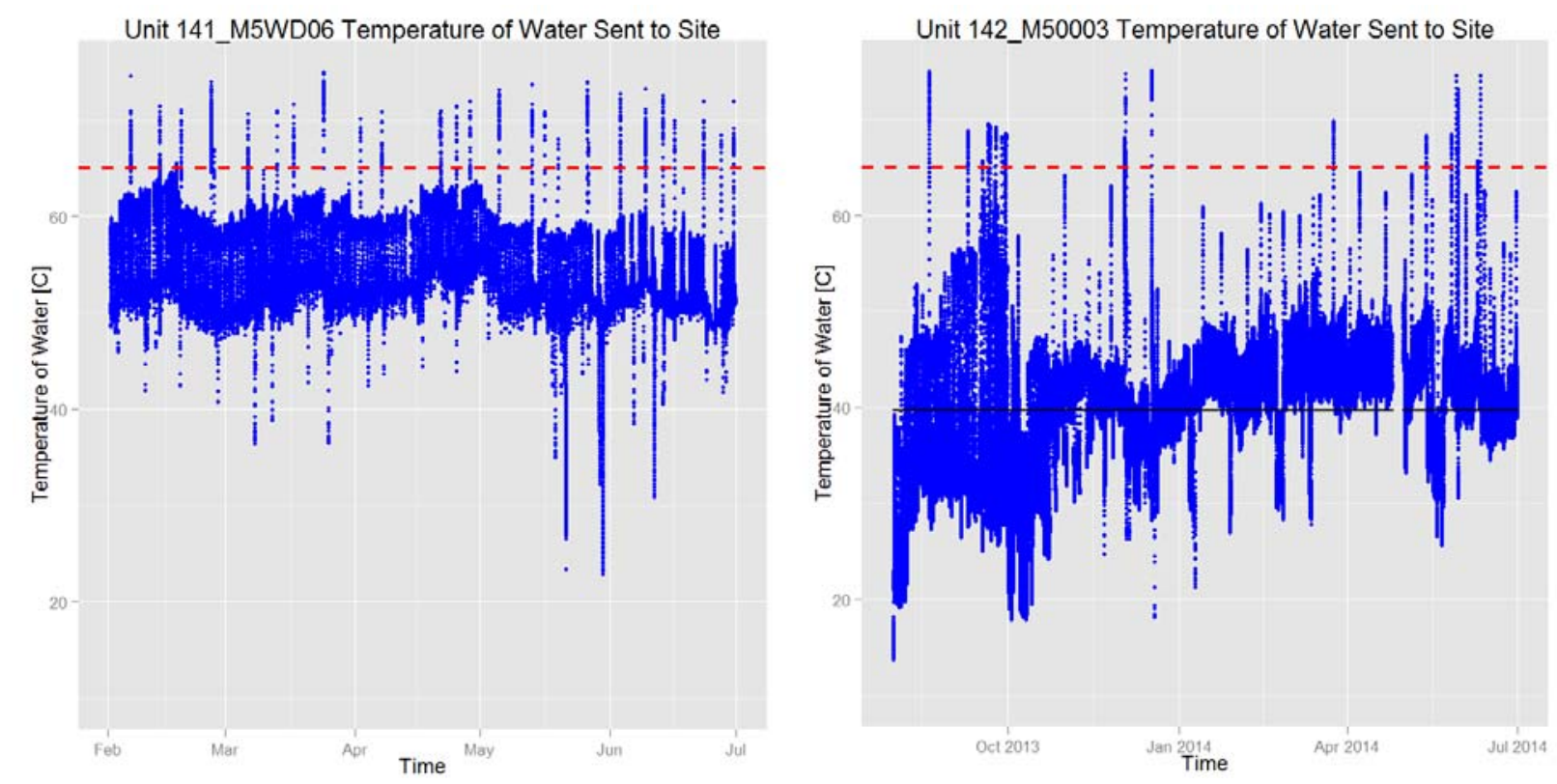

\section{B.7 Natural Gas Input}
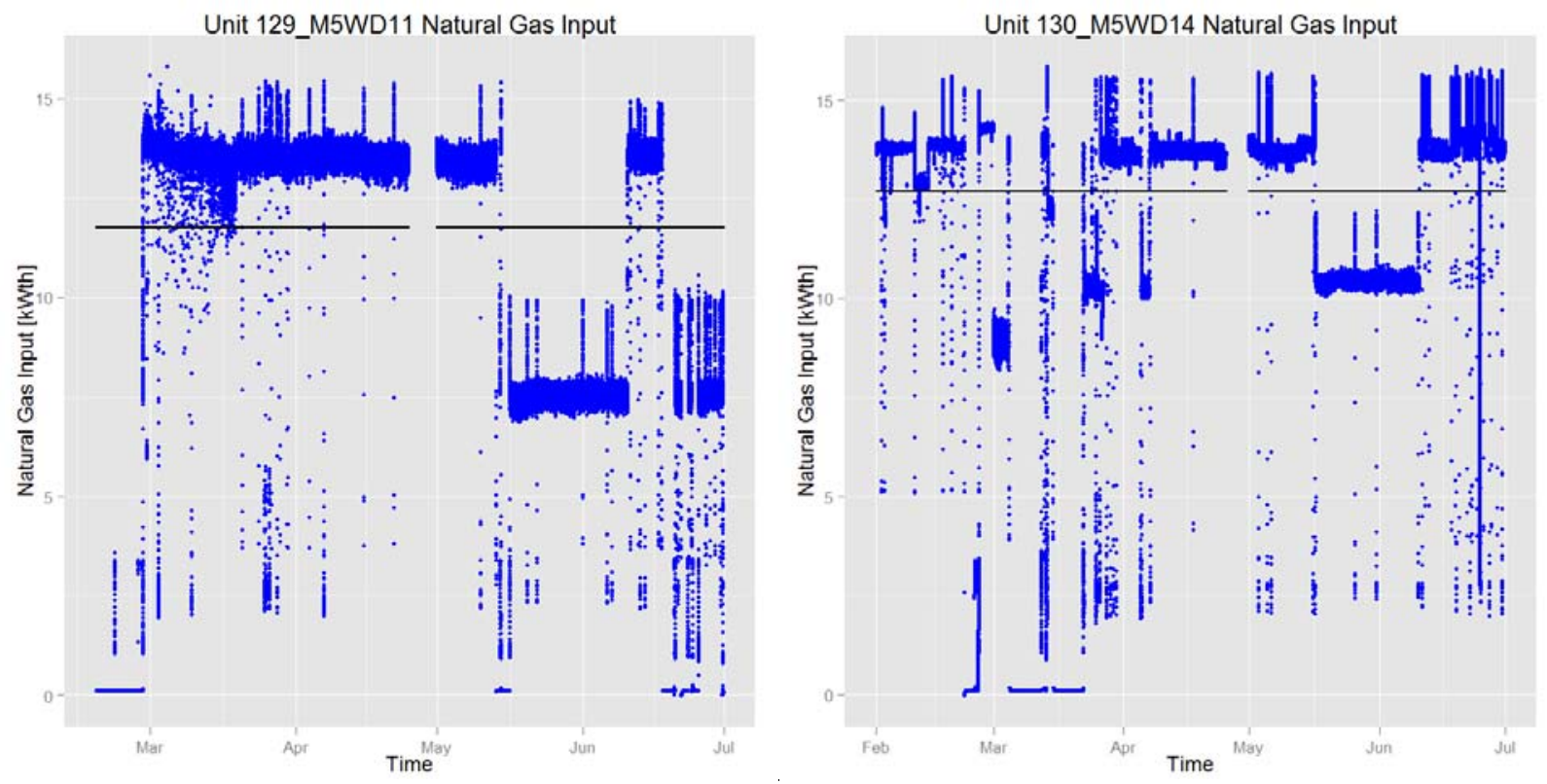

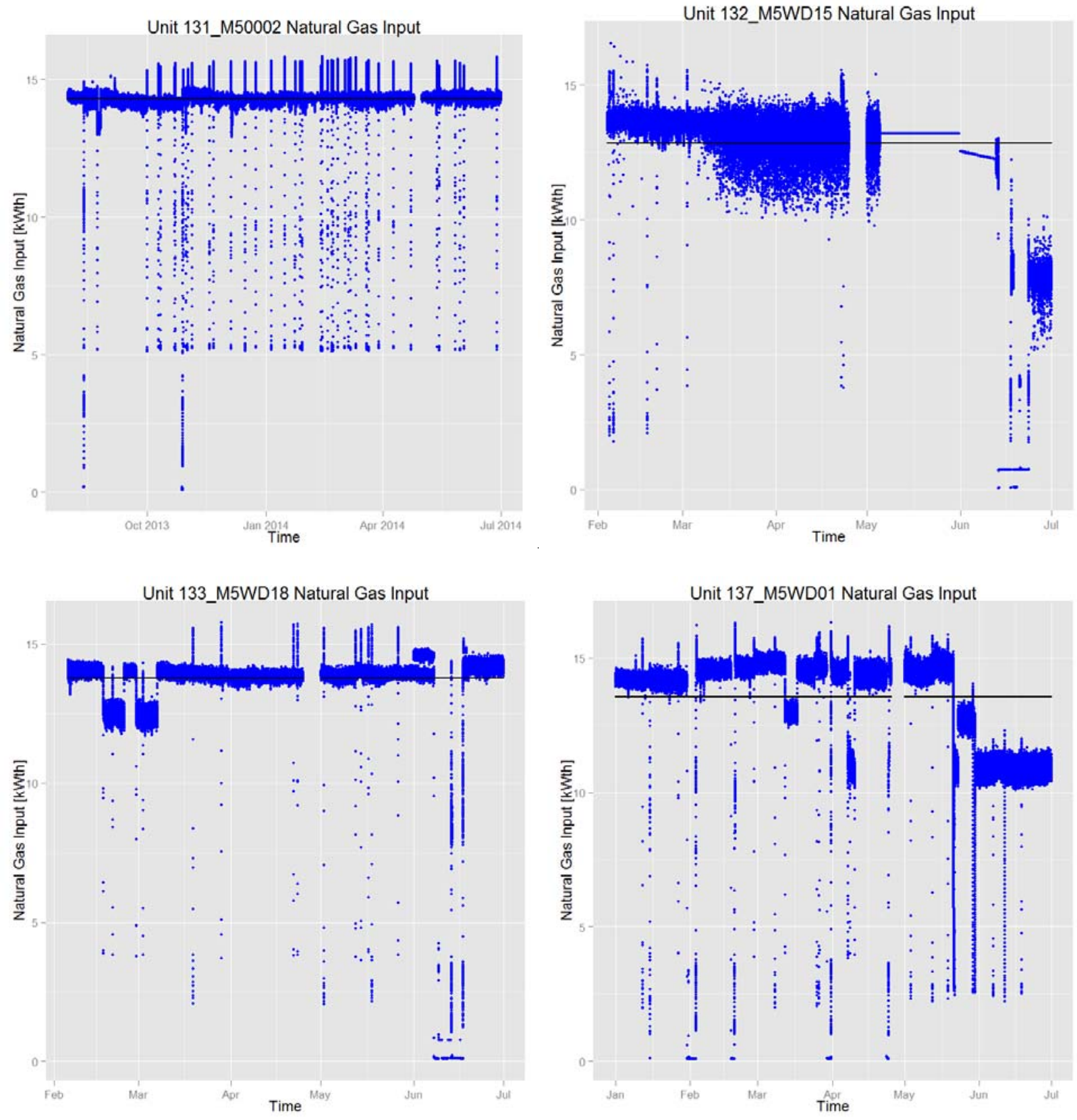

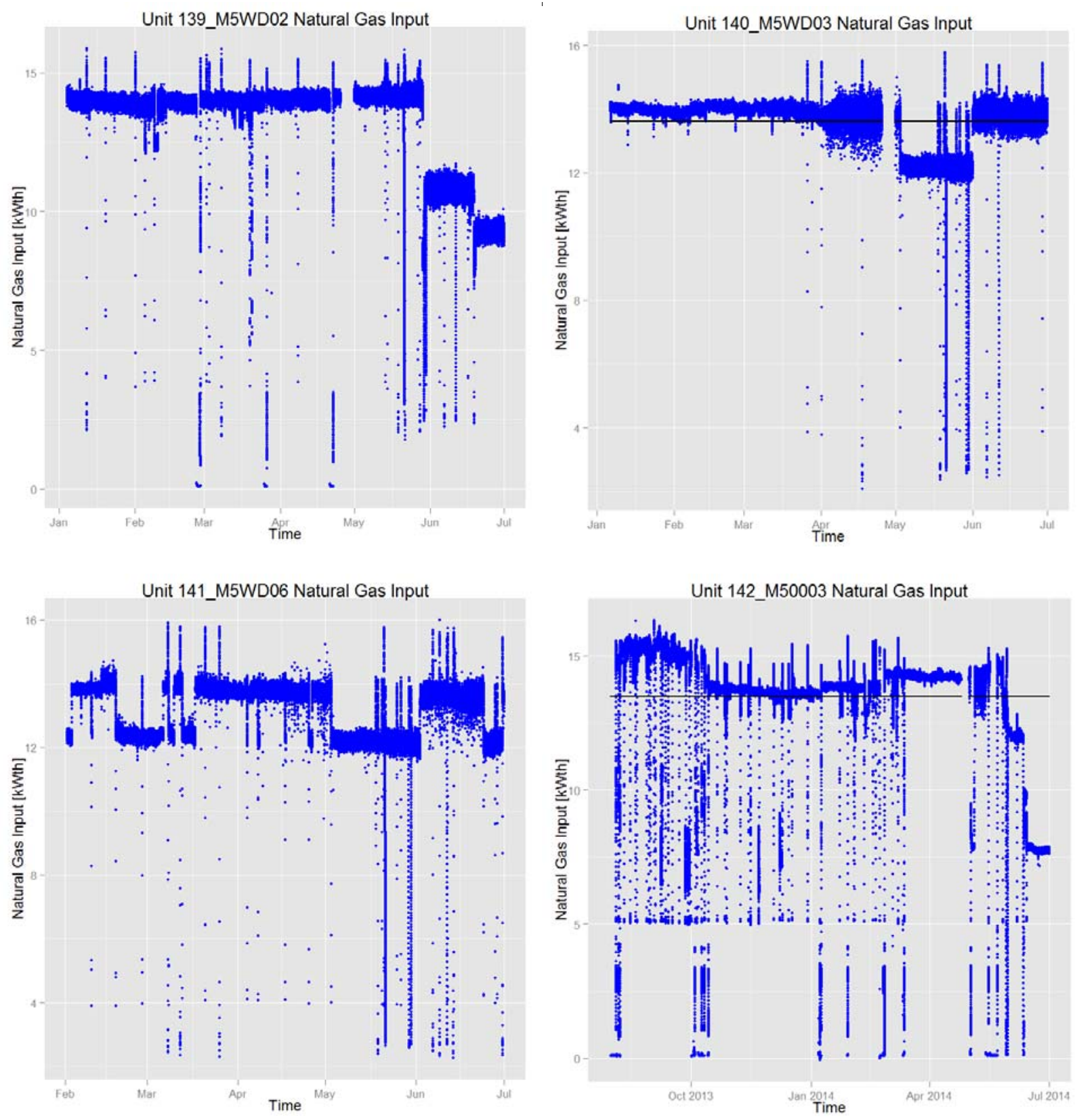


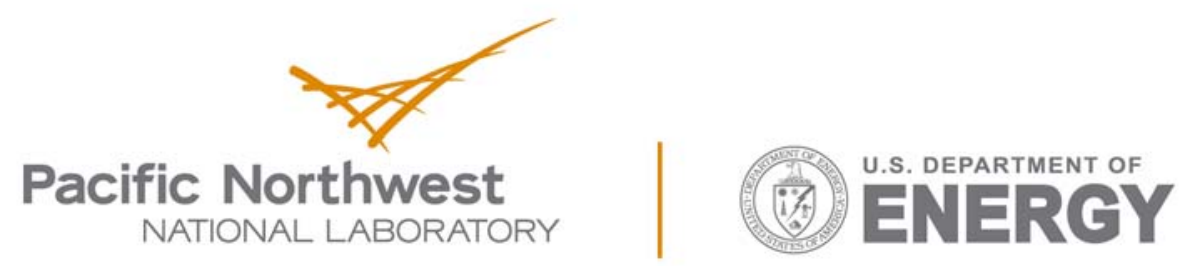

Proudly Operated by Battelle Since 1965

902 Battelle Boulevard

P.O. Box 999

Richland, WA 99352

1-888-375-PNNL (7665)

www.pnnl.gov 